NUREG/CR-6438

BMI-2188

\title{
The Effect of Cyclic and Dynamic Loads on Carbon Steel Pipe
}

Manuscript Completed: February 1996

Date Published: February 1996

Prepared by

D. L. Rudland, P. M. Scott, G. M. Wilkowski

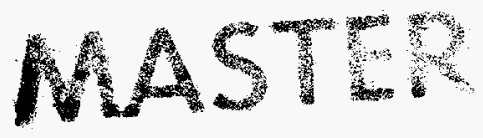

Battelle

505 King Avenue

Columbus, OH 43201-2693

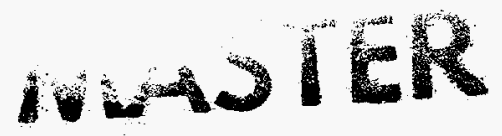

M. Mayfield, NRC Project Manager

Prepared for

Division of Engineering Technology

Office of Nuclear Regulatory Research

U.S. Nuclear Regulatory Commission

Washington, DC 20555-0001

NRC Job Code D2060 


\section{DISCLAMMER}

Portions of this document may be illegible in electronic image products. Images are produced from the best available original document. 


\begin{abstract}
This report presents the results of four 152-mm (6-inch) diameter, unpressurized, circumferential through-wall-cracked, dynamic pipe experiments fabricated from STS410 carbon steel pipe manufactured in Japan. For three of these experiments, the through-wall crack was in the base metal. The displacement histories applied to these experiments were a quasi-static monotonic, dynamic monotonic, and dynamic, cyclic $(R=-1)$ history. The through-wall crack for the third experiment was in a tungsten-inert-gas weld, fabricated in Japan, joining two lengths of STS410 pipe. The displacement history for this experiment was the same history applied to the dynamic, cyclic base metal experiment. The test temperature for each experiment was $300 \mathrm{C}(572 \mathrm{~F})$.

The objective of these experiments was to compare a Japanese carbon steel pipe material with United States pipe material, to ascertain whether this Japanese steel was as sensitive to dynamic and cyclic effects as United States carbon steel pipe.

In support of these pipe experiments, quasi-static and dynamic, tensile and fracture toughness tests were conducted. An analysis effort was performed that involved comparing experimental crack initiation and maximum moments with predictions based on available fracture prediction models, and calculating J-R curves for the pipe experiments using the $\eta$-factor method.
\end{abstract}



EXECUTIVE SUMMARY xiii

ACKNOWLEDGMENTS xvii

NOMENCLATURE $\mathrm{xix}$

PREVIOUS REPORTS IN SERIES xxiii

1.0 INTRODUCTION

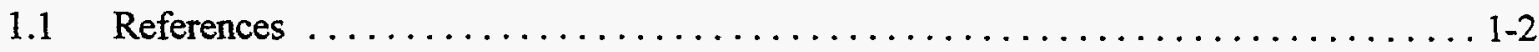

2.0 MATERIAL CHARACTERIZATION EFFORTS $\ldots \ldots \ldots \ldots \ldots \ldots \ldots \ldots \ldots \ldots \ldots \ldots \ldots$

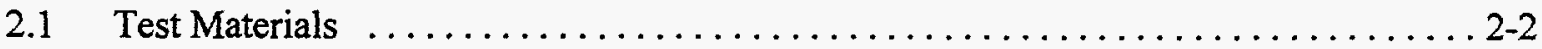

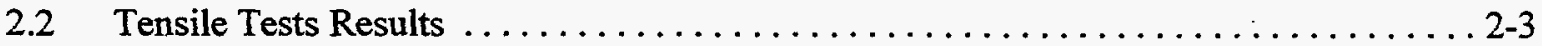

2.2.1 Base Metal Results . . . . . . . . . . . . . . . . . . . . . 2-3

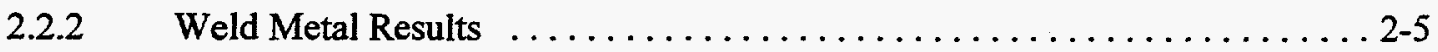

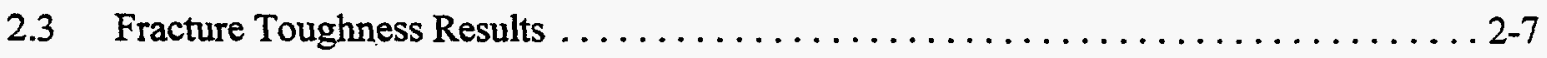

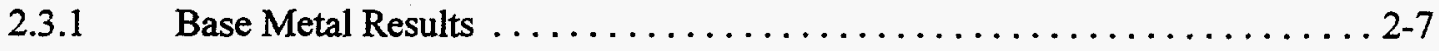

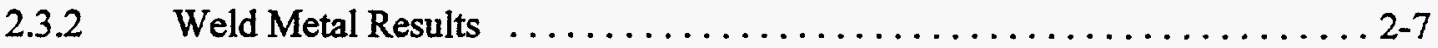

2.4 Summary of Effect of Dynamic Loads on Material Properties $\ldots \ldots \ldots \ldots \ldots \ldots \ldots 2-8$

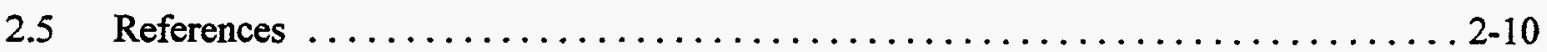

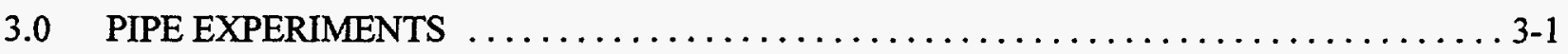

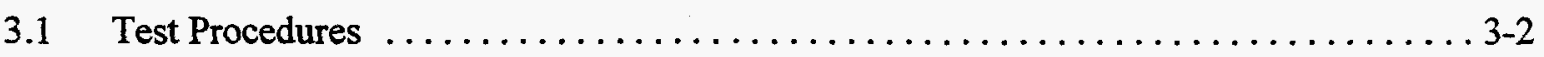

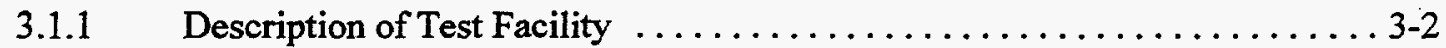

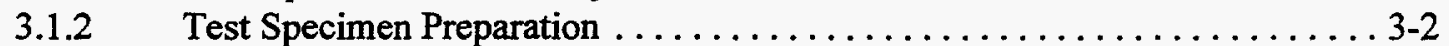

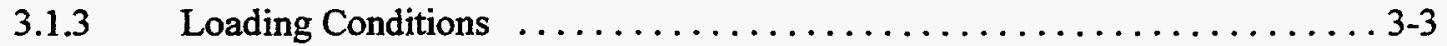

3.1.4 Instrumentation, Data Acquisition, and Data Reduction $\ldots \ldots \ldots \ldots \ldots$.

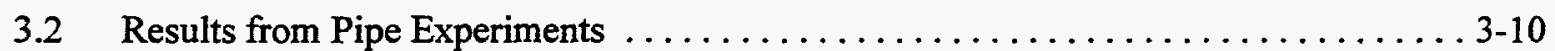

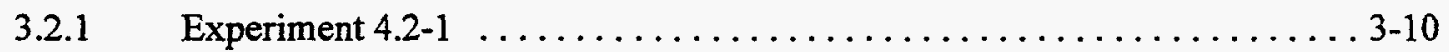

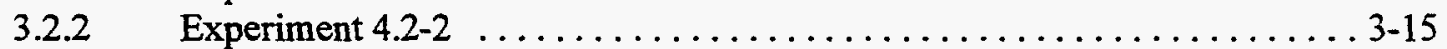

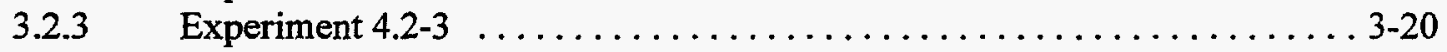

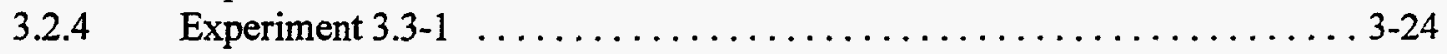




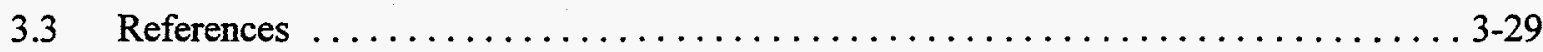

4.0 ANALYSIS OF PIPE FRACTURE EXPERIMENTS $\ldots \ldots \ldots \ldots \ldots \ldots \ldots \ldots \ldots \ldots \ldots$.

4.1 Comparison of Results with Fracture Prediction Analyses $\ldots \ldots \ldots \ldots \ldots \ldots \ldots \ldots$. 4-1

4.1.1 Comparison of Experimental Moments at Crack Initiation

4.1.2 Comparison of Maximum Experimental Moments with Fracture

Analysis Predictions . . . . . . . . . . . . . . . . . . .

4.2 Calculation of J-R Curves from Pipe Experiments $\ldots \ldots \ldots \ldots \ldots \ldots \ldots \ldots \ldots \ldots$

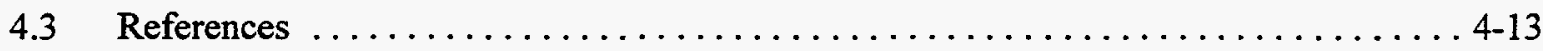

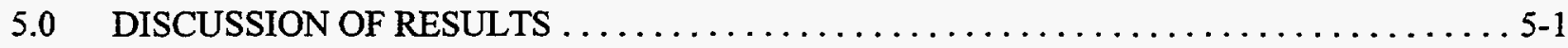

5.1 Effect of Loading Rate on the Fracture Behavior of STS410

Carbon Steel and an Associated TIG Weld ..................... $5-1$

5.2 Effect of Cyclic Load Histories on the Fracture Behavior of STS410 Carbon Steel ............................... 5

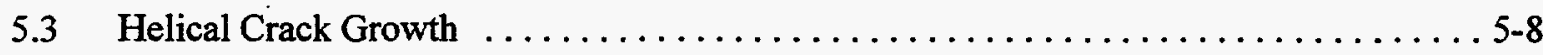

5.4 Dynamic Strain Aging Sensitivity of Carbon Steels $\ldots \ldots \ldots \ldots \ldots \ldots \ldots \ldots \ldots$

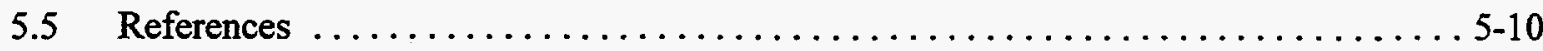

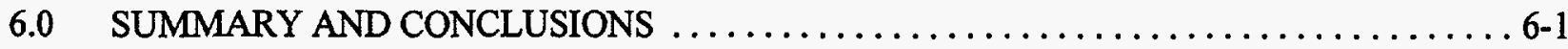




\section{LIST OF FIGURES}

Figure

2.1 Engineering stress-strain curves for STS410 base metal specimens $\ldots \ldots \ldots \ldots \ldots \ldots \ldots 2-4$

2.2 True stress-strain curves for STS410 base metal specimens $\ldots \ldots \ldots \ldots \ldots \ldots \ldots \ldots \ldots$

2.3 Engineering stress-strain curves for $\Pi I G$ weld specimens $\ldots \ldots \ldots \ldots \ldots \ldots \ldots \ldots \ldots$

2.4 True stress-strain curves for the TIG weld specimens $\ldots \ldots \ldots \ldots \ldots \ldots \ldots \ldots \ldots \ldots$

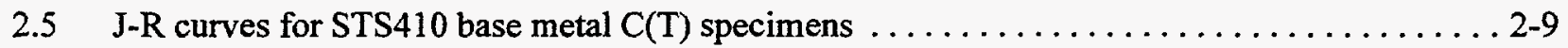

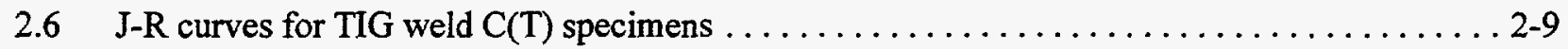

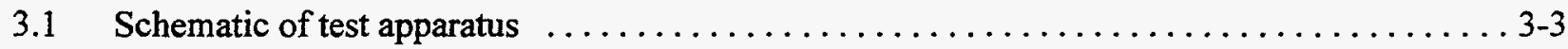

3.2 Load-displacement plot from Experiment 1.2-3 (stainless steel, quasi-static, cyclic [R=0] experiment) from Subtask 1.2 of IPIRG-1 program illustrating the meaning of the cyclic plastic displacement $\left(\delta_{\text {cyc }}\right)$

3.3 Instrumentation layout for Experiments $4.2-1,4.2-2,4.2-3$, and $3.3-1 \ldots \ldots \ldots \ldots \ldots$

3.4 Rotation device for Experiments $4.2-1,4.2-2$, and $4.2-3 \ldots \ldots \ldots \ldots \ldots \ldots \ldots \ldots \ldots \ldots$

3.5 Normalized east crack tip electric potential versus east crack tip crack-mouth-opening displacement for Experiment 4.2-1

3.6 Upper envelope of the normalized east crack tip electric potential data versus east crack tip crack-mouth-opening displacement data

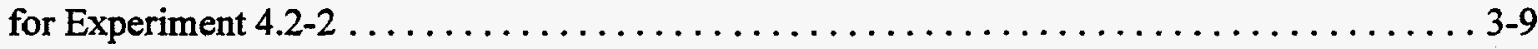

3.7 Normalized east crack tip electric potential versus east crack tip crack-mouth-opening displacement for Experiment 4.2-2 (only data corresponding to positive increasing loads are shown)

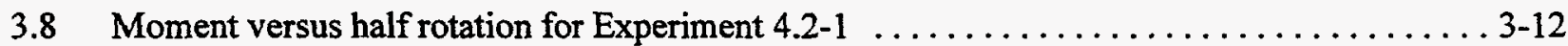

3.9 Normalized east crack tip electric potential versus east crack tip crack-mouth-opening displacement for Experiment 4.2-1

3.10 Normalized west crack tip electric potential versus west crack tip crack-mouth-opening displacement for Experiment 4.2-1 


\section{LIST OF FIGURES}

Figure

3.11 Crack-mouth-opening displacements versus the pipe displacement at the load points

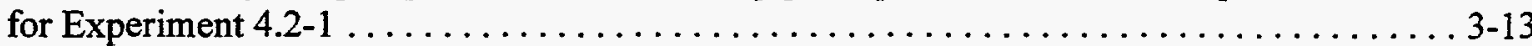

3.12 Moment versus center crack-mouth-opening displacement

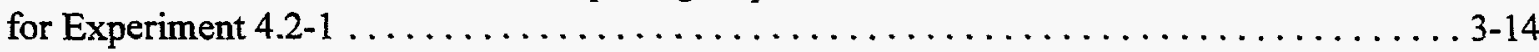

3.13 Average projected crack growth per crack tip versus the pipe displacement load points for Experiment 4.2-1

3.14 Moment versus half rotation for Experiment 4.2-2 (first and second loadings shown)

3.15 Upper envelope of the normalized east crack tip electric-potential data versus east crack tip crack-mouth-opening displacement data for Experiment 4.2-2

3.16 Upper envelope of the normalized west crack tip electric-potential data versus west crack tip crack-mouth-opening displacement data for Experiment 4.2-2

3.17 Normalized east crack tip electric-potential versus east crack tip crack-mouth-opening displacement for Experiment 4.2-2 (only data corresponding to positive increasing moments are shown)

3.18 Normalized west crack tip electric-potential versus west crack tip crack-mouth-opening displacement for Experiment 4.2-2 (only data corresponding to positive increasing moments are shown)

3.19 Crack-mouth-opening displacements versus the pipe displacement at the load points for Experiment 4.2-2 (only data corresponding to increasing positive moment values for Cycle 8 are shown)

3.20 Moment versus crack center crack-mouth-opening displacement for Experiment 4.2-2 (only data corresponding to the upper envelope are shown)

3.21 Average projected crack growth per crack tip versus the pipe displacement at the load points for Experiment 4.2-2

3.22 Moment versus half rotation for Experiment 4.2-3 (first and second loading blocks shown) 


\section{LIST OF FIGURES}

Figure

Page

3.23 Upper envelope of the normalized east crack tip electric-potential data versus

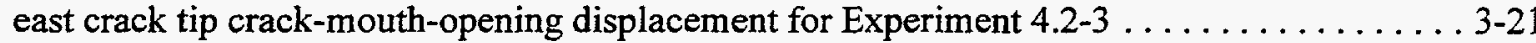

3.24 Upper envelope of the normalized west crack tip electric-potential

data versus pipe displacement at the load points for Experiment $4.2-3 \ldots \ldots \ldots \ldots \ldots \ldots 3-22$

3.25 Normalized east crack tip electric-potential versus east crack tip crack-mouth-opening displacement for Experiment 4.2-3 (only data corresponding to positive increasing moments are shown)

3.26 Normalized west crack tip electric-potential versus load-point displacement for Experiment 4.2-3 (only data corresponding to positive increasing moments are shown) . . . 3-23

3.27 Crack-mouth-opening displacement versus load-point displacement for Cycle 13 of Experiment 4.2-3 (only data corresponding to positive increasing moment values

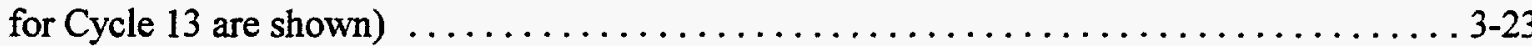

3.28 Crack section moment versus crack center crack-mouth-opening displacement for Experiment 4.2-3 (only data corresponding to the upper envelope are shown)

3.29 Average projected crack growth per crack tip versus the pipe displacement

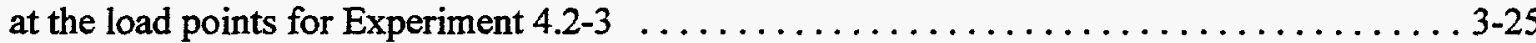

3.30 Crack section moment versus half rotation for Experiment $3.3-1 \ldots \ldots \ldots \ldots \ldots \ldots \ldots .26$

3.31 Normalized d-c electric potential at Crack Tip A versus crack-mouth-opening

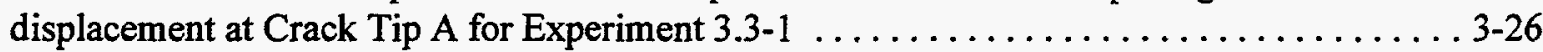

3.32 Normalized d-c electric potential at Crack Tip B versus crack-mouth-opening displacement at Crack Tip B for Experiment 3.3-1

3.33 CMOD versus pipe displacement at the load point for Experiment $3.3-1 \ldots \ldots \ldots \ldots .27$

3.34 Crack section moment versus centerline CMOD for Experiment $3.3-1 \ldots \ldots \ldots \ldots \ldots \ldots 3-28$

3.35 Average projected crack growth per crack tip versus pipe displacement

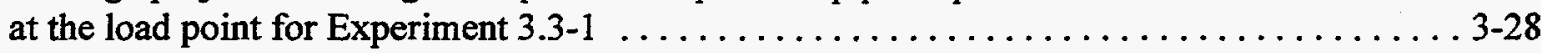

4.1 Quasi-static base metal stress-strain curve with Ramberg-Osgood representation of the data superimposed

4.2 Extrapolated quasi-static base metal $\mathrm{J}_{\mathrm{M}}-\mathrm{R}$ curve with actual $\mathrm{C}(\mathrm{T})$ specimen data superimposed 


\section{LIST OF FIGURES}

Figure

$\underline{\text { Page }}$

4.3 Extrapolated quasi-static weld metal $\mathrm{J}_{\mathrm{M}}-\mathrm{R}$ curve with actual $\mathrm{C}(\mathrm{T})$ specimen data superimposed

4.4 Comparison of experimental moments at crack initiation with predicted moments at crack initiation based on the GE-EPRI, LBB.ENG2, and R6 Revision 3 Option 1 analyses

4.5 Comparison of maximum experimental moments with maximum predicted moments based on the NSC, DPZP, GE/EPRI, LBB.ENG2, and R6 Revision 3 Option 1 analyses

$4.6 \mathrm{~J}_{\mathrm{D}}$-Resistance curves for Experiments $4.2-1,4.2-2,4.2-3$, and $3.3-1 \ldots \ldots \ldots \ldots \ldots \ldots .11$

4.7 Comparison of STS410 pipe and $\mathrm{C}(\mathrm{T})$ specimen $\mathrm{J}-\mathrm{R}$ curves $\ldots \ldots \ldots \ldots \ldots \ldots \ldots \ldots \ldots$

4.8 Comparison of STS410 TIG welded pipe and welded C(T) specimen J-R curves

5.1 Comparison of stress-strain curve for the A106 Grade B pipe material used in Subtask 1.2 of IPIRG-1 (DP2-F30) with the stress-strain curve for the STS410 pipe material evaluated as part of this effort (IP-F13)

5.2 Comparison of stress-strain curve for the A106B SAW used in IPIRG-1 (DP2-F29W) with the stress-strain curve for the TIG weld in STS410 evaluated in this program

5.3 Comparison of load-displacement curves for Experiments 4.2-1 and 3.3-1

5.4 Comparison of load-displacement curves for Experiments 4.2-1 and 3.3-1 up to the point of crack initiation

5.5 STS-410 and A106 Grade B J-R curve comparison

5.6 Plot of the ratio of cyclic $(R=-1)$ to monotonic fracture toughness from the pipe $\eta$-factor analysis as a function of the yield-to-ultimate strength ratio for the 152-mm (6-inch) nominal diameter through-wall-cracked pipe experiments conducted as part of this program and Subtask 1.2 of the IPIRG-1 program 


\section{LIST OF TABLES}

Table

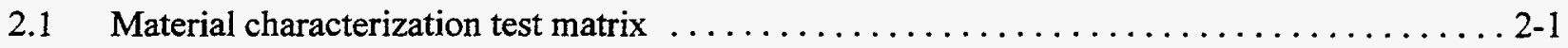

2.2 Material characterization test specimen numbering scheme $\ldots \ldots \ldots \ldots \ldots \ldots \ldots \ldots \ldots 2$

2.3 Tensile test summary for Japanese carbon steel pipe

(STS410) and associated TIG weld

2.4 Summary of C(T) specimen fracture toughness results for Japanese STS410 base metal

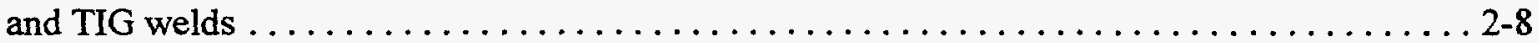

3.1 Test conditions for Japanese STS410 carbon steel pipe tests $\ldots \ldots \ldots \ldots \ldots \ldots \ldots \ldots \ldots$

3.2 Target loading scheme for dynamic, cyclic experiments $\ldots \ldots \ldots \ldots \ldots \ldots \ldots \ldots \ldots \ldots$

3.3 Pipe fracture data collected in Experiments 4.2-1, 4.2-2, 4.2-3, and 3.3-1 $\ldots \ldots \ldots \ldots \ldots$.4

3.4 Empirical constants for relating electric potential data

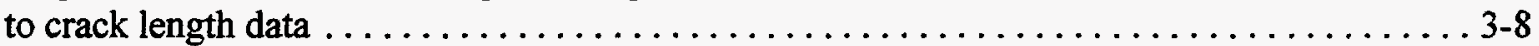

3.5 Summary of key results from Experiments $4.2-1,4.2-2,4.2-3$, and $3.3-1 \ldots \ldots \ldots \ldots \ldots 3-11$

4.1 Quasi-static STS410 carbon steel base metal tensile properties used in fracture analyses .

4.2 Comparison of experiment moments at crack initiation with GE/EPRI, LBB.ENG2, and R6 Revision 3 Option 1 predictions

4.3 Comparison of ratios of experimental-to-predicted moments at crack initiation and maximum moment for experiments conducted in this program and IPIRG-1

Subtask 1.2, Ref. 4.9

4.4 Comparison of maximum experimental moments with Net-Section-Collapse,

Dimensionless-Plastic-Zone Parameter, GE/EPRI, LBB.ENG2, and R6

predictions .

4.5 Comparison of $\mathrm{J}_{\mathrm{i}}$ values from pipe experiments with $\mathrm{J}_{\mathrm{i}}$ values from

$\mathrm{C}(\mathrm{T})$ specimens 



\section{EXECUTIVE SUMMARY}

This report presents the results from four $152 \mathrm{~mm}$ (6-inch) nominal diameter, circumferential throughwall-cracked, dynamic pipe experiments. Three were directly funded by the Japanese members of the Second International Piping Integrity Research Group IPIRG-2 program, and one was funded using joint IPIRG-2 funds. This series of experiments was part of a larger program being conducted in Japan with the purpose of developing a Japanese leak-before-break (LBB) criterion for carbon steel piping systems. The specific objective of this series of experiments was to ascertain whether Japanese STS410 carbon steel pipe is as sensitive to dynamic and cyclic loading effects as the A106 Grade B carbon steel pipe steels previously tested at Battelle during the IPIRG-1 program. (Note: STS410 pipe is identical to STS42 pipe, but the STS410 standard is written using SI units.)

In order to satisfy this objective, one quasi-static and three dynamic, four-point bend, circumferentially through-wall-cracked pipe fracture experiments were conducted. The test specimens for each experiment were fabricated from lengths of 152-mm (6-inch) nominal diameter, Schedule 120, STS410 carbon steel pipe. Each of the pipe lengths were from the same heat of pipe. The pipe dimensions and flaw dimensions for each experiment were nearly the same. For three of the experiments, the initial through-wall crack was located in the base metal. The displacement-time histories applied to these three base metal experiments were a quasi-static, monotonic, a dynamic, monotonic and a dynamic, cyclic $(R$ $=-1$ ) history used in similar IPIRG-1 pipe tests. The through-wall crack in the fourth experiment was in the center of a tungsten-inert-gas (TIG) weld, fabricated by Hitachi in Japan, joining two lengths of 152 $\mathrm{mm}$ (6-inch) nominal diameter STS410 pipe. The displacement-time history applied to this length of pipe was the same dynamic, cyclic history applied to the dynamic, cyclic base metal experiment. The test temperature for each of these pipe experiments was $300 \mathrm{C}(572 \mathrm{~F})$. Each test specimen was unpressurized.

In support of these pipe fracture experiments, a series of quasi-static and dynamic tensile tests and a series of quasi-static and dynamic compact (tension) fracture toughness tests were conducted.

A limited analysis effort was also undertaken as part of this program. The analysis efforts consisted of (1) comparing the experimental crack initiation moments and maximum moments with predictions based on available fracture prediction models, and (2) calculating J-R curves for the pipe experiments using the $\eta$-factor method.

The key findings from the material characterization efforts were:

- Loading the tensile specimens at dynamic rates (approximately $1 \mathrm{sec}^{-1}$ and $10 \mathrm{sec}^{-1}$ ) lowered the ultimate tensile strength of both the STS 410 base metal and the TIG weld approximately 15 to 25 percent when compared with the tensile data developed at quasi-static loading rates*. In addition, the fracture elongation for the base metal tensile specimens at the dynamic testing rates was approximately 60 percent greater than the elongation at quasi-static testing rates.

The yield strength of the base metal was increased 15 percent while the yield strength of the weld metal was decreased 20 percent as the strain rate was increased from $10^{-4} / \mathrm{sec}$ to $10 / \mathrm{sec}$. 
The increase in loading rate did not significantly affect the elongation of the weld metal tensile specimens.

- The TIG weld was stronger than the STS410 base metal. The quasi-static weld metal ultimate tensile strength was approximately 40 percent higher than the quasi-static base metal tensile strength. The dynamic (nominally $1 \mathrm{sec}^{-1}$ strain rate) weld metal tensile strength was approximately 45 percent higher than the comparable dynamic base metal tensile strength. The dynamic (nominally $10 \mathrm{sec}^{-1}$ strain rate) weld metal tensile strength was approximately 25 percent higher than the comparable dynamic base metal tensile strength.

- For the base metal $C(T)$ specimens, the average $J_{i}$ value for the highest loading rate $(0.2$ seconds to crack initiation) was 25 percent higher than the average $J_{i}$ value for the quasi-static or slower dynamic ( 10 seconds to crack initiation) loading rates. For the TIG weld specimens, the $\mathrm{J}_{\mathrm{i}}$ values at the higher loading rates were approximately 35 percent less than the $\mathrm{J}_{\mathrm{i}}$ values for the quasi-static tests. The higher loading rates did not significantly affect the J-R curves, for either the base metal or weld metal specimens after approximately $1 \mathrm{~mm}(0.04 \mathrm{inch})$ of crack extension.

- The quasi-static weld metal $J_{i}$ value for the TIG weld was twice the quasi-static $J_{i}$ value for the STS 410 base metal. The dynamic base metal and dynamic weld metal $\mathrm{J}_{\mathrm{i}}$ values are comparable. However, the weld metal J-R curves were quite a bit higher than the base metal $\mathrm{J}-\mathrm{R}$ curves for both the quasi-static and dynamic loading rate cases after approximately $1 \mathrm{~mm}$ ( 0.04 inch) of crack extension.

The key findings from the pipe experiments were:

- The maximum moment for the quasi-static monotonic experiment was approximately 10 percent higher than the maximum moment for the dynamic monotonic experiment. This reduction is believed to be influenced more by the difference in the crack growth angle from the initial circumferential crack plane than by the loading rate. The crack in the quasi-static experiment grew at a 48 degree angle from the circumferential plane, while the crack in the dynamic monotonic experiment grew at a 38 degree angle from the circumferential plane. Generally, as the angle from the crack plane increases, the load-carrying capacity and displacements increase. Up to the point of crack initiation, there was no significant difference between the load-displacement response of these two experiments.

- The maximum moment from the dynamic, cyclic base metal experiment was 7 percent less than the maximum moment from the dynamic, monotonic base metal experiment, and 11 percent less than the maximum moment from the dynamic, cyclic weld metal experiment. Neither of these reductions are very significant. Both are just outside the scatter in maximum moment values typically observed in this type of pipe fracture experiment. The slight difference in moment values for the two base metal experiments indicates that this material may not be very susceptible to cyclic damage for through-wall cracks in this pipe size. The somewhat greater difference in moment values for the two cyclic experiments is an artifact of the fact that the weld metal is stronger and tougher than the base metal. The reason why this difference is not as great as might be expected based on the differences in strength and toughness properties between the base and weld metals is that shortly after the crack initiated 
in the weld metal experiment, the crack turned out of the weld and grew in the weaker, less tough base metal.

- For identical displacement-time load histories, the base metal, cyclic experiment initiated on the eighth loading cycle at a moment value of $63.3 \mathrm{kN}-\mathrm{m}(560,300 \mathrm{in}-\mathrm{lbs})$ while the weld metal, cyclic experiment initiated on the thirteenth loading cycle at a moment value of 83.2 $\mathrm{kN}-\mathrm{m}(736,400 \mathrm{in}-\mathrm{lbs})$. This large increase in moment capacity at crack initiation for the weld metal experiment is due to the fact that the strength and toughness of the weld metal is significantly greater than that of the base metal.

- No unstable crack instabilities, i.e., crack jumps, occurred in any of these through-wall-cracked pipe experiments.

The key findings from the analyses of these pipe experiments were:

- The experimental moments at crack initiation were 1 to 30 percent greater than the predicted moments at crack initiation for each of these experiments when the predictions were based on the GE/EPRI and R6 Revision 3 Option 1 methods. When the predictions were based on the LBB.ENG2 method, the experimental moments at crack initiation were up to 10 percent less than the predicted moments. Conversely, the fracture ratios (i.e., the ratio of the experimentalto-predicted moments) at crack initiation for the IPIRG-1 Subtask 1.2 dynamic, through-wallcracked pipe experiments were typically less than 1.0 for all three analysis methods considered. This difference may be an artifact of using quasi-static material property data in the analyses of both sets of experiments. If the dynamic data were used in the analysis of the STS410 experiments conducted as part of this effort, the fracture ratios at crack initiation may not change significantly in that the base metal ultimate strength is slightly lowered, but the base metal $J_{i}$ value is slightly raised at the higher loading rates. However, if dynamic data were used in the analysis of the A106 Grade B experiments conducted as part of IPIRG-1, the fracture ratio at crack initiation would increase significantly due to the greater reduction in the ultimate strength and the reduction in the $J$ value at crack initiation. As a result of this greater increase in the fracture ratios for the A106 Grade B pipe experiments when dynamic material property data are used in the analyses, the fracture ratios for the two sets of experiments would be more in line with each other. This finding that the fracture ratios for this STS410 material were less sensitive to the choice of quasi-static or dynamic material property data than the fracture ratios for the similar size A106 Grade B material evaluated in IPIRG-1, suggests that this STS410 material may be less sensitive to loading rate effects than that particular A106 Grade B pipe.

- The value of $J$ at crack initiation $\left(J_{i}\right)$ calculated from the $\eta$-factor analysis for the dynamic cyclic pipe experiment with the crack in the TIG weld was approximately 2 times higher than the $\mathrm{J}_{\mathrm{i}}$ value for the dynamic monotonic, base metal experiment and 5 times higher than the $\mathrm{J}_{\mathrm{i}}$ value for the dynamic cyclic, base metal experiment. The average $C(T)$ specimen $J_{i}$ value for the weld specimens was also higher than the average $C(T)$ specimen $J_{i}$ value for the base metal specimens, but not to the degree observed for the pipe experiments. Once the crack in the cyclic weld metal pipe experiment initiated, the J-R curve leveled off and tended to mirror the cyclic base metal experiment J-R curve. This was not surprising in that once the crack in the 
weld metal experiment initiated, it turned out of the weld and grew in the weaker, less tough base metal. As a result, one would expect the fracture resistance for this experiment to be similar to that of the cyclic base metal experiment once the crack started to grow. It was also found that the J-R curves for the two cyclic experiments were both significantly below the J-R curves for the dynamic, monotonic, base metal experiment. For this stress ratio $(R=-1)$, this reduction in the J-R curve is to be expected. This lowering of the J-R curves for the cyclic $(R=-1)$ experiments was observed previously for the IPIRG-1 Subtask 1.2 cyclic throughwall-cracked pipe experiments.

As a result of these findings the following conclusions were drawn:

- The STS410 carbon steel pipe material and the associated TIG weld evaluated in this program may be slightly susceptible to dynamic strain aging effects, although the extent of their susceptibility is probably less than some of the U.S. manufactured carbon steel materials evaluated at Battelle in the Degraded Piping, IPIRG-1, and Short Cracks in Piping and Piping Welds programs. The absence of any crack instabilities, i.e., crack jumps, in any of the pipe experiments also suggests that this material may not be highly sensitive to dynamic strain aging effects. (Note, however, some U.S. steels tested in the Short Cracks in Piping and Piping Welds program show even less susceptibility to dynamic strain aging than this STS410 pipe. There is a high degree of variability of dynamic strain aging sensitivity within U.S. steel grades tested in these programs.)

- Based on a comparison of maximum loads for the two dynamic base metal experiments, the STS410 carbon steel pipe material appears to be less sensitive to cyclic loading effects than the A106 Grade B pipe material evaluated in Subtask 1.2 of the IPIRG-1 program. However, when one compares the J-R curves for the pipe experiments from the $\eta$-factor analyses, one sees a dramatic reduction in toughness due to cyclic loading. This material seems to be more sensitive to cyclic loading after crack initiation than before. Since crack initiation is relatively close to the maximum load in small diameter pipe tests, this may explain why the maximum loads for the two base metal experiments agree so closely. For larger diameter pipes where the initiation load is further from the maximum load, there may be more significant effects of cyclic loading on the maximum load value.

- The through-wall cracks in the STS410 carbon steel pipe experiments all grew out of the circumferential crack plane, much in the same manner as the through-wall cracks tested in the U.S. manufactured carbon steel pipe materials evaluated in the Degraded Piping, IPIRG-1, and Short Cracks programs. Such behavior is typically attributed to toughness anisotropy effects. Experience to date suggests that the angled crack growth has a positive effect in increasing the maximum loads and displacements. 


\section{ACKNOWLEDGMENTS}

This program was undertaken on the behalf of a consortium of the Japanese IPIRG-2 participants. The IPIRG-2 program was an international group program with the scope of studying the fracture behavior of nuclear piping systems subjected to dynamic and cyclic load histories characteristic of a seismic event. The program was managed by the USNRC, with Mr. Mike Mayfield being the overall program monitor. Japan is one of the 15 member countries which belonged to the group. Their representative to the IPIRG Technical Advisory Group (TAG) was Dr. Koichi Kashima of the Central Research Institute of Electric Power Industry (CRIEPI). The authors would also like to express their appreciation to Dr. Kashima for his assistance in developing this program. In Japan, the work described in this report was coordinated by Mr. Jun-ichi Kawahata of Hitachi. The authors would also like to express their appreciation to Mr. Kawahata for his assistance. The authors would also like to thank Mr. Naoki Miura of CRIEPI, an IPIRG-2 visiting scientist at Battelle, who reviewed this report for the purpose of ascertaining its clarity to his colleagues in Japan.

The authors would also like to thank some of their colleagues at Battelle who provided technical assistance during the conduct of this program. Those individuals include Mr. Paul Held, Mr. Dennis Rider, Mr. George Wall, Mr. Mike Oliver, Mr. Dave Roberts, Mr. Tom Kilinski, and Mr. Rick Olson. Appreciation is also expressed to Mr. Robert LaBounty who provided the video documentation of the pipe experiments conducted as part of this program. Finally, the authors would like to thank Mrs. Verna Kreachbaum for her assistance in coordinating this report. 



\section{NOMENCLATURE}

\section{SYMBOLS}

a

b

c

$\mathrm{C}_{\mathrm{M}}$

D

$\mathrm{d} J / \mathrm{da}$

E

F

h

$\mathbf{h}^{\prime}$

$h^{\prime \prime}$

I

J

$\mathrm{J}_{\text {elastic }}$

$\mathbf{J}_{\mathrm{i}}$

$J_{M}$

$\mathbf{J}_{\text {plastic }}$

$\mathbf{J}_{\text {Total }}$

K

L

M
Crack length

Half the pipe circumference

Half crack length

Machine compliance

Pipe diameter

Change in J with respect to crack growth

Elastic modulus

Compliance function from GE/EPRI Handbook

Function of the crack angle used in $\eta$ factor analysis

First derivative of the function $h$ with respect to the crack length $\Theta$

Second derivative of the function $\mathrm{h}$ with respect to the crack length $\Theta$

Area moment of inertia

J-integral fracture parameter

Elastic component of J

$\mathrm{J}$ at crack initiation

Modified form of $J$

Plastic component of J

Elastic plus plastic components of $\mathrm{J}$

LEFM stress intensity factor parameter

Inner span in a four-point bend pipe experiment

Moment 
n

P

R

$R_{\text {m }}$

t

$\mathrm{V}_{2}$

Z

$\alpha$

$\delta$

$\delta_{\mathrm{cyc}}$

$\delta_{i}$

$\Delta$

$\Delta_{\mathrm{EL}, \mathrm{C}}$

$\Delta_{\mathrm{EL}, \mathrm{M}}$

$\Delta_{\mathrm{EL}, \mathrm{NC}}$

$\Delta_{\mathrm{PL}}$

$\Delta \mathrm{K}$

$\epsilon$

$\epsilon_{\text {。 }}$

$\gamma$

$\eta$

$\phi$

$\sigma$
Ramberg-Osgood parameter, strain hardening exponent

Half of the total applied load in a four-point bend experiment

Stress ratio or minimum/maximum load

Mean pipe radius

Pipe wall thickness

Compliance function in the GE/EPRI Handbook

Outer span in a four-point bend pipe experiment

Ramberg-Osgood parameter

Displacement

Cyclic plastic displacement increment

Displacement at crack initiation for the dynamic monotonic experiment

Load-line displacement

Elastic component of displacement due to the crack

Elastic component of displacement due to machine compliance

Elastic component of uncracked pipe displacement

Plastic displacement

Change in stress intensity factor $(\mathrm{K})$

Strain

Ramberg-Osgood parameter, reference strain

Function of the crack angle used in $\eta$-factor analysis, ratio of $h^{\prime}$ to $h^{\prime \prime}$

Geometric constant used in general analytical procedure where $J_{\text {Plastic }}$ is calculated using experimental load, displacement, and crack growth data

Half of the total pipe rotation

Stress 
$\sigma_{0}$

$\theta$

\section{ACRONYMS AND INTTIALISMS}

$\mathrm{AC}$

ASTM

CMOD

COA

$\mathrm{C}(\mathrm{T})$

d-c

d-c EP

DPZP

DSA

Dyn

EDM

EP

$\mathrm{EP}_{\mathrm{B}}$

$\mathrm{EP}_{\mathrm{c}}$

EPRI

FM

GE

HS

IPIRG

IPIRG-1

Alternating current

Crack-opening area

Compact (Tension)

Direct current

Dynamic strain aging

Dynamic

Electric potential

Frequency modulated

General Electric

High speed
American Society for Testing and Materials

Crack-mouth-opening displacement

Direct-current electric potential

Dimension-Plastic-Zone Parameter

Electric discharge machine

Base metal reference electric potential

Electric potential across the center of the crack

Electric Power Research Institute

International Piping Integrity Research Group

First International Piping Integrity Research Group Program 
Nomenclature

IPIRG-2 Second International Piping Integrity Research Group Program

J-R J-resistance

LBB Leak-Before-Break

L-C Orientation that indicates crack plane is normal to longitudinal axis $(\mathrm{L})$ and crack growth direction is circumferential (C)

LVDT Linear variable differential transformer

LWR Light water reactor

MPA Staatliche Materialprüfungsanstatt (University of Stuttgart)

Mono Monotonic

MTS Materials Testing Systems (Supplier of servo-hydraulic equipment)

NSC Net-Section-Collapse

NUPEC Nuclear Power Engineering Company (Japan)

PC

Personal computer

QS

Quasi-static

SAW Submerge-arc weld

TIG Tungsten-inert-gas weld

TWC Through-wall crack

U.S. United States

USNRC United States Nuclear Regulatory Commission 


\section{PREVIOUS REPORTS IN SERIES}

\section{Previous Related Documents from NRC's International Piping Integrity Research Group (IPIRG) Program}

"Evaluation and Refinement of Leak-Rate Estimation Models," NUREG/CR-5128, Revision 1, June 1994.

"Loading Rate Effects on Strength and Fracture Toughness of Pipe Steels Used in Task 1 of the IPIRG Program," Topical Report, NUREG/CR-6098, October 1993.

"Stability of Cracked Pipe Under Inertial Stresses," NUREG/CR-6233, Volume 1, August 1994.

\section{Reports from the Short Cracks in Piping and Piping Weld Program}

"Short Cracks in Piping and Piping Welds," First Semiannual Report, NUREG/CR-4599, Vol. 1, No. 1, March 1991.

"Short Cracks in Piping and Piping Welds," Second Semiannual Report, NUREG/CR-4599, Vol. 1, No. 2, April 1992.

"Short Cracks in Piping and Piping Welds," Third Semiannual Report, NUREG/CR-4599, Vol. 2, No. 1, September 1992.

"Short Cracks in Piping and Piping Welds," Fourth Semiannual Report, NUREG/CR-4599, Vol. 2, No. 2, February 1993.

"Short Cracks in Piping and Piping Welds," Fifth Semiannual Report, NUREG/CR-4599, Vol. 3, No. 1, October 1993.

"Short Cracks in Piping and Piping Welds," Sixth Semiannual Report, NUREG/CR-4599, Vol. 3, No. 2 , March 1994.

"Short Cracks in Piping and Piping Welds," Seventh Program Report, NUREG/CR-4599, BMI-2173, Vol. 4, No. 1, April 1995.

Assessment of Short Through-Wall Circumferential Cracks in Pipes--Experiments and Analysis," NUREG/CR-6235, April 1995.

"Fracture Evaluations of Fusion-Line Cracks in Nuclear Pipe Bimetallic Welds," NUREG/CR-6297, April 1995. 
Previous Reports in Series

"Effect of Dynamic Strain Aging on the Strength and Toughness of Nuclear Ferritic Piping at LWR Temperatures," NUREG/CR-6226, October 1994.

"Effects of Toughness Anisotropy and Combined Tension, Torsion, and Bending Loads on Fracture Behavior of Ferritic Nuclear Pipe," NUREG/CR-6299, April 1995.

"Refinement and Evaluation of Crack-Opening Analyses for Short Circumferential Through-Wall Cracks in Pipes," NUREG/CR-6300, April 1995.

"Probabilistic Pipe Fracture Evaluations for Leak-Rate Detection Applications," NUREG/CR-6004, April 1995.

"Validity Limits in J-Resistance Curve Determination--Volume 1: An Assessment of the $\mathrm{J}_{\mathrm{M}}$ Parameter," NUREG/CR-6264, Volume 1, February 1995.

"Validity Limits in J-Resistance Curve Determinations--Volume 2: A Computational Approach to Ductile Crack Growth Under Large-Scale Yielding Condition," NUREG/CR-6264, Volume 2, February 1995.

"Stainless Steel Submerged Arc Weld Fusion Line Toughness," NUREG/CR-6251, April 1995.

\section{Previous Related Documents from NRC's Degraded Piping Program - Phase II}

"Degraded Piping Program - Phase II," Semiannual Report, NUREG/CR-4082, Vol. 1, Oct. 1984.

"Degraded Piping Program - Phase II," Semiannual Report, NUREG/CR-4082, Vol. 2, June 1985.

"Degraded Piping Program - Phase II," Semiannual Report, NUREG/CR-4082, Vol. 3, March 1986.

"Degraded Piping Program - Phase II," Semiannual Report, NUREG/CR-4082, Vol. 4, July 1986.

"Degraded Piping Program - Phase II," Semiannual Report, NUREG/CR-4082, Vol. 5, Dec. 1986.

"Degraded Piping Program - Phase II," Semiannual Report, NUREG/CR-4082, Vol. 6, April 1988.

"Degraded Piping Program - Phase II," Semiannual Report, NUREG/CR-4082, Vol. 7, March 1989.

"Degraded Piping Program - Phase II," Semiannual Report, NUREG/CR-4082, Vol. 8, March 1989.

"NRC Leak-Before-Break (LBB.NRC) Analysis Method for Circumferentially Through-Wall Cracked Pipes Under Axial Plus Bending Loads," Topical Report, NUREG/CR-4572, March 1986. 
"Elastic-Plastic Finite Element Analysis of Crack Growth in Large Compact Tension and

Circumferentially Through-Wall-Cracked Pipe Specimen--Results of the First Battelle/NRC Analysis

Round Robin," Topical Report, NUREG/CR-4573, September 1986.

"An Experimental and Analytical Assessment of Circumferential Through-Wall Cracked Pipes Under Pure Bending," Topical Report, NUREG/CR-4574, June 1986.

"Predictions of J-R Curves With Large Crack Growth From Small Specimen Data," Topical Report, NUREG/CR-4687, September 1986.

"An Assessment of Circumferentially Complex-Cracked Pipe Subjected to Bending," Topical Report, NUREG/CR-4687, September 1986.

"Analysis of Cracks in Stainless Steel TIG Welds," Topical Report, NUREG/CR-4806, November 1986.

"Approximate Methods for Fracture Analyses of Through-Wall Cracked Pipes," Topical Report, NUREG/CR-4853, January 1987.

"Assessment of Design Basis for Load-Carrying Capacity of Weld-Overlay Repair," Topical Report, NUREG/CR-4877, February 1987.

"Analysis of Experiments on Stainless Steel Flux Welds," Topical Report, NUREG/CR-4878, February 1987.

"Experimental and Analytical Assessment of Circumferentially Surface-Cracked Pipes Under Bending," Topical Report, NUREG/CR-4872, April 1987.

\section{Previous Related Documents from NRC's Degraded Piping Program - Phase I}

"Summary of Results from the IPIRG-2 Round-Robin Analyses," Technical Report, NUREG/CR-6337, January 1996.

\section{Other Related Program Reports}

"Validation of Analysis Methods for Assessing Flawed Piping Subjected to Dynamic Loading," NUREG/CR-6234, August 1994. 



\subsection{INTRODUCTION}

This report presents the results of a series of four 152-mm (6-inch) nominal diameter, circumferential through-wall-cracked, dynamic pipe experiments conducted for a consortium of the Japanese IPIRG-2 member organizations. Three of these experiments were entirely funded by the Japanese IPIRG-2 members. One experiment was funded with the general IPIRG-2 program funds. The pipe material used in each of these pipe experiments was a carbon steel (STS410) manufactured in Japan. The crack for three of the experiments was located in the base metal. The crack for the fourth experiment was located in the center of a tungsten-inert-gas (TIG) weld manufactured in Japan and joining two sections of STS410.

This series of experiments was part of a larger program being carried out in Japan with the purpose of developing a Japanese leak-before-break (LBB) criterion for carbon steel piping systems. The specific objective of this series of experiments was to compare a carbon steel pipe material manufactured in Japan with carbon steel pipe materials manufactured in the United States to ascertain whether this Japanese pipe steel was as sensitive to dynamic and cyclic effects as the carbon steel pipe steels manufactured in the United States that were previously tested in the IPIRG-1 program (Ref. 1.1).

The pipe samples tested in this series of experiments were all loaded in four-point bending. Two base metal specimens were prepared for monotonic tests; one quasi-static and one dynamic. In addition, one base metal and one weld metal specimen were prepared for testing using a dynamic, cyclic load history with a stress ratio (R) of -1 using the same cyclic displacement function used in the IPIRG-1 Subtask 1.2 pipe experiments in References 1.1 and 1.2.

In addition to the pipe experiments, which are discussed in detail in Section 3 of this report, this report also presents the results from the material characterization efforts carried out for both the pipe material and the associated weld metal. Both quasi-static and dynamic tensile and quasi-static and dynamic compact (tension) fracture toughness tests were conducted on both materials. The results of these efforts are discussed in Section 2 of this report.

Section 4 of the report presents the results of the limited analyses of the pipe experiments that were conducted as part of this effort. The analysis efforts included: (1) comparing the moment at crack initiation and maximum moment with available fracture prediction analyses, and (2) calculating J-R curves for the pipe experiments and comparing those results with the J-R curves from the $C(T)$ fracture toughness specimens. The fracture prediction analyses evaluated in this effort include: (a) the NetSection-Collapse (NSC) analysis, (b) the Dimensionless-Plastic-Zone-Parameter (DPZP) analysis, and (c) the GE/EPRI and LBB.ENG2 J-estimation scheme analyses, and (d) the R6 Revision 3 Option 1 method. The maximum moment values from these four experiments were compared with each of the analysis methods while the moments at crack initiation were compared only with the J-estimation scheme analyses, i.e., GE/EPRI and LBB.ENG2, and the R6 Revision 3 Option 1 analysis method. The J-R curves from the pipe experiments were calculated using the $\eta$-factor method using the loaddisplacement-crack growth data for each experiment. Further details of each of these analysis methods are provided in Section 4. 
Section 5 presents a discussion of the results from these experiments. As part of this discussion, both the effect of dynamic and cyclic loading on the response of this Japanese carbon steel pipe steel will be assessed.

The report concludes with a summary and conclusion section in Section 6.

\subsection{References}

1.1 Wilkowski, G., Kramer, G., Vieth, P., Francini, R., and Scott, P., "The Effect of Cyclic Loading During Ductile Tearing on Circumferentially Crack Pipe -- Analytical Results," ASME PVP Vol. 280, pp 221-240, June 1994.

1.2 Scott, P., Kramer, G., Vieth, P., Francini, R., and Wilkowski, G., "The Effect of Dynamic and Cyclic Loading During Ductile Tearing on Circumferentially Crack Pipe -- Analytical Results," ASME PVP Vol. 280, pp 221-240, June 1994. 


\subsection{MATERIAL CHARACTERIZATION EFFORTS}

This section of the report presents the quasi-static and dynamic tensile test results as well as the quasistatic and dynamic fracture toughness test results obtained using $C(T)$ specimens. The dynamic rates used in these efforts correspond to high amplitude, low frequency, seismic rates as determined in similar IPIRG-1 experiments (Ref. 2.1). All of these tests were conducted using a monotone increasing displacement-control, i.e., there was no cyclic loading in these tests. Table 2.1 shows the material characterization test matrix, while Table 2.2 shows the test specimen numbering scheme.

Table 2.1 Material characterization test matrix

\begin{tabular}{|c|c|c|c|c|c|}
\hline & \multirow[b]{2}{*}{ Test Type } & \multicolumn{2}{|c|}{$\begin{array}{l}\text { Longitudinal } \\
\text { Tensile Tests }\end{array}$} & \multicolumn{2}{|c|}{$\begin{array}{c}\text { C(T) Specimen } \\
\text { Fracture } \\
\text { ToughnessTests } \\
\text { (L-C Orientation) } \\
\end{array}$} \\
\hline & & $\begin{array}{l}\text { Quasi- } \\
\text { Static }\end{array}$ & Dynamic & $\begin{array}{l}\text { Quasi- } \\
\text { Static }\end{array}$ & Dynamic \\
\hline Material & $\begin{array}{l}\text { 152-mm (6-inch) diameter } \\
\text { STS } 410 \text { carbon steel }\end{array}$ & $\mathrm{x}$ & $\mathrm{x}$ & $\mathrm{x}$ & $\mathbf{x}$ \\
\hline Crack Location & $\begin{array}{l}\text { Base Metal } \\
\text { Weld Metal }\end{array}$ & $\begin{array}{l}\mathrm{x} \\
\mathrm{x}\end{array}$ & $\begin{array}{c}\mathbf{x} \\
\dot{x}\end{array}$ & $\begin{array}{l}\mathrm{x} \\
\mathrm{x}\end{array}$ & $\begin{array}{l}\mathrm{x} \\
\mathrm{x}\end{array}$ \\
\hline Test Temperature & $300 \mathrm{C}(572 \mathrm{~F})$ & $\mathbf{x}$ & $\mathbf{x}$ & $\mathbf{x}$ & $\mathrm{x}$ \\
\hline Strain Rate & $\begin{array}{l}4 \times 10^{-4} / \text { second } \\
1 / \text { second } \\
10 / \text { second }\end{array}$ & $\mathrm{x}$ & $\begin{array}{l}\mathrm{x} \\
\mathrm{x}\end{array}$ & & \\
\hline $\begin{array}{l}\text { Time to Achieve } \\
\text { Crack Initiation }\end{array}$ & $\begin{array}{l}600 \text { seconds } \\
0.2 \text { second } \\
10 \text { seconds }\end{array}$ & & & $\mathbf{x}$ & $\begin{array}{l}x \\
x\end{array}$ \\
\hline Duplicate Tests & & $\mathrm{x}$ & $\mathrm{x}$ & $\mathbf{x}$ & $\mathrm{x}$ \\
\hline $\begin{array}{l}\text { Total Number of } \\
\text { Tests }\end{array}$ & & 4 & 8 & 4 & 8 \\
\hline
\end{tabular}


Table 2.2 Material characterization test specimen numbering scheme

\begin{tabular}{|c|c|c|c|}
\hline $\begin{array}{l}\text { Specimen* } \\
\text { Number }\end{array}$ & $\begin{array}{l}\text { Test } \\
\text { Type }\end{array}$ & $\begin{array}{c}\text { Target } \\
\text { Test Speed }\end{array}$ & Material \\
\hline IPF13-T1 & QS Tensile & $4 \times 10^{-4} / \mathrm{sec}$ & Base Metal \\
\hline IPF13-T2 & QS Tensile & $4 \times 10^{-4} / \mathrm{sec}$ & Base Metal \\
\hline IPF13-T4 & HS Tensile & $1 / \mathrm{sec}$ & Base Metal \\
\hline IPF13-T6 & HS Tensile & $10 / \mathrm{sec}$ & Base Metal \\
\hline IPF13-T7 & HS Tensile & $10 / \mathrm{sec}$ & Base Metal \\
\hline IPF13-T8 & HS Tensile & $1 / \mathrm{sec}$ & Base Metal \\
\hline IPF14-T1w & QS Tensile & $4 \times 10^{-4} / \mathrm{sec}$ & Weld Metal \\
\hline IPF16-T2W & QS Tensile & $4 \times 10^{-4} / \mathrm{sec}$ & Weld Metal \\
\hline IPF16-T3w & HS Tensile & $10 / \mathrm{sec}$ & Weld Metal \\
\hline IPF16-T4w & HS Tensile & $1 / \mathrm{sec}$ & Weld Metal \\
\hline IPF14-T2w & HS Tensile & $1 / \mathrm{sec}$ & Weld Metal \\
\hline IPF13-1 & QS C(T) & $600 \mathrm{sec}$ to init & Base Metal \\
\hline IPF13-2 & QS C(T) & $600 \mathrm{sec}$ to init & Base Metal \\
\hline IPF13-4 & HS C(T) & $10 \mathrm{sec}$ to init & Base Metal \\
\hline IPF 13-5 & HS C(T) & $0.2 \mathrm{sec}$ to init & Base Metal \\
\hline IPF13-6 & HS C(T) & $0.2 \mathrm{sec}$ to init & Base Metal \\
\hline IPF13-7 & HS C(T) & $10 \mathrm{sec}$ to init & Base Metal \\
\hline IPF 16-1w & QS C(T) & $600 \mathrm{sec}$ to init & Weld Metal \\
\hline IPF16-2w & QS C(T) & $600 \mathrm{sec}$ to init & Weld Metal \\
\hline IPF $16-3 w$ & HS C(T) & $10 \mathrm{sec}$ to init & Weld Metal \\
\hline IPF $16-4 w$ & HS C(T) & $10 \mathrm{sec}$ to init & Weld Metal \\
\hline IPF 16-5w & HS C(T) & $0.2 \mathrm{sec}$ to init & Weld Metal \\
\hline IPF16-6w & HS C(T) & $0.2 \mathrm{sec}$ to init & Weld Metal \\
\hline
\end{tabular}

* Planned eight dynamic tensile tests but only seven produced good data.

\subsection{Test Materials}

All material used in this study was supplied by Hitachi. All base metal specimens were fabricated from 152-mm (6-inch) nominal diameter, Schedule 120, STS410 carbon steel pipe. The weld specimens were machined from three tungsten-inert-gas (TIG) welds fabricated in Japan by joining two sections of 152mm (6-inch) nominal diameter, Schedule 120, STS410 carbon steel pipe. The pipe sections used in the 
fabrication of the base metal tensile and $C(T)$ specimens, and the pipe sections used for the weld metal specimens, were all from the same heat of pipe as the pipes used in the pipe fracture experiments.

The test welds for the pipe experiments and material tests. were all made at the same time using the same procedures. Cracks were introduced into the center of the weld for the weld metal $\mathrm{C}(\mathrm{T})$ and pipe tests. There was essentially no weld crown on the outside surface of the pipe, but the toe of the weld extended somewhat toward the center of the pipe.

\subsection{Tensile Tests Results}

In order to completely characterize the tensile properties of this material, quasi-static and dynamic tensile tests were conducted on both the base and weld metals. The quasi-static base metal specimens were round-bar threaded-end specimens having a gage-section diameter of $6.35 \mathrm{~mm}(0.25 \mathrm{inch})$ and a reduced section length of $31.75 \mathrm{~mm}$ (1.25 inch). The dynamic base metal specimens were flat, pinloaded specimens having a width of $6.35 \mathrm{~mm}(0.25 \mathrm{inch})$, a thickness of $3.18 \mathrm{~mm}(0.125 \mathrm{inch})$, and a gage length of $8.89 \mathrm{~mm}(0.35 \mathrm{inch})$. The quasi-static and dynamic weld metal specimens were flat, pinloaded specimens having a width of $4.44 \mathrm{~mm}(0.175 \mathrm{inch})$, a thickness of $3.18 \mathrm{~mm}(0.125 \mathrm{inch})$, and gage length of $8.89 \mathrm{~mm}(0.35 \mathrm{inch})$. The width of these weld specimens had to be reduced in order to insure that the gage section was fabricated entirely of weld metal because of the small size of the supplied TIG weld. All tensile specimen geometries were consistent with those used in both the IPIRG-1 and IPIRG-2 programs. All tensile specimens were manufactured with the tensile axis parallel with the pipe axis.

All tensile tests were conducted at $300 \mathrm{C}(572 \mathrm{~F})$. The quasi-static base metal round-bar specimen tests were conducted in a screw driven $133 \mathrm{kN}(30,000 \mathrm{lbs})$ Instron test machine. The strains were measured using a high temperature MTS extensometer. The flat specimens used in the quasi-static weld experiments and the dynamic base metal and weld experiments were tested in a $22 \mathrm{kN}(5,000 \mathrm{lb})$ servohydraulic test system. The strains in all of these flat specimen tests were measured using a high temperature clip gage mounted on knife edges that were welded to the integral flags on the specimens. Note, during IPIRG-1, the strains for the high speed tensile tests were measured using an optical extensometer. However, through the course of IPIRG-2, it was discovered that this equipment was no longer producing acceptable strain data. Therefore, a new high speed set-up was developed and tested for use in IPIRG-2. Load, stroke, strain and time were collected for all tensile tests using LabTech Notebook data acquisition software, and later reduced using Quatro-Pro software.

\subsubsection{Base Metal Results}

Table 2.3 summarizes the tensile test results for both the STS410 base metal and the TIG weld. Figure 2.1 shows engineering stress-strain curves for the base metal specimens. True stress-strain curves up to the onset of necking are shown in Figure 2.2 for these same specimens. (Note, due to limitations with the strain monitoring systems, especially in the high speed tensile tests, the absolute strain values in the low strain range should be used with caution. This is readily evident in examining Figures 2.1 and 2.2 in which dramatically different elastic modulus values are evident for the different strain rates.) From 


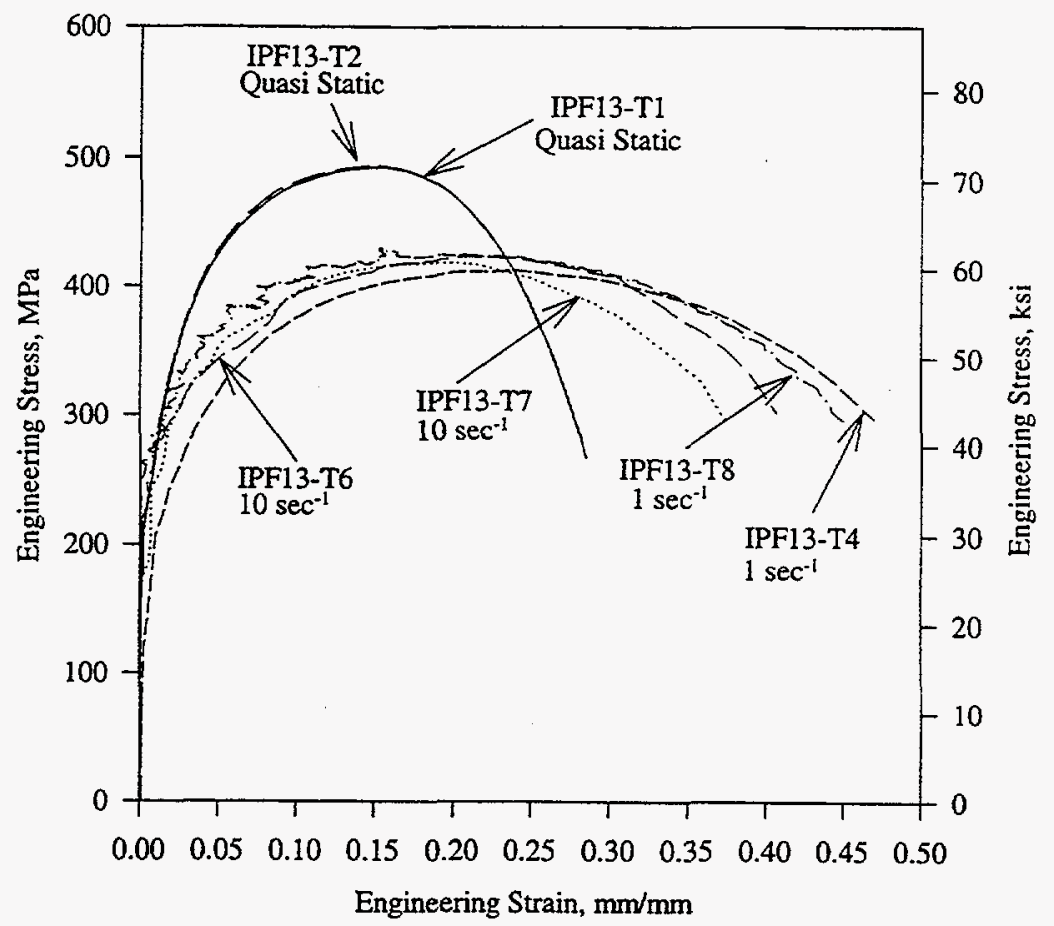

Figure 2.1 Engineering stress-strain curves for STS410 base metal specimens

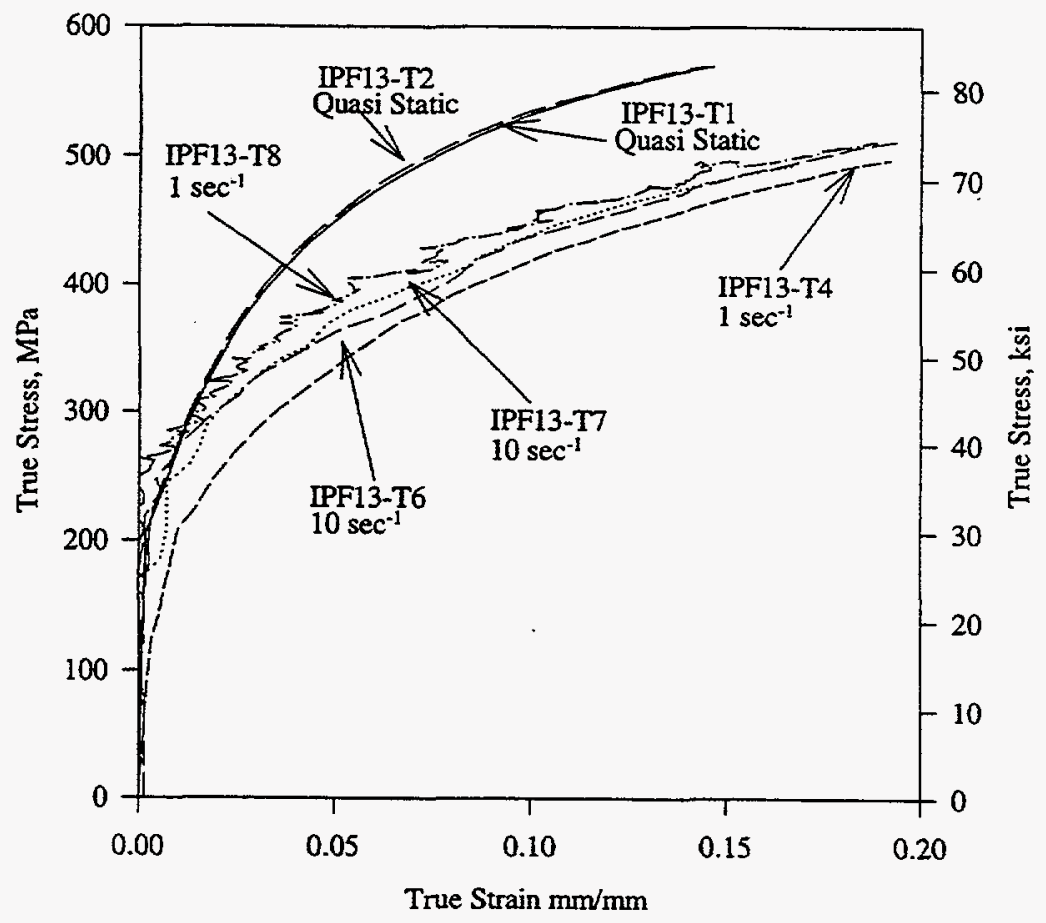

Figure 2.2 True stress-strain curves for STS410 base metal specimens 
Table 2.3 Tensile test summary for Japanese carbon steel pipe (STS410) and associated TIG weld

\begin{tabular}{|c|c|c|c|c|c|c|}
\hline \multirow{2}{*}{$\begin{array}{c}\text { Specimen } \\
\text { Identification } \\
\text { Number }\end{array}$} & \multirow{2}{*}{$\begin{array}{c}\text { Actual } \\
\text { Strain } \\
\text { Rate, } \\
\text { sec }^{-1}\end{array}$} & \multicolumn{2}{|c|}{$\begin{array}{c}\text { 0.2 Percent } \\
\text { Offset Yield } \\
\text { Strength }\end{array}$} & \multicolumn{2}{|c|}{$\begin{array}{c}\text { Ultimate } \\
\text { Tensile } \\
\text { Strength } \\
\end{array}$} & \multirow[t]{2}{*}{$\begin{array}{c}\text { Percent } \\
\text { Elongation }\end{array}$} \\
\hline & & $\mathbf{M P a}$ & ksi & $\mathbf{M P a}$ & ksi & \\
\hline IPF13-T1 & $4 \times 10^{-4}$ & 215.8 & 31.3 & 492.6 & 71.4 & 28.5 \\
\hline IPF13-T2 & $4 \times 10^{-4}$ & 217.2 & 31.5 & 493.7 & 71.6 & 28.3 \\
\hline IPF13-T4 & 1.0 & 180.0 & 26.1 & 413.0 & 59.9 & 48.5 \\
\hline IPF13-T6 & 9.9 & 224.1 & 32.5 & 423.5 & 61.4 & 42.6 \\
\hline IPF13-T7 & 12.0 & 255.8 & 37.1 & 417.8 & 60.6 & 41.6 \\
\hline IPF13-T8 & 1.4 & 260.6 & 37.8 & 430.9 & 62.5 & 48.0 \\
\hline IPF16-T2w & $4 \times 10^{-4}$ & 479.9 & 69.6 & 671.6 & 97.4 & 36.3 \\
\hline IPF14-T1w & $4 \times 10^{-4}$ & 551.6 & 80.0 & 715.0 & 103.7 & 36.6 \\
\hline IPF16-T3w & 12 & 420.0 & 60.9 & 526.1 & 76.3 & 33.3 \\
\hline IPF16-T4w & 1.4 & 402.0 & 58.3 & 587.5 & 85.2 & 33.2 \\
\hline IPF14-T2w & 1.6 & 448.9 & 65.1 & 621.2 & 90.1 & 34.2 \\
\hline
\end{tabular}

Figures 2.1 and 2.2, it can be seen that the strength of this material is sensitive to dynamic effects. As the strain rate is increased from quasi-static to dynamic rates (nominally 1 to $10 \mathrm{sec}^{-1}$ ), the ultimate strength is decreased approximately 15 percent while the final elongation is increased approximately 60 percent. As the strain rate was increased from $1 \mathrm{sec}^{-1}$ to $10 \mathrm{sec}^{-1}$, no significant difference was apparent in the tensile properties. The change in the tensile properties has been attributed to the material's susceptibility to dynamic strain aging, DSA (Ref. 2.2).

\subsubsection{Weld Metal Results}

Figures 2.3 and 2.4 show engineering and true stress-strain curves, respectively, for the weld specimens. From Figures 2.3 and 2.4, it can be seen that the strength of this material is sensitive to dynamic effects. As the strain rate is increased from quasi-static to dynamic rates (nominally $1 \mathrm{sec}^{-1}$ ), the ultimate strength decreased approximately 13 percent and the final elongation decreased approximately 8 percent. As the strain rate was increased from $1 \mathrm{sec}^{-1}$ to $10 \mathrm{sec}^{-1}$, a further decrease in tensile strength of 13 percent was apparent. In addition, the dynamic weld metal high speed tensile specimens exhibited load fluctuations 


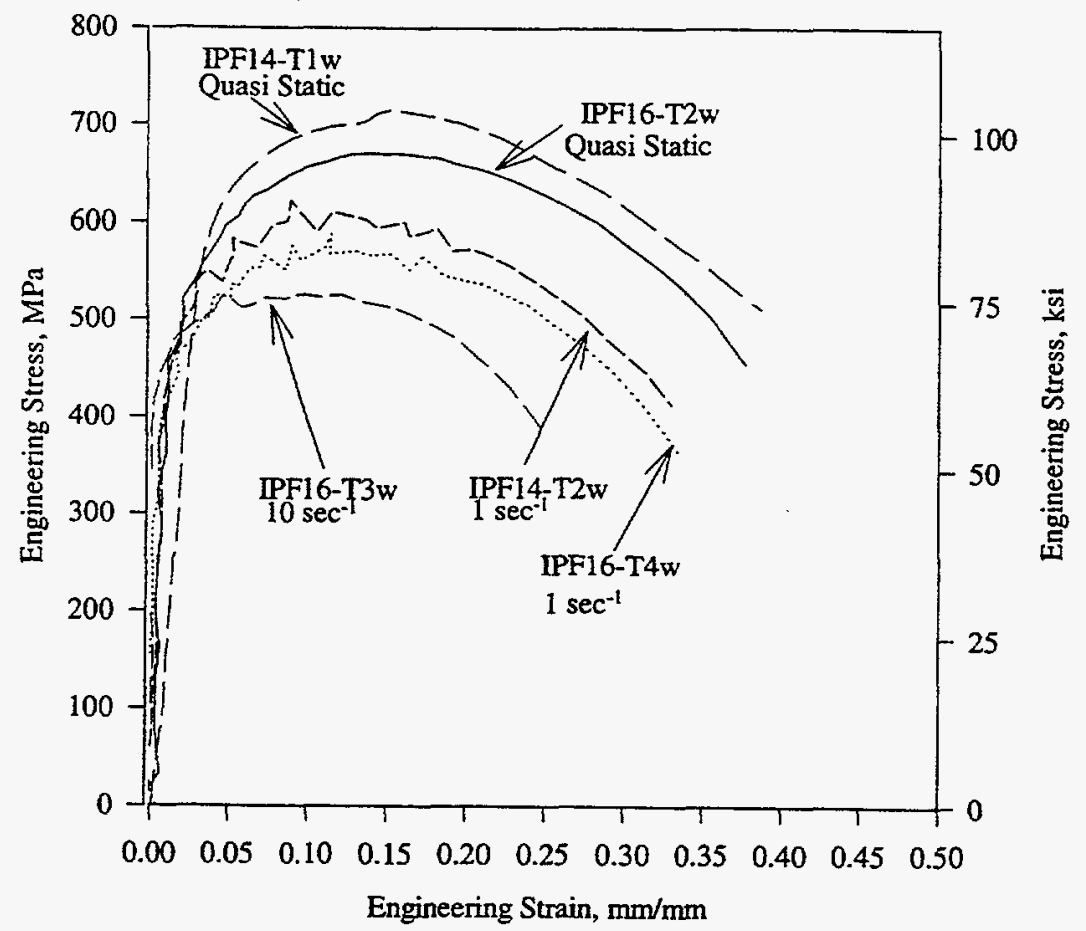

Figure 2.3 Engineering stress-strain curves for TIG weld specimens

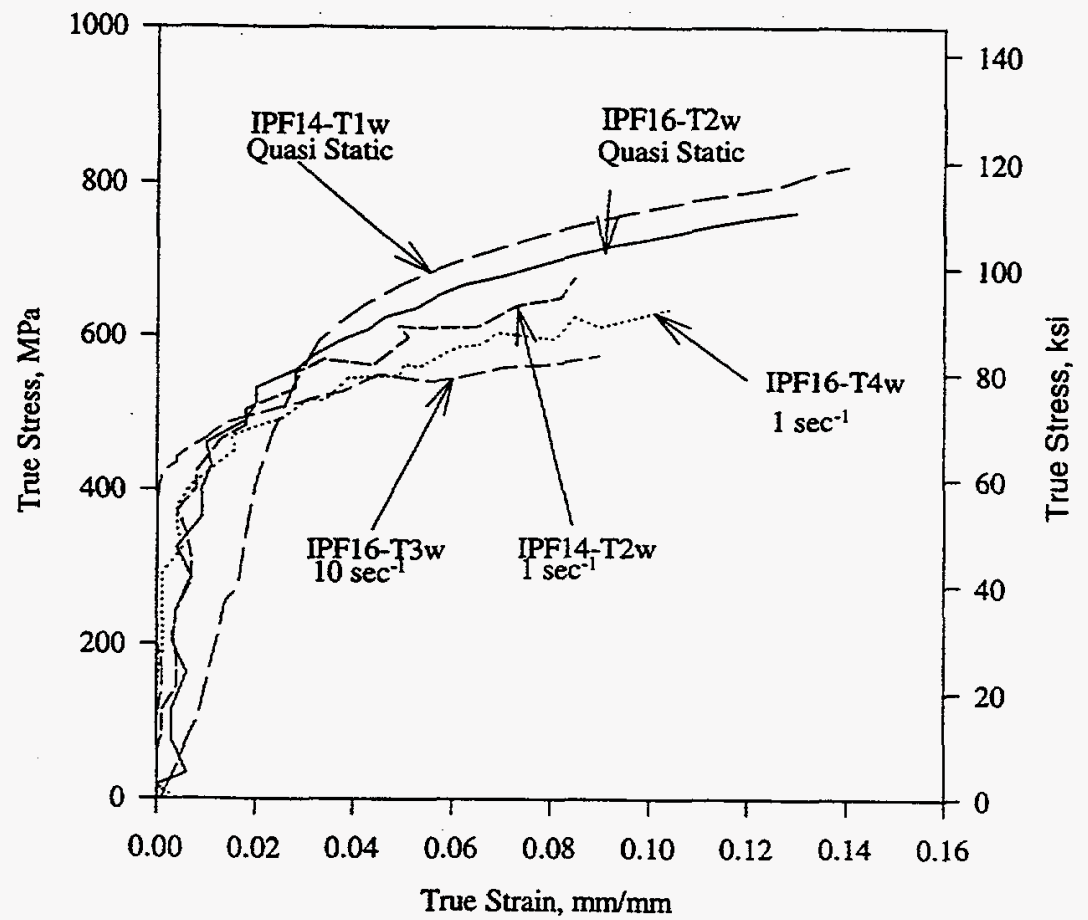

Figure 2.4 True stress-strain curves for the TIG weld specimens 
(i.e., serrations on the stress-strain curve) during the course of the tests. This phenomena is typical of ferritic steels that are sensitive to dynamic strain aging (DSA) (Ref. 2.2).

\subsection{Fracture Toughness Results}

Fracture toughness tests at $300 \mathrm{C}(572 \mathrm{~F})$ on side-grooved $1 / 2 \mathrm{~T}$ compact tension, $\mathrm{C}(\mathrm{T})$, specimens were conducted on both the base and weld metal per ASTM E1152/E813. The side grooves were 10 percent of the specimen thickness per side (total of 20 percent) as per the ASTM E1152 test standard. All C(T) specimens were manufactured without flattening and were fabricated in the L-C orientation, simulating the growth of a circumferential through-wall crack in a pipe. Both quasi-static and dynamic loading rates were used in these tests. Standard heater tapes were used to produce the desired test temperature. All specimens were fatigue precracked according to the specifications in ASTM E1152. The quasi-static $\mathrm{C}(\mathrm{T})$ specimen tests were conducted in a screw driven $133 \mathrm{kN}(30,000 \mathrm{lbs})$ Instron test machine. The dynamic $\mathrm{C}(\mathrm{T})$ specimens were tested in a $22 \mathrm{kN}(5,000 \mathrm{lb})$ servohydraulic test system. The crackmouth-opening displacement (CMOD) data were measured for all $C(T)$ specimens using a high temperature MTS clip gage. The d-c electric potential method was used to monitor crack initiation and crack growth. For the quasi-static tests, the direct current magnitude was adjusted to give a potential of approximately $400 \mu \mathrm{V}$ at the start of the test. For the dynamic tests, the current was increased to provide a starting potential of approximately $4,000 \mu \mathrm{V}$. The larger potential for the dynamic tests was used to minimize the effect of a voltage pulse that is generated within ferromagnetic materials when they are subjected to dynamic loading rates (Ref. 2.1). Load, stroke, EP and CMOD were collected for all C(T) tests using the LabTech Notebook data acquisition software, and later reduced using Quatro-Pro software.

\subsubsection{Base Metal Results}

Table 2.4 shows a summary of the toughness results for both the base and weld metals. Figure 2.5 shows the J-R curves for the STS 410 base metal. As can be seen, the effect of strain rate on the fracture toughness of this material is minimal. The $C(T)$ specimens which were loaded at the fastest rate, i.e., crack initiation in 0.2 seconds, had an average $J$ value at crack initiation $\left(\mathrm{J}_{\mathrm{i}}\right)$ approximately 25 percent higher than the average $J_{i}$ value for the quasi-static specimens and the dynamic specimens whose cracks initiated in approximately 10 seconds. Furthermore, the specimens whose crack initiated in about 10 seconds seem to have a slightly lower resistance than the other specimens; however, even these specimens fall within a reasonable scatter band of the others. None of the specimens tested exhibited crack instabilities during the course of the tests. Such crack instabilities would be indicative of severe dynamic strain aging (Ref. 2.2).

\subsubsection{Weld Metal Results}

Figure 2.6 shows the J-R curves for the TIG weld in the STS410 pipe. As with the base metal, the weld metal seems to show no significant toughness sensitivity to increasing strain rate. There seems to be some sensitivity in $\mathrm{J}_{\mathrm{i}}$, i.e., as the strain rate is increased the value of $\mathrm{J}$ at crack initiation is decreased. Also, the value of $\mathrm{dJ} / \mathrm{da}$ is increased as the strain rate is increased. However, this could be scatter in 
Table 2.4 Summary of C(T) specimen fracture toughness results for Japanese STS410 base metal and TIG welds

\begin{tabular}{|c|c|c|c|c|c|}
\hline \multirow{2}{*}{$\begin{array}{c}\text { Specimen } \\
\text { Identification }\end{array}$} & \multirow{2}{*}{$\begin{array}{l}\text { Approximate } \\
\text { Time to Crack } \\
\text { Initiation, } \\
\text { second }\end{array}$} & \multicolumn{2}{|c|}{$\mathbf{J}_{\mathbf{i}}$} & \multicolumn{2}{|c|}{$\mathbf{d} \mathbf{J}_{M} / \mathbf{d a}$} \\
\hline & & lb/in & $\mathrm{kN} / \mathrm{m}$ & $\mathrm{lb} / \mathbf{i n}^{2}$ & $\mathbf{M I N} / \mathbf{m}^{2}$ \\
\hline IPF13-1 & 600. & 2,224 & 389.5 & 32,273 & 222.5 \\
\hline IPF13-2 & 600 & 2,101 & 367.9 & 29,207 & 201.4 \\
\hline IPF 13-4 & 10 & 2,199 & 385.1 & 25,778 & 172.7 \\
\hline IPF13-5 & 0.2 & 2,897 & 507.4 & 25,666 & 177.0 \\
\hline IPF 13-6 & 0.2 & 2,545 & 445.7 & 29,042 & 200.2 \\
\hline IPF13-7 & 10 & 2,257 & 395.3 & 24,015 & 165.6 \\
\hline IPF16-1w & 600 & 4,754 & 832.6 & 26,272 & 181.1 \\
\hline IPF $16-2 w$ & 600 & 3,936 & 689.3 & 34,942 & 240.9 \\
\hline IPF16-3w & 10 & 2,346 & 410.8 & 52,119 & 359.4 \\
\hline IPF16-4w & 10 & 2,619 & 458.7 & 51,331 & 353.9 \\
\hline IPF16-5w & 0.2 & 3,642 & 637.8 & 46,637 & 321.6 \\
\hline IPF16-6w & 0.2 & 2,483 & 434.8 & 51,430 & 354.6 \\
\hline
\end{tabular}

the data, since the selection of crack initiation from electric potential data is sometimes very difficult. As with the base metal, none of the specimens tested exhibited crack instabilities during the course of the tests indicating that this weld is probably not highly sensitive to dynamic strain aging.

\subsection{Summary of Effect of Dynamic Loads on Material Properties}

The two materials investigated in this effort, an STS410 carbon steel and an STS410 carbon steel TIG weld, showed similar responses to increased displacement rates in mechanical property tests. Both materials, because of their susceptibility to dynamic strain aging, showed marked effects of strain rate in tensile tests. The tensile strength was decreased as the strain rate increased in both cases. The final elongation increased with increasing strain rate in the base metal, but decreased with increasing strain rate in the weld material. 


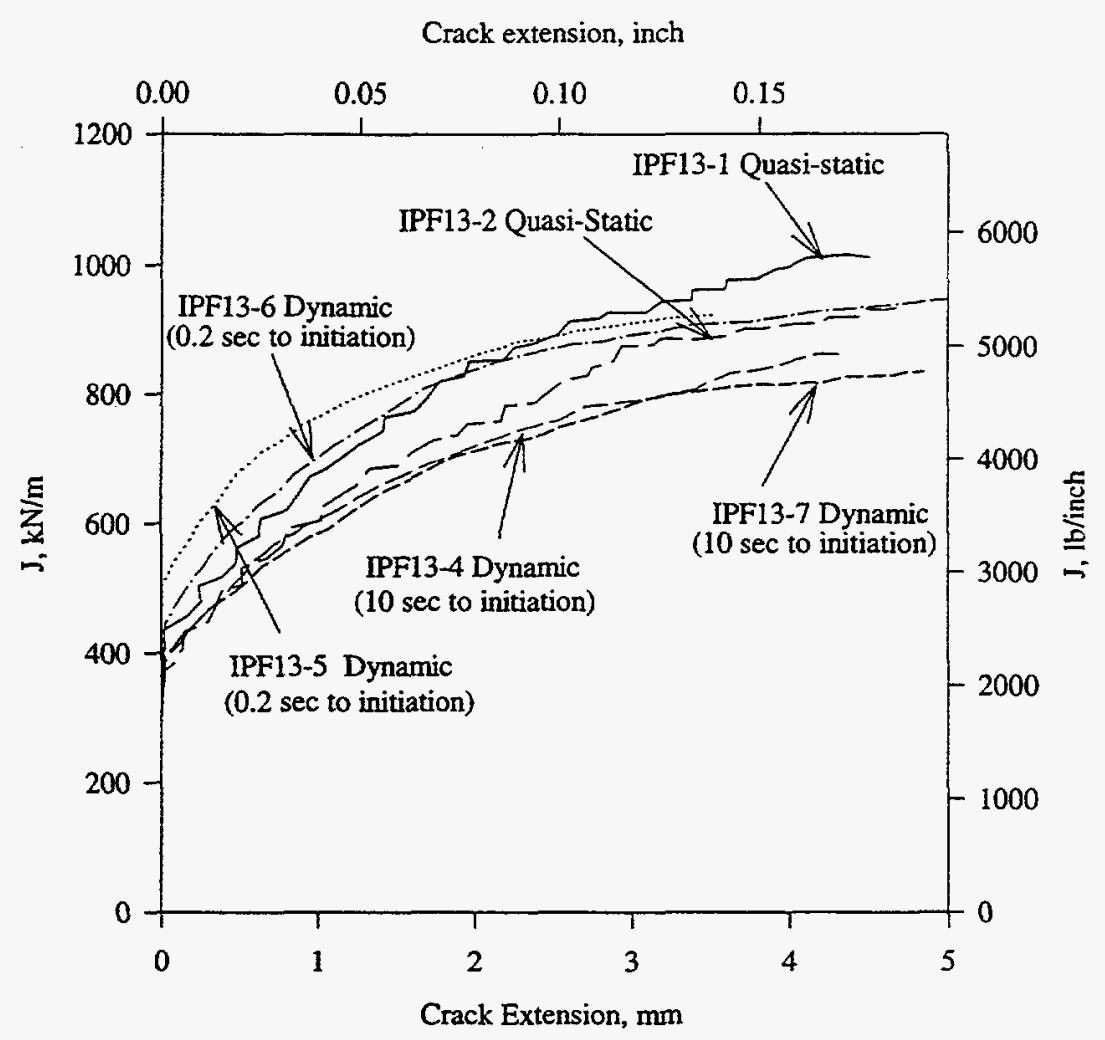

Figure 2.5 J-R curves for STS410 base metal C(T) specimens

Crack extension, inch

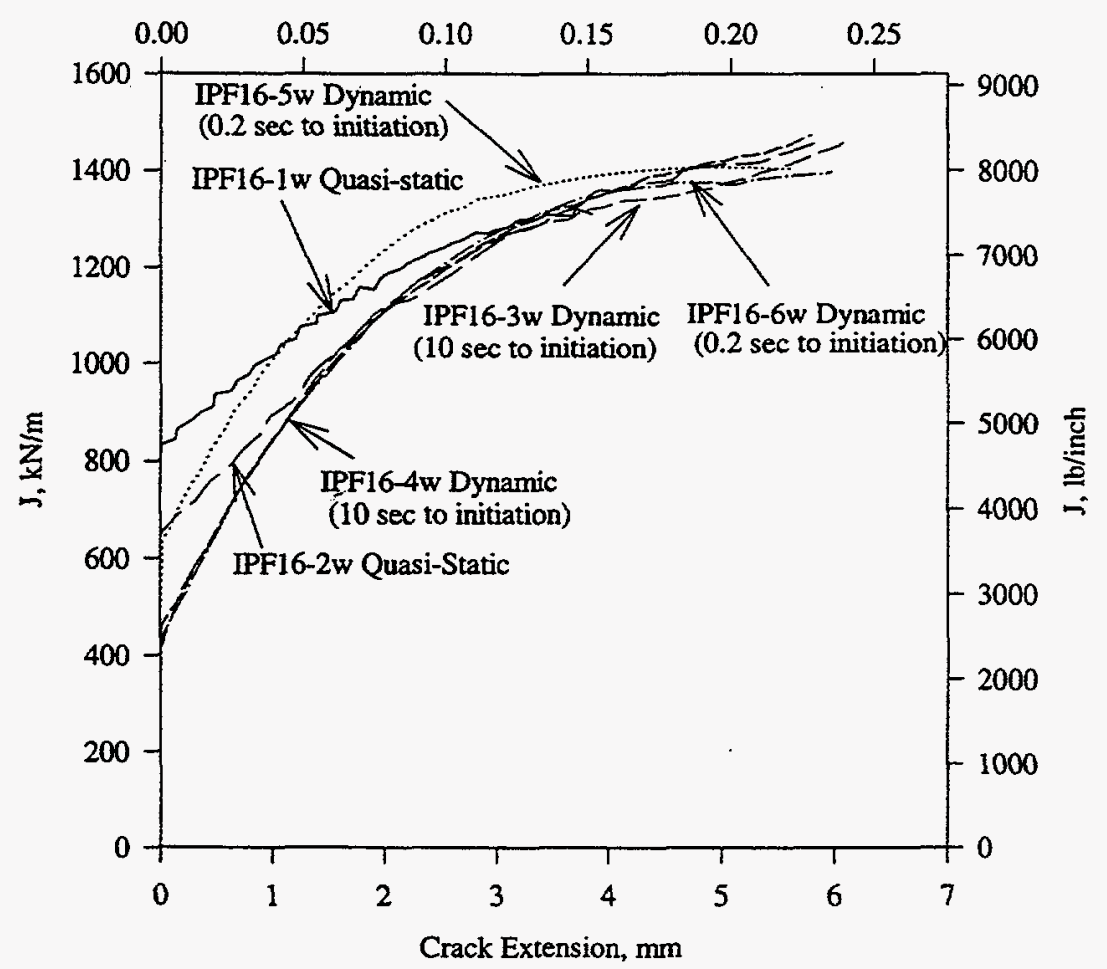

Figure 2.6 J-R curves for TIG weld C(T) specimens 
With respect to fracture toughness, the effect of increasing the displacement rate for both materials was minimal. Some very slight differences were seen in the J-R curves, especially near crack initiation, but a distinct change in properties was not apparent.

The small change in fracture resistance at increasing displacement rate is somewhat surprising since the tensile strength was decreased significantly. In Reference 2.1 , specimens that were made from Pipe DP2-F29 material, showed both a decrease in tensile strength as well as a decrease in fracture toughness with increasing displacement rates. However, specimens from Pipe DP2-F30 showed that the tensile strength was reduced as the strain rate was increased, but only a modest change in fracture toughness was observed as the displacement rate was increased. Finally, for a low toughness submerged-arc weld (SAW) in Pipe DP2-F29 (i.e., weld DP2-F29W), dynamic testing significantly raised the J-R curve. The reason for the different response to increasing strain rate in carbon steels, is not fully understood at this time. It has been hypothesized that the differences may come from the way the interstitial atoms react with the dislocation structure at elevated temperatures to produce the many different effects associated with dynamic strain aging.

\subsection{References}

2.1 Marschall, C. W., Landow, M. P., and Wilkowski, G. M., "Loading Rate Effects on Strength and Fracture Toughness of Pipe Steels Used in Task 1 of the IPIRG Program," NUREG/CR-6098, BMI-2175, October 1993.

2.2 Marschall, C. W., Rosenfield, A. R., Held, P., and Wilkowski, G. M., "A Screening Criterion for Dynamic Strain Aging Sensitivity of Ferritic Nuclear Piping Steels," ASME PVP Vol. 280, pp 199-206, June 1994. 


\subsection{PIPE EXPERIMENTS}

This section discusses the four 152-mm (6-inch) nominal diameter, displacement-controlled, throughwall-cracked (TWC) pipe experiments. The test specimen preparation, test setup, and test procedures were the same for all four experiments. The only difference between experiments was the crack location (base metal versus center of the weld) and load history. The test matrix for the four pipe experiments conducted in four-point bending is shown in Table 3.1.

Table 3.1 Test conditions for Japanese STS410 carbon steel pipe tests

\begin{tabular}{|c|c|c|c|c|}
\hline & $\begin{array}{c}\text { Base Metal } \\
\text { Dynamic } \\
\text { Monotonic }\end{array}$ & $\begin{array}{c}\text { Base Metal } \\
\text { Dynamic } \\
\text { Cyclic } \\
R=-1 \\
\end{array}$ & $\begin{array}{c}\text { Weld Metal } \\
\text { Dynamic } \\
\text { Cyclic } \\
R=-1 \\
\end{array}$ & $\begin{array}{l}\text { Base Metal } \\
\text { Quasi-static } \\
\text { Monotonic }\end{array}$ \\
\hline Experiment Number & $4.2-1$ & $4.2-2$ & $4.2-3$ & $3.3-1$ \\
\hline Specimen Number & IP-F10 & IP-F11 & IP-F12 & IP-F13 \\
\hline Actual Pipe Diameter & $\begin{array}{l}168.3 \mathrm{~mm} \\
\text { (6.625 inches) }\end{array}$ & $\begin{array}{l}165.6 \mathrm{~mm} \\
\text { (6.520 inches) }\end{array}$ & $\begin{array}{l}166.2 \mathrm{~mm} \\
\text { (6.545 inches) }\end{array}$ & $\begin{array}{l}166.0 \mathrm{~mm} \\
\text { (6.535 inches) }\end{array}$ \\
\hline $\begin{array}{l}\text { Actual Pipe Wall } \\
\text { Thickness }\end{array}$ & $\begin{array}{l}14.5 \mathrm{~mm} \\
(0.570 \text { inches })\end{array}$ & $\begin{array}{l}14.5 \mathrm{~mm} \\
(0.571 \text { inches })\end{array}$ & $\begin{array}{l}14.4 \mathrm{~mm} \\
\text { (0.566 inches) }\end{array}$ & $\begin{array}{l}14.5 \mathrm{~mm} \\
(0.569 \mathrm{inch})\end{array}$ \\
\hline Crack Location & Base Metal & Base Metal & Weld Metal & Base Metal \\
\hline $\begin{array}{l}\text { Total Through-Wall } \\
\text { Crack Length }\end{array}$ & 60 degrees & 60 degrees & 60 degrees & 60 degrees \\
\hline Test Temperature & $\begin{array}{l}300 \mathrm{C} \\
(572 \mathrm{~F})\end{array}$ & $\begin{array}{l}300 \mathrm{C} \\
(572 \mathrm{~F})\end{array}$ & $\begin{array}{l}300 \mathrm{C} \\
(572 \mathrm{~F})\end{array}$ & $\begin{array}{l}300 \mathrm{C} \\
(572 \mathrm{~F})\end{array}$ \\
\hline Load History & $\begin{array}{l}\text { Dynamic } \\
\text { Monotonic } \\
\text { Four-Point } \\
\text { Bending }\end{array}$ & $\begin{array}{l}\text { Dynamic } \\
\text { Cyclic }(\mathrm{R}=1) \\
\text { Four-Point } \\
\text { Bending }\end{array}$ & $\begin{array}{l}\text { Dynamic } \\
\text { Cyclic } \\
\text { Four-Point } \\
\text { Bending }\end{array}$ & $\begin{array}{l}\text { Quasi-static } \\
\text { Monotonic } \\
\text { Four-Point } \\
\text { Bending }\end{array}$ \\
\hline Target Loading Rate & $\begin{array}{l}25 \mathrm{~mm} / \mathrm{second} \\
(1 \mathrm{inch} / \mathrm{sec})\end{array}$ & $\begin{array}{l}25 \mathrm{~mm} / \mathrm{second} \\
(1 \mathrm{inch} / \mathrm{sec})\end{array}$ & $\begin{array}{l}25 \mathrm{~mm} / \mathrm{second} \\
(1 \mathrm{inch} / \mathrm{sec})\end{array}$ & $\begin{array}{l}0.07 \mathrm{~mm} / \mathrm{sec} \\
(0.003 \mathrm{inch} / \mathrm{sec})\end{array}$ \\
\hline Outer Loading Span & $\begin{array}{l}1.524 \mathrm{~m} \\
\text { ( } 60 \text { inches) }\end{array}$ & $\begin{array}{l}1.524 \mathrm{~m} \\
\text { (60 inches) }\end{array}$ & $\begin{array}{l}1.524 \mathrm{~m} \\
\text { (60 inches) }\end{array}$ & $\begin{array}{l}1.524 \mathrm{~m} \\
\text { (60 inches) }\end{array}$ \\
\hline Inner Loading Span & $\begin{array}{l}0.610 \mathrm{~m} \\
\text { (24 inches) }\end{array}$ & $\begin{array}{l}0.610 \mathrm{~m} \\
\text { (24 inches) }\end{array}$ & $\begin{array}{l}0.610 \mathrm{~m} \\
(24 \text { inches })\end{array}$ & $\begin{array}{l}0.610 \mathrm{~m} \\
\text { (24 inches) }\end{array}$ \\
\hline
\end{tabular}




\subsection{Test Procedures}

\subsubsection{Description of Test Facility}

Figure 3.1 is a schematic of the test configuration used for these four experiments. This test configuration is identical to the test configuration used in the cyclic through-wall-cracked pipe experiments conducted as part of Subtask 1.2 of the IPIRG-1 program (Ref. 3.1). Note, in between Experiments 4.2-1 and 4.2-2, it was discovered that some of the plastic inserts/washers used to electrically isolated the top half of the load frame for electric potential measurements were cracked. As a result, new inserts/washers were fabricated for the last three experiments. Prior to the conduct of Experiment 4.2-2, i.e., the dynamic cyclic, base metal experiment, the machine compliance of the test frame with both the old and new inserts was measured using an uncracked section of pipe. The machine compliance with the old inserts was found to be $1.435 \times 10^{-5} \mathrm{~m} / \mathrm{kN}\left(2.513 \times 10^{-6} \mathrm{in} / \mathrm{lb}\right)$. The machine compliance with the new inserts was found to be $1.127 \times 10^{-5} \mathrm{~m} / \mathrm{kN}\left(1.974 \times 10^{-6} \mathrm{in} / \mathrm{lb}\right)$.

\subsubsection{Test Specimen Preparation}

The test specimens for each of the four pipe experiments was a section of 152-mm (6-inch) nominal diameter, Schedule 120, STS410 carbon steel pipe supplied to Battelle by Hitachi. The Battelle pipe identification numbers for these sections of pipe were IP-F10 through IP-F13. The overall lengths of the pipe samples were $2.1 \mathrm{~m}$ (7 feet). For Experiment 3.3-1, a $305 \mathrm{~mm}$ (12 inch) section of IP-F13 was welded to two $914 \mathrm{~mm}$ ( $36 \mathrm{inch}$ ) sections of IP-F10. The initial machined through-wall crack for Experiments 4.2-1, 4.2-2 and 3.3-1 was in the base metal of Pipe Sections IP-F10, IP-F11 and IP-F13, respectively. The initial machined through-wall crack for Experiment 4.2-3 was in the center of a shop fabricated tungsten-inert-gas (TIG) weld joining two pieces of STS410 pipe. The pipe identification number for this welded pipe section was IP-F12. There was essentially no weld crown on the outside diameter, but there was a significant weld crown on the inside diameter. In addition to the pipes used in the pipe experiments, Hitachi also supplied four shorter lengths of pipe from the same heat of pipe for use in the material characterization studies. The Battelle pipe identification numbers for these sections of pipe were IP-F13 through IP-F16. The $305 \mathrm{~mm}$ (12 inch) section of IP-F13 used in Experiment 3.3-1 was a remaining section from the base metal material property evaluation pieces that was not used. Three of these shorter sections of pipe (i.e., IP-F14, IP-F15, and IP-F16) contained girth welds which were fabricated using the same procedures as the girth weld tested in Pipe Experiment 4.2-3. Tensile and C(T) specimens were fabricated from the girth welds in Pipes IP-F14 and IP-F16.

The machined through-wall flaws in these pipe experiments were introduced into the pipe samples using electric discharge machining (EDM) techniques. For each experiment, the length of the EDM notch was $81.3 \mathrm{~mm}$ ( 3.2 inches) as measured along the outside pipe surface. This was 15.4 percent of the pipe circumference, i.e., 55 degrees. The flawed test specimen was then loaded in Battelle's $580 \mathrm{kN}$ (130 kip) MTS fatigue machine using the same four-point bend fixturing as used in the IPIRG-1 Subtask 1.2 displacement-controlled cyclic pipe experiments, see Figure 3.1. Prior to the actual experiments, the EDM flawed pipes were precracked in four-point bending using a minimum and maximum load of 


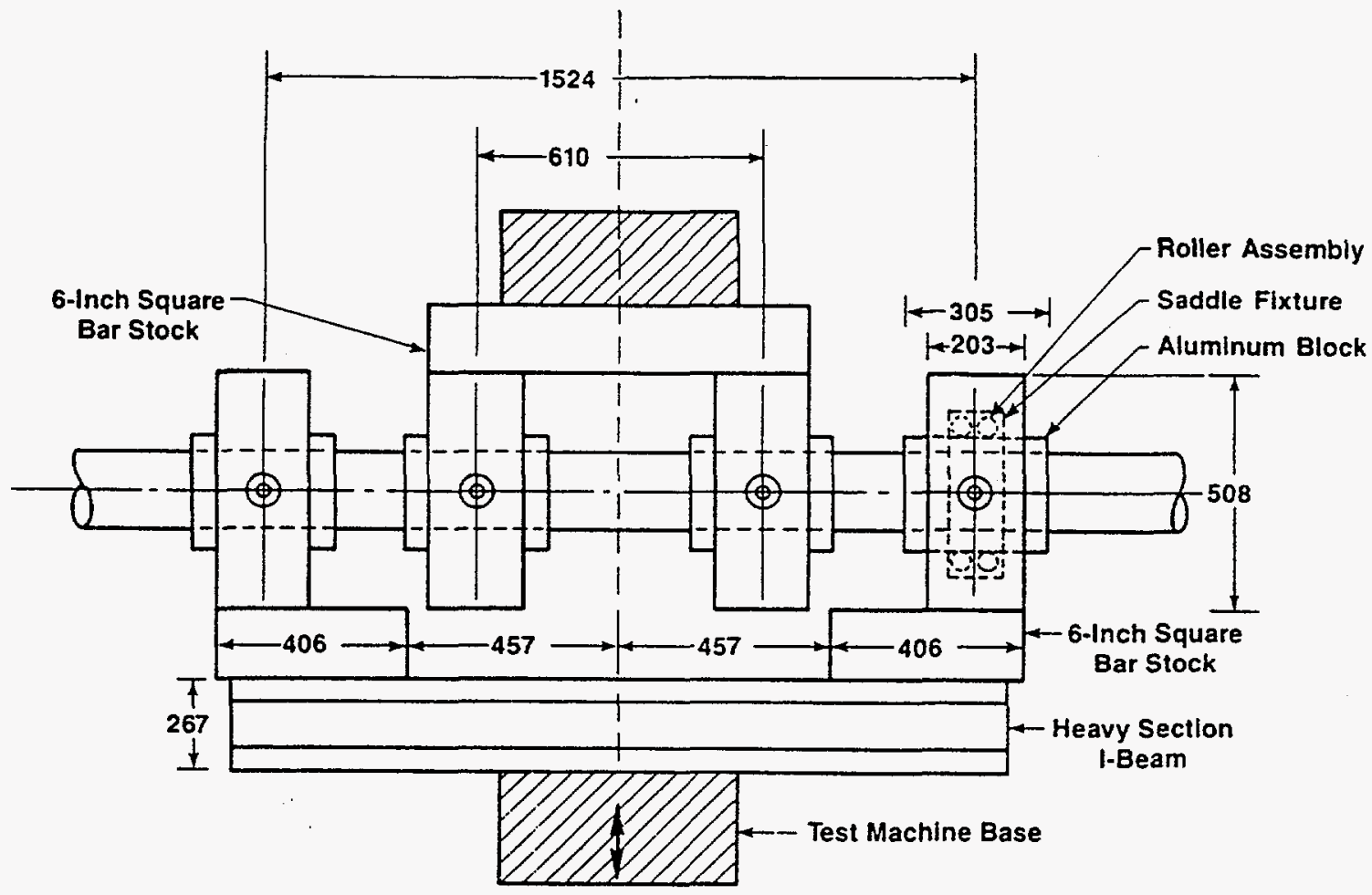

Note: All 4 saddle fixtures are identical to the detail. All dimensions in millimeters.

Figure 3.1 Schematic of test apparatus

$7.56 \mathrm{kN}(1,700 \mathrm{lbs})$ and $75.6 \mathrm{kN}(17,000 \mathrm{lbs})$, respectively. The calculated $\Delta \mathrm{K}$ values for this crack length, and this load range, using Sander's K-solution for a through-wall-cracked pipe (Ref. 3.2) was approximately $46 \mathrm{MPa} \sqrt{\mathrm{m}}$ (40 ksi $\sqrt{ }$ inch). The test specimen was cyclically loaded until the cracks had extended $2.54 \mathrm{~mm}(0.1$ inches $)$ at both crack tips such that the crack lengths of the fatigue precracked test specimens were 16.7 percent of the pipe circumference, i.e., 60 degrees. The number of cycles required to sharpen and grow the four cracks ranged from 10,200 to 46,250 cycles. This precracking load turned out to be 38 to 44 percent of the maximum load, which is close to the ASTM E1152 recommendation of precracking at less than 50 percent of the limit load.

\subsubsection{Loading Conditions}

The test specimens were loaded in four-point bending without internal pipe pressure. The inner and outer spans for the four-point bending were $610 \mathrm{~mm}$ ( 24 inches) and 1,524 mm (60 inches), respectively. The test temperature for each experiment was $300 \mathrm{C}(572 \mathrm{~F})$.

The quasi-static, monotonic base metal experiment (Experiment 3.3-1) was conducted in three stages. However, since this was a slow test, the pipe was not loaded to a set displacement. During the first stage, the pipe was loaded to just beyond maximum load and unloaded. The pipe was then loaded and unloaded two more times after sufficient crack growth had occurred.

The dynamic monotonic base metal experiment (Experiment 4.2-1), was also conducted in three stages. During the first stage, the test specimen was loaded to a displacement of $25 \mathrm{~mm}$ (1 inch) at a target 
loading rate of $25 \mathrm{~mm} / \mathrm{second}$ ( $1 \mathrm{inch} / \mathrm{second}$ ). During the second and third stages, the test specimen was loaded another $51 \mathrm{~mm}$ ( 2 inches) during each load cycle for a total displacement for the three load cycles of $127 \mathrm{~mm}$ ( 5 inches). For the second and third stages of loading, the target loading rate was again 25 $\mathrm{mm} / \mathrm{second}$ ( $1 \mathrm{inch} / \mathrm{second}$ ). In between each loading cycle, the test specimen was unloaded to mark the fracture surface.

The two cyclic displacement-controlled experiments, Experiments 4.2-2 and 4.2-3, were controlled using a BASIC computer program written for the cyclic pipe tests from Subtask 1.2 of IPIRG-1 (Ref. 3.1). This program performs the fully reversed loading $(R=-1)$ by loading the specimen to a prescribed displacement, recording the peak load, and then loading the specimen in compression to the negative value of the previous peak load value. These loading/unloading cycles were continued throughout the experiment. The target loading scheme in Table 3.2 was used during these tests.

Table 3.2 Target loading scheme for dynamic, cyclic experiments

\begin{tabular}{ccc}
\hline Loading No. & $\delta_{\mathrm{cyc}} / \delta_{\mathrm{i}}$ & No. of cycles \\
\hline 1 & 0.1 & 25 \\
2 & 0.025 & 20 \\
3 & 0.2 & 10 \\
\hline
\end{tabular}

The quantity $\delta_{\text {cyc }} / \delta_{i}$ is the ratio of the cyclic displacement increment $\left(\delta_{\text {cyc }}\right)$, as illustrated in Figure 3.2 , to the displacement at crack initiation $\left(\delta_{i}\right)$ for the dynamic, monotonic experiment, Experiment 4.2-1.

\subsubsection{Instrumentation, Data Acquisition, and Data Reduction}

The same instrumentation scheme was used for all four experiments. Table 3.3 lists the data collected during these experiments. Figure 3.3 illustrates the specific location of the instrumentation on the pipe in relation to the through-wall crack.

Table 3.3 Pipe fracture data collected in Experiments 4.2-1, 4.2-2, 4.2-3, and 3.3-1

- Total applied load

- Load-line displacement

- d-c EP measurements at each crack tip and at the crack centerline

- Crack-mouth-opening displacement at each crack tip and the crack centerline

- Pipe rotation on one side of the through-wall cracked pipe

- Pipe temperature at 6 locations on the outside pipe surface 


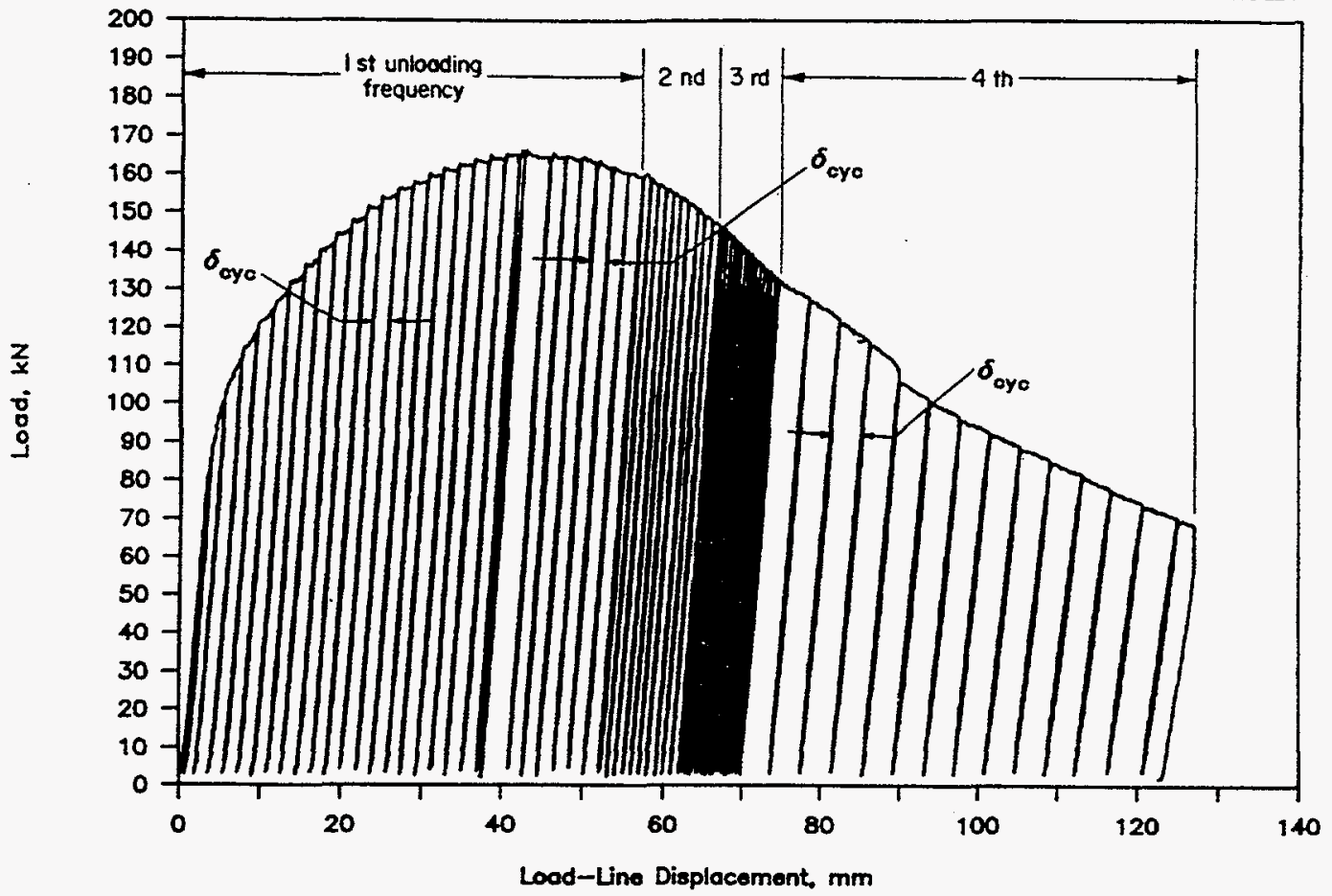

Figure 3.2 Load-displacement plot from Experiment 1.2-3 (stainless steel, quasi-static, cyclic $[R=0]$ experiment) from Subtask 1.2 of IPIRG-1 program illustrating the meaning of the cyclic plastic displacement $\left(\delta_{\text {cyc }}\right)$

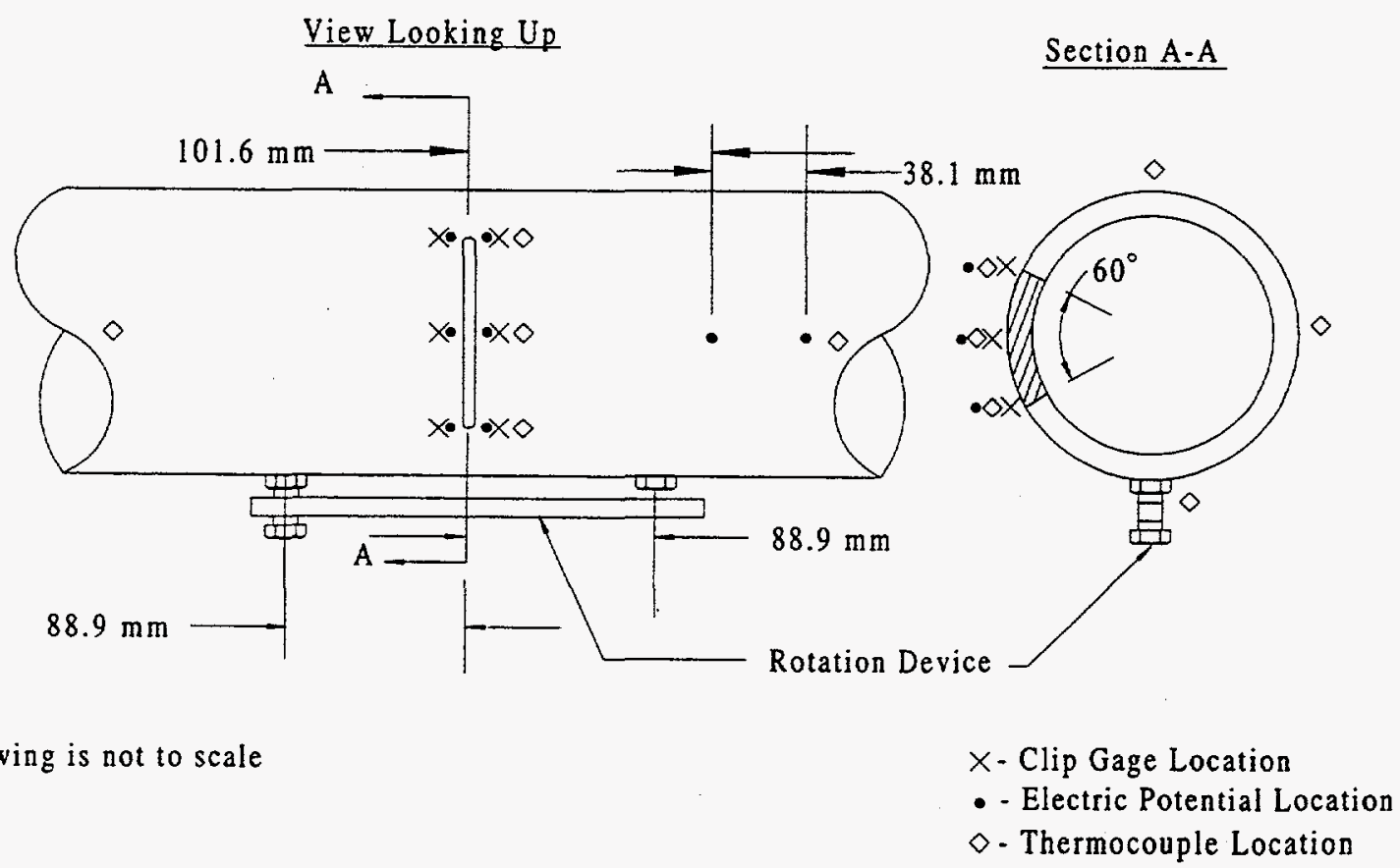

Figure 3.3 Instrumentation layout for Experiments 4.2-1, 4.2-2, 4.2-3, and 3.3-1 
At the actuator location, the applied displacement was measured using an LVDT. Signal conditioning for the LVDT was accomplished using an AC signal conditioner incorporated into the MTS servohydraulic control console. In addition to being a measured output signal, the actuator displacement was also the feedback signal for the servo-controller.

At the actuator location, the applied force was measured directly using a strain-gage-based load cell of $890 \mathrm{kN}$ (200 kip) capacity, manufactured by the Lebeau Corporation. The load-cell output was conditioned by a d-c signal conditioner module in the servo-hydraulic control console.

Crack initiation and crack growth data were collected using several direct-current electric potential (d-c EP) probes, i.e., one at the crack centerline and one at each crack tip. The base metal reference electric potential probes were located about $101.6 \mathrm{~mm}$ ( 4 inches) from the plane of the crack and were spaced $38.1 \mathrm{~mm}$ (1.5 inches) apart. The probes for the electric potential measurements were the iron wire of an iron-constantan (Type J) thermocouple. Voltages developed at the EP probes were amplified by Ectron 751 EL-M563 amplifiers.

The current source for the d-c EP measurements was an Exide Dynacell SD70 battery, which supplies up to 16,000 amperes of current at 1.75 volts when short circuited. This large current supply was used since dynamically loaded ferritic steel specimens generate a piezoelectric voltage which interferes with the d-c EP data needed for crack initiation determination. The large current makes the piezoelectric voltage negligible with respect to the actual signal to be measured.

The crack section rotation data were measured using an LVDT based device for the three dynamic experiments. Figure 3.4 illustrates the details of the LVDT arrangement used to determine the crack section rotations. For the quasi-static experiment (Experiment 3.3-1), inclinometers were used to measure crack-section rotation.

Crack-mouth-opening displacements (CMOD) were measured across the crack centerline and at each crack tip using clip gages which were calibrated prior to the experiments to $25.4 \mathrm{~mm}(1.0 \mathrm{inch})$ of displacement.

Experimental data were collected using a 486-series personal computer (PC) using sampling rates of 1 $\mathrm{kHz}$ for the dynamic, monotonic experiment, $200 \mathrm{~Hz}$ for the two dynamic, cyclic experiments and $1 \mathrm{~Hz}$ for the quasi-static, monotonic experiment. A 24 channel Racal FM tape recorder was used as a backup in the event there was a problem with the primary PC based system. Labtech Notebook data acquisition and control software was used to collect and assemble the data during each experiment.

Data reduction and graphing of all data were performed using Quatro Pro software. The data reduction included converting voltages to engineering units, calculating derived data from the raw data, and generating plots of the results. Crack initiation was determined by examining the d-c electric potential signal at each crack tip as a function of the crack-mouth-opening displacement at each tip. A departure from linearity has been shown to indicate the onset of ductile tearing. An example of crack initiation detection is shown in Figure 3.5. During fully reversed loadings, the detection of crack initiation using the $d-c$ electric potential method is very difficult. For the cyclic experiments, the data points corresponding the upper envelope of the load-displacement curve were plotted. An example of this plot 
Section 3

PIPE EXPERIMENTS
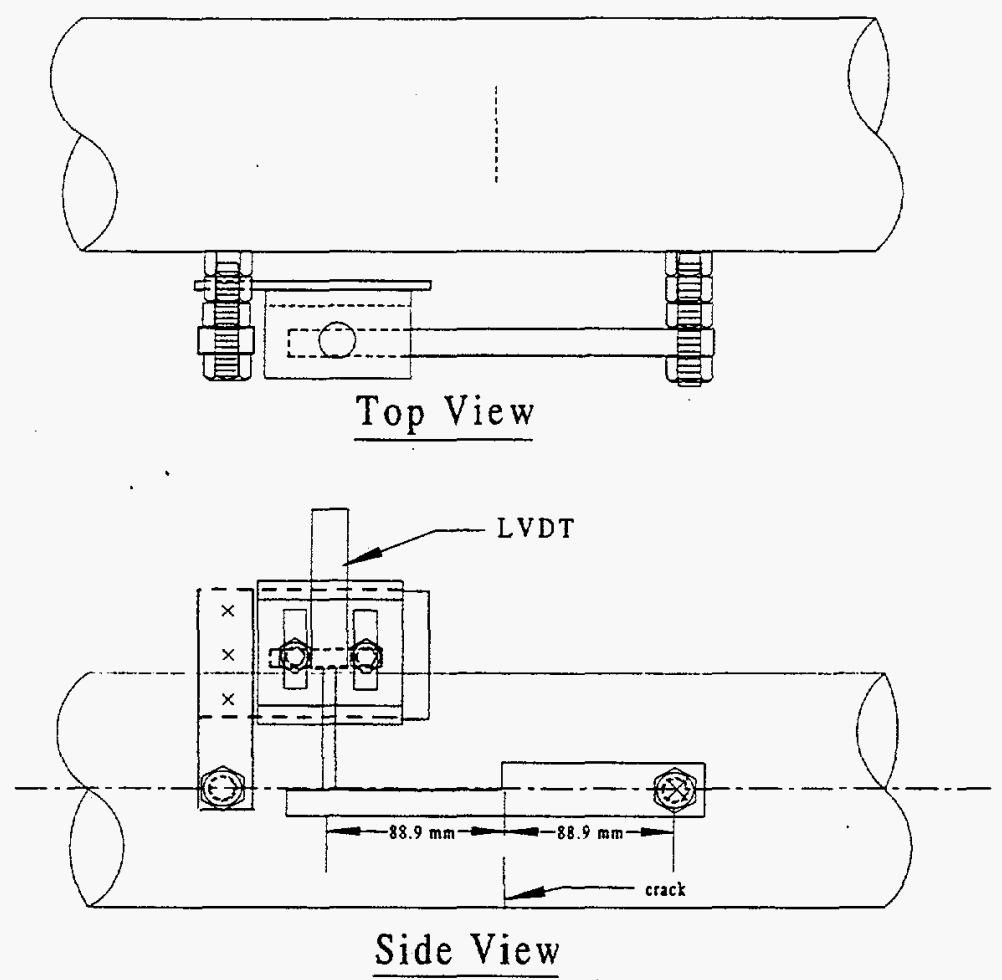

Figure 3.4 Rotation device for Experiments 4.2-1, 4.2.2, and 4.2-3

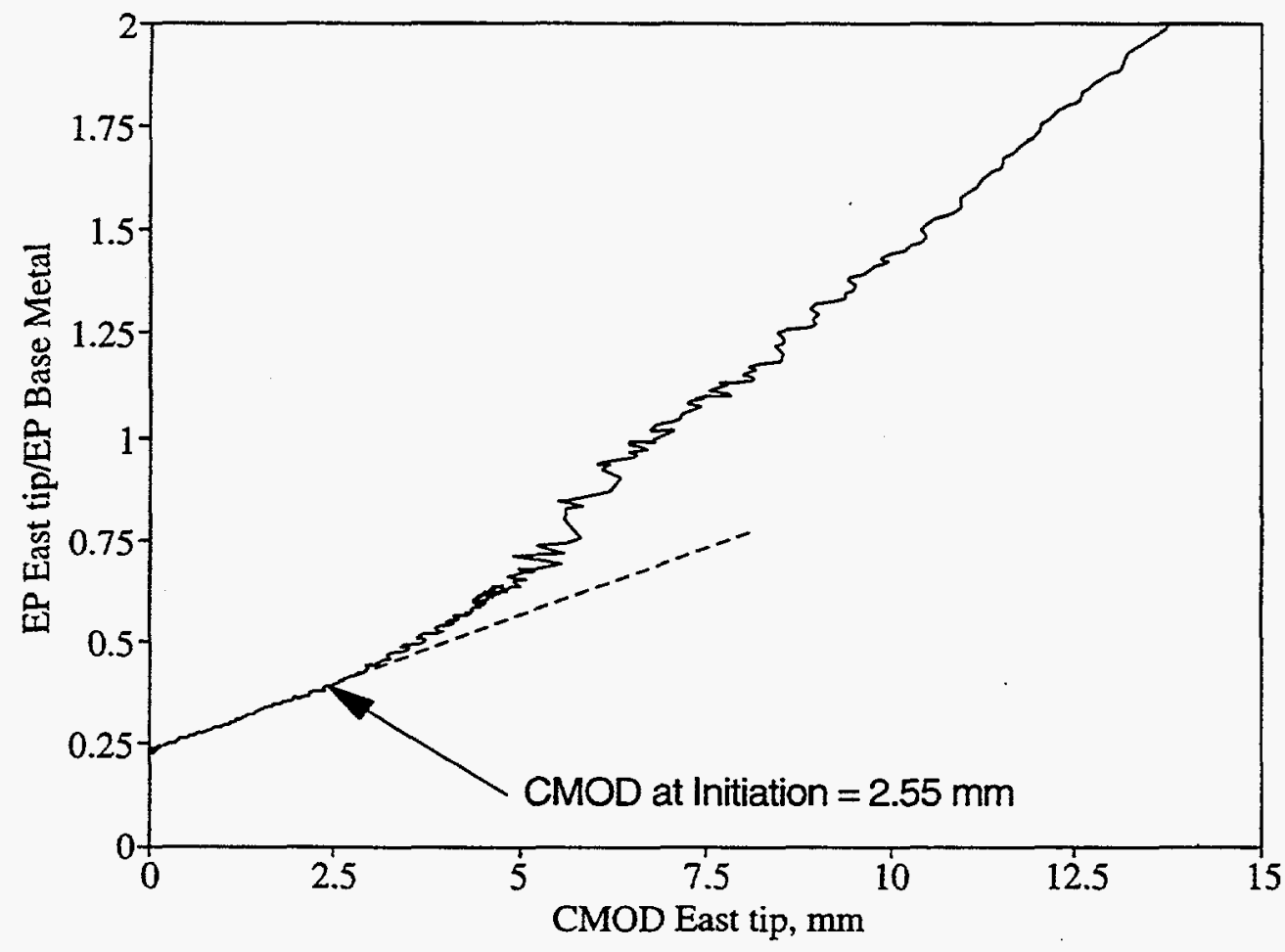

Figure 3.5 Normalized east crack tip electric potential versus east crack tip crack-mouth-opening displacement for Experiment 4.2-1 
is shown in Figure 3.6. The cycle where the slope of the EP versus CMOD data increased was labeled the initiation cycle. The data corresponding to all positive, increasing loads was then plotted for a few cycles that surrounded the initiation cycle. A distinct change in the slope of this $\mathrm{d}-\mathrm{c}$ EP versus CMOD curve in the initiation cycle was labeled the initiation point. An example of this method of crack initiation detection is shown in Figure 3.7.

The existing d-c EP versus circumferential crack growth calibration curve could not be used since the initial circumferential cracks grew in a helical direction. This typically occurs due to toughness anisotropy in ferritic steel pipes where the toughness is lower in the axial or sometimes the helical direction (Ref. 3.3). Hence, a calibration curve was developed specific to each experiment from the d-c electric potential at the crack centerline and the crack closure marks on the fracture surface. An equation of the following form was used to fit the measured crack lengths from the crack closure marks with the measured electric potential data:

$$
\frac{\theta}{\pi}=A^{\prime}+B^{\prime}\left(\frac{E P_{c}}{E P_{B}}\right)+C^{\prime}\left(\frac{E P_{c}}{E P_{B}}\right)^{2}+D^{\prime}\left(\frac{E P_{c}}{E P_{B}}\right)^{3}
$$

where $\theta / \pi$ is a normalized average crack length projected back to the circumferential plane, and $\mathrm{EP}_{\mathrm{C}} / \mathrm{EP}_{\mathrm{B}}$ is the centerline electric potential data normalized by the base metal electric potential. The crack centerline electric potential data were fit to the measured crack length data using the Sigma Plot curve fitting software. When the curve fits were developed, the only constraint used was that at zero crack growth, the centerline electric potential was set to the initiation value found. Table 3.4 shows the calculated values of the constants from Equation 3.1 for the four pipe experiments.

Table 3.4 Empirical constants for relating electric potential data to crack length data

\begin{tabular}{ccccc}
\hline $\begin{array}{c}\text { Experiment } \\
\text { Number }\end{array}$ & $\mathbf{A}^{\prime}$ & $\mathbf{B}^{\prime}$ & $\mathbf{C}^{\prime}$ & $\mathbf{D}^{\prime}$ \\
\hline $4.2-1$ & 0 & 0.1446022 & -0.016703 & 0.0008748 \\
$4.2-2$ & 0 & 0.0730083 & -0.003674 & 0.00091342 \\
$4.2-3$ & 0.05647 & 0.035604 & $-7.108 \times 10^{-4}$ & $4.978 \times 10^{-6}$ \\
$3.3-1$ & 0 & 0.2457 & -0.0664 & 0.0128 \\
\hline
\end{tabular}

The calculated moments were based on the geometry of the loading arrangement, dimensions of the pipe, total applied loads, and the load-point displacements. Kinematic corrections for the relatively short moment arm lengths and large deformations were made for the loading arrangement used in these experiments. 


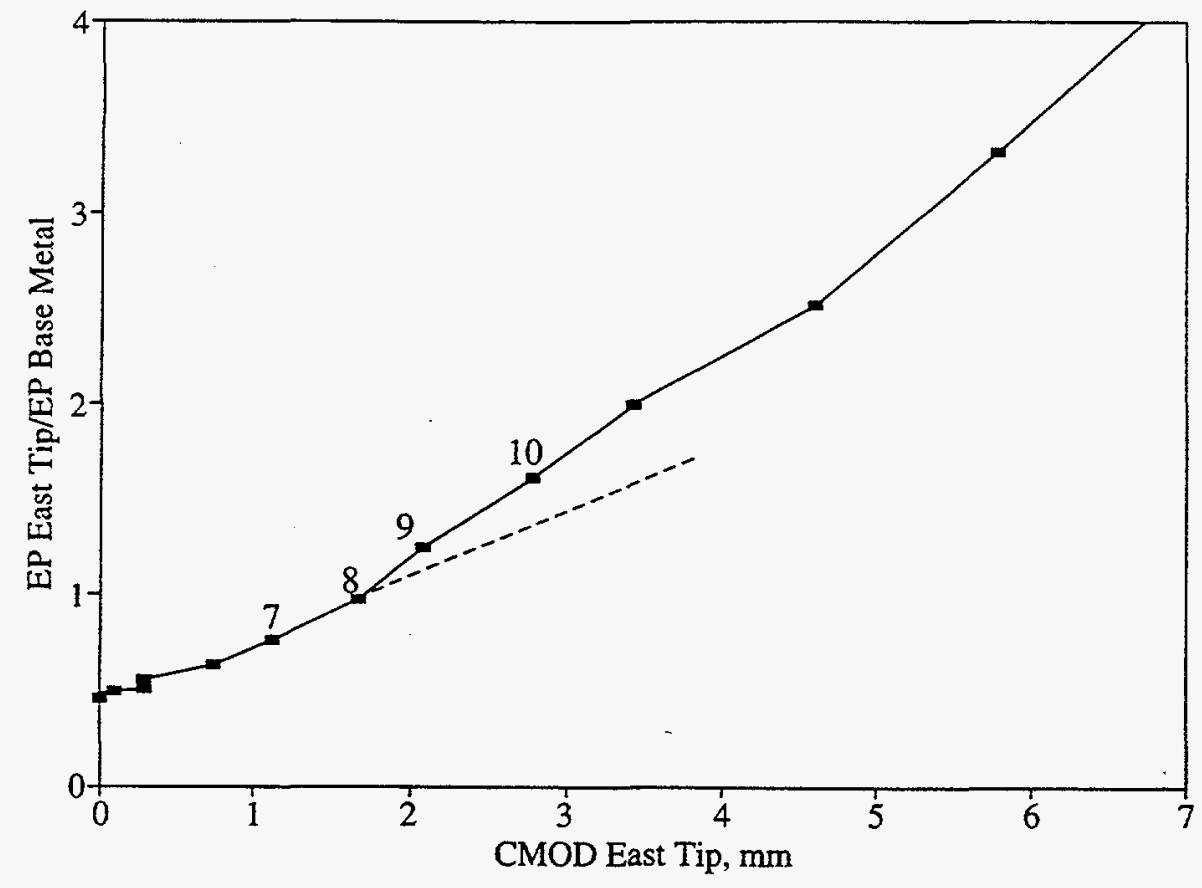

Figure 3.6 Upper envelope of the normalized east crack tip electric potential data versus east crack tip crack-mouth-opening displacement data for Experiment 4.2-2

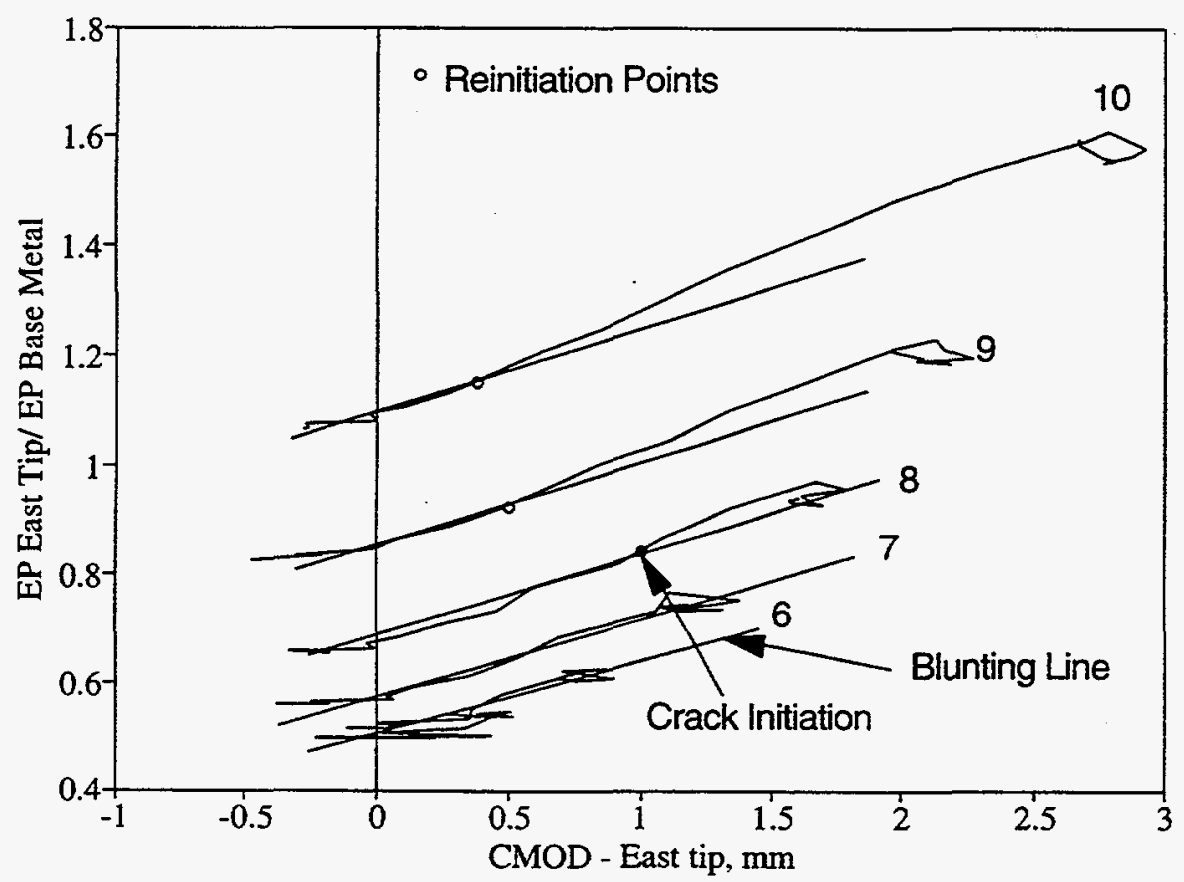

Figure 3.7 Normalized east crack tip electric potential versus east crack tip crack-mouth-opening displacement for Experiment 4.2-2 (only data corresponding to positive increasing loads are shown) 
The rotation due to the crack was calculated from the LVDT and its support geometry.

\subsection{Results from Pipe Experiments}

The key results from the four pipe fracture experiments conducted as part of this effort are presented in this section of the report. A summary of the key results is presented in Table 3.5. Included in Table 3.5 are the experiment number, pipe dimensions, crack location, loading history, crack size, quasi-static material property data (i.e., yield strength, ultimate strength, and value of $J$ at crack initiation from a $\mathrm{C}(\mathrm{T})$ specimen), moment at crack initiation, maximum moment, and test machine compliance.

\subsubsection{Experiment 4.2-1}

Figure 3.8 is a plot of the crack section moment data as a function of the crack section rotation data for Experiment 4.2-1. The moment data shown in this figure, and reported throughout this report, have been kinematically corrected to account for the relatively large displacements and short moment arm lengths. The rotation data shown in this figure, and elsewhere in this report, are the half rotation angle $(\phi)$, i.e., the average rotation of the pipe to its initial horizontal position, see Figure 3.8. From Figure 3.8, the maximum moment for this experiment was $84.08 \mathrm{kN}-\mathrm{m}(744,200 \mathrm{in}-\mathrm{lbs})$.

Figures 3.9 and 3.10 are plots of the normalized electric potential (EP) data at the east and west crack tips, respectively, (normalized to the base metal electric potential data), as a function of the crack-mouthopening displacements (CMOD) at their respective crack tips. From Figures 3.9 and 3.10, it can be seen that there is a distinct increase in slope for both of these figures at a CMOD level of approximately 2.5 $\mathrm{mm}(0.1 \mathrm{inch})$. This increase in slope of the EP versus CMOD data is indicative of crack initiation. Knowing that the CMOD at the two crack tips was approximately $2.5 \mathrm{~mm}(0.1 \mathrm{inch})$, we can see from Figure 3.11 that the CMOD at the crack centerline at crack initiation was approximately $3.87 \mathrm{~mm}(0.152$ inch). With that piece of data, the crack-section moment versus crack centerline CMOD data plot, see Figure 3.12, can be used to establish the moment value at crack initiation as being $68.68 \mathrm{kN}-\mathrm{m}(607,900$ in-lbs). This is 81.7 percent of the maximum moment for the experiment, i.e., $84.08 \mathrm{kN}-\mathrm{m}(744,200 \mathrm{in}$ lbs).

Figure 3.11 is a plot of the crack-mouth-opening displacements at the crack centerline and both crack tips as a function of the pipe displacement at the load points for this experiment. (Note, the load-point displacement is the load-line displacement measured from the LVDT in the load train, corrected for the test machine compliance.) These CMOD data used in conjunction with the crack growth data can be used to verify crack-opening-area (COA) analyses to be used in leak-rate analyses for leak-before-break (LBB) considerations.

Figure 3.13 is a plot of the through-wall-crack growth as a function of the pipe displacement at the load points for Experiment 4.2-1. The through-wall-crack growth data shown in Figure 3.13, and reported 
Table 3.5 Summary of key results from Experiments 4.2-1, 4.2-2, 4.2-3, and 3.3-1

\begin{tabular}{|c|c|c|c|c|}
\hline Experiment Number & 4.2-1 & 4.2-2 & 4.2-3 & 3.3-1 \\
\hline Experiment Moment at Crack Initiation, $\mathrm{kN}-\mathrm{m}$ & 68.68 & 63.50 & 83.20 & 71.32 \\
\hline Experiment Maximum Moment, $\mathrm{kN}-\mathrm{m}$ & 84.08 & 78.44 & 87.98 & 92.76 \\
\hline Quasi-Static Yield Strength, MPa & 221.0 (a) & 221.0 (a) & $516.0(b)$ & 221.0 (a) \\
\hline Quasi-Static Ultimate Strength, MPa & $493.0(\mathrm{a})$ & $493.0(a)$ & 693.0 (b) & $493.0(\mathrm{a})$ \\
\hline Quasi-Static $\mathrm{J}$ at Initiation, $\mathrm{kN} / \mathrm{m}$ & $378.6(a)$ & $378.6(a)$ & 760.9 (b) & $378.6(a)$ \\
\hline Crack Location & Base Metal & Base Metal & Weld Metal & Base Metal \\
\hline Number of Cycles to Crack Initiation & $N / A^{(c)}$ & 8 & 13 & N/A \\
\hline Number of Cycles to Maximum Moment & $\mathrm{N} / \mathrm{A}$ & 14 & 13 & N/A \\
\hline Loading Rate ${ }^{(d)}$ & DYN & DYN & DYN & QS \\
\hline Load Ratio (Min/Max) $)^{(e)}$ & Mono & $R=-1$ & $R=-1$ & Mono \\
\hline \multicolumn{5}{|l|}{$\begin{array}{l}\text { Load-Line Displacement Increments between } \\
\text { Cycles, } \mathrm{mm}\end{array}$} \\
\hline First Loading Block & N/A & 1.6002 & 1.6002 & N/A \\
\hline Second Loading Block & N/A & 0.8001 & 0.8001 & N/A \\
\hline Third Loading Block & N/A & 3.2004 & 3.2004 & N/A \\
\hline Measured Outside Pipe Diameter, mm & 168.3 & 165.6 & 166.2 & 166.0 \\
\hline Measured Wall Thickness, mm & 14.5 & 14.5 & 14.4 & 14.5 \\
\hline $\begin{array}{l}\text { Total TWC Length, Percent of } \\
\text { Circumference }\end{array}$ & 16.67 & 16.67 & 16.67 & 16.60 \\
\hline Machine Compliance, $\mathrm{mm} / \mathrm{kN}$ & 0.01435 & 0.01127 & 0.01127 & 0.01127 \\
\hline
\end{tabular}
(a) Base metal.
(b) Weld metal.
(c) N/A = Not applicable.
(d) $\mathrm{DYN}=$ dynamic, $\mathrm{QS}=$ quasi-static.
(e) Mono $=$ monotonic $(\mathrm{R}=1)$. 


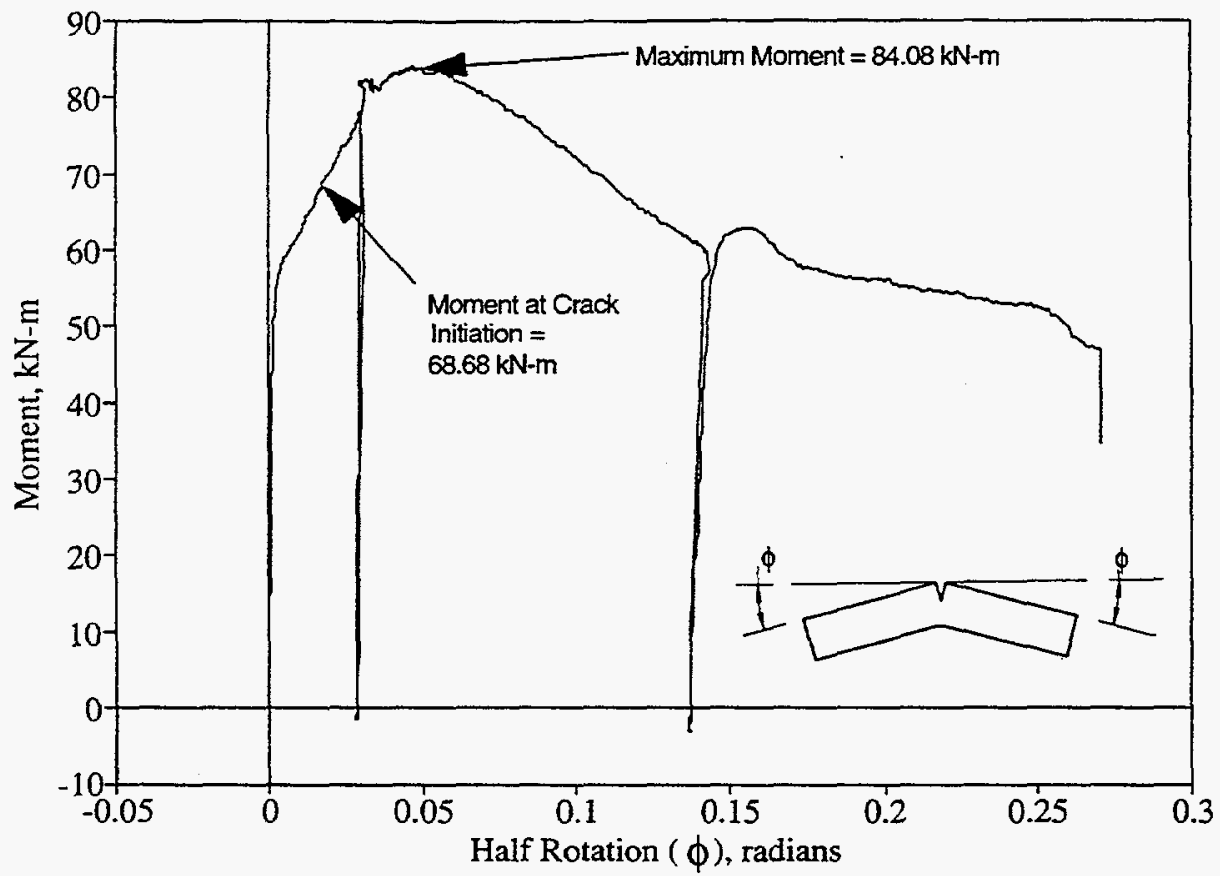

Figure 3.8 Moment versus half rotation for Experiment 4.2-1

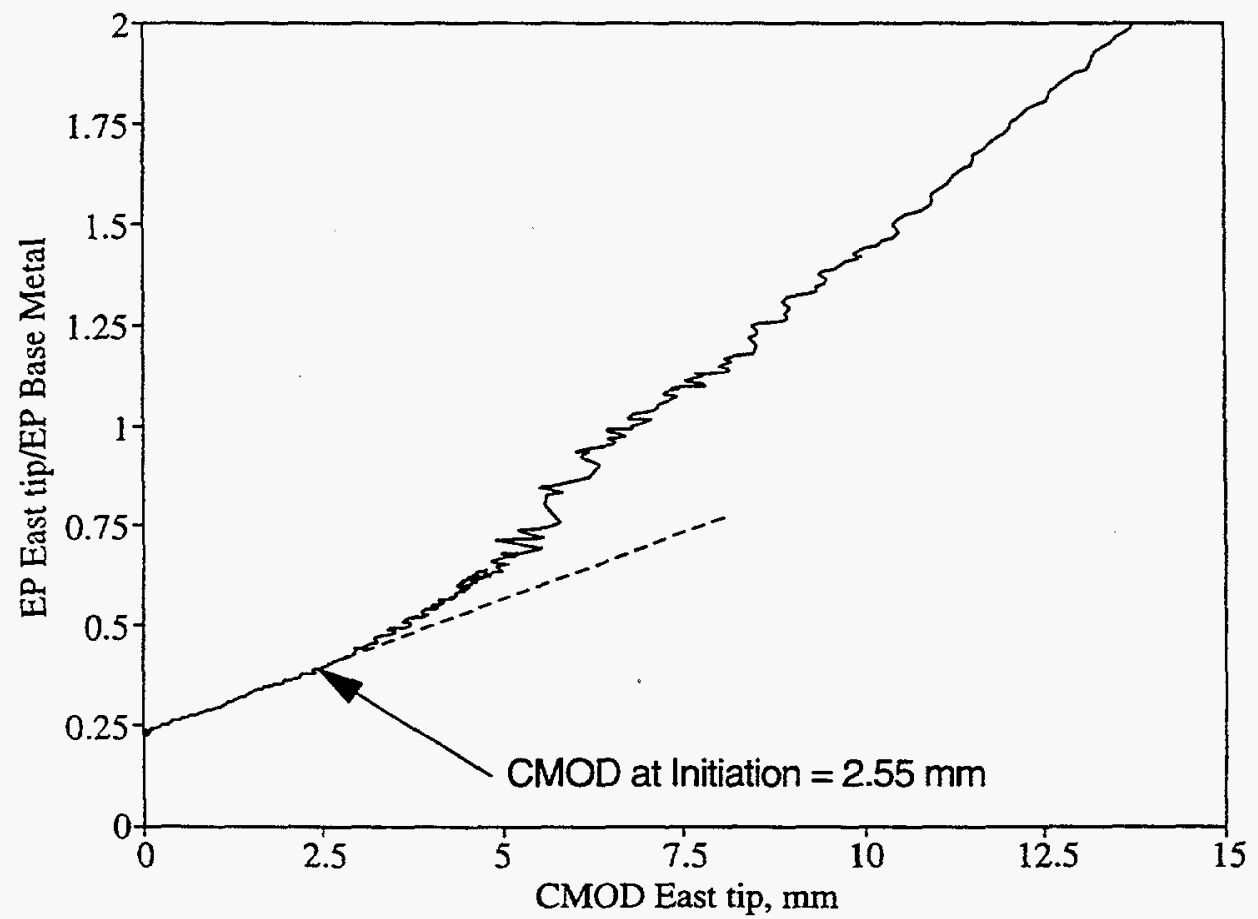

Figure 3.9 Normalized east crack tip electric potential versus east crack tip crack-mouth-opening displacement for Experiment 4.2-1 


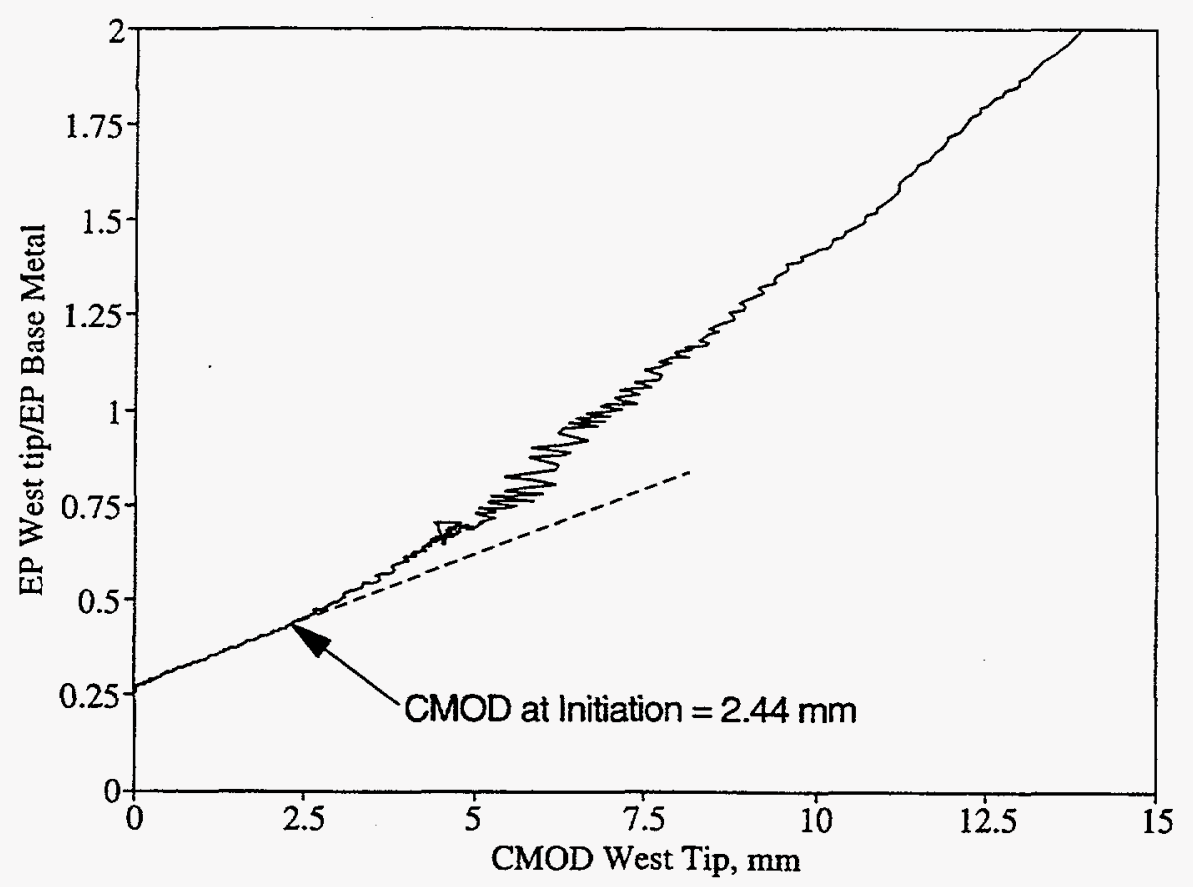

Figure 3.10 Normalized west crack tip electric potential versus west crack tip crack-mouth-opening displacement for Experiment 4.2-1

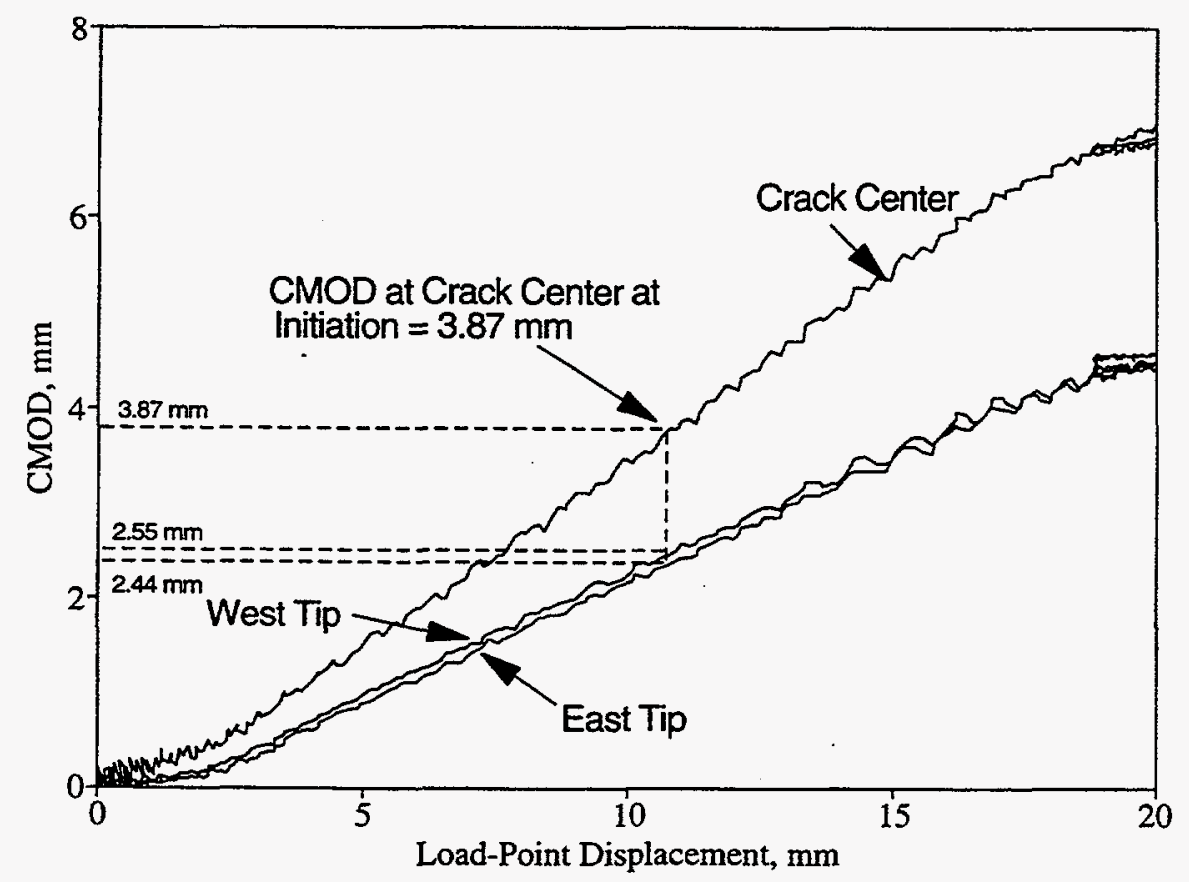

Figure 3.11 Crack-mouth-opening displacements versus the pipe displacement at the load points for Experiment 4.2-1 


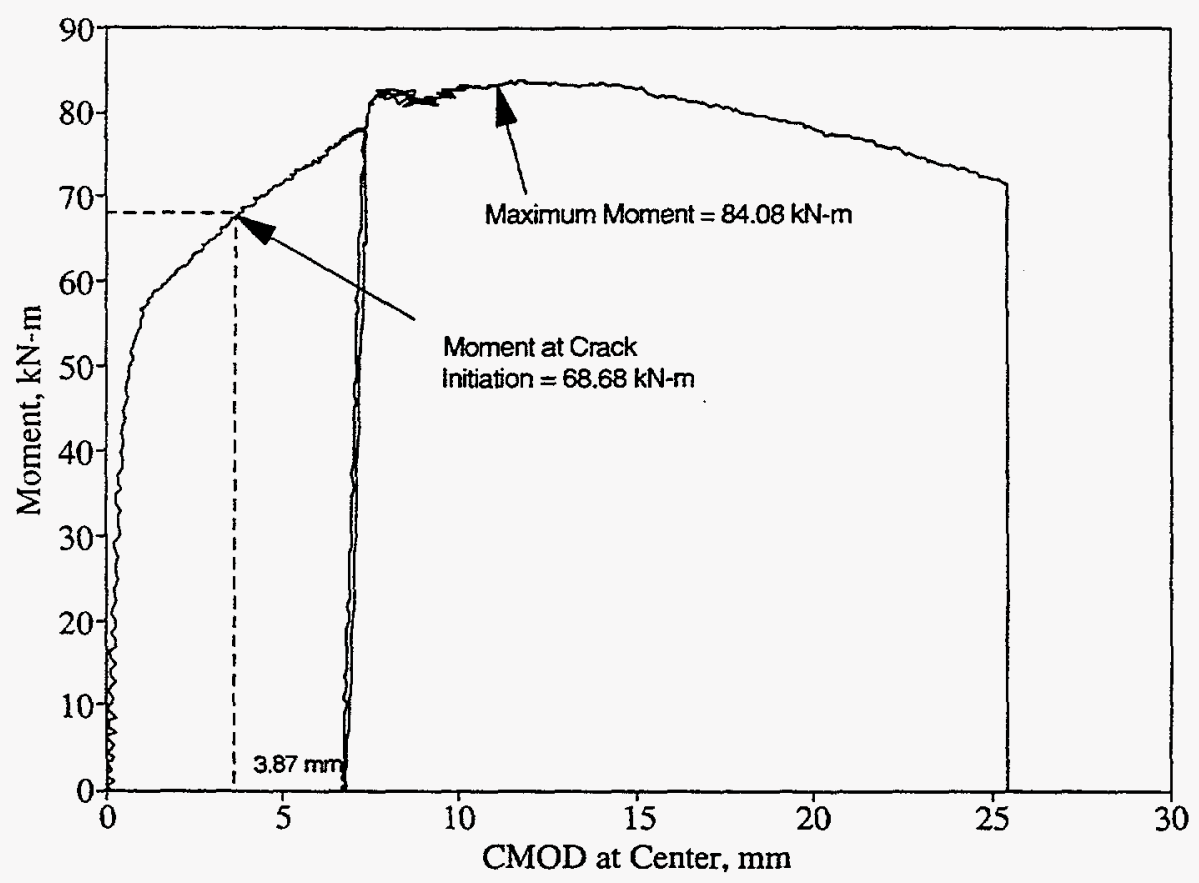

Figure 3.12 Moment versus center crack-mouth-opening displacement for Experiment 4.2-1

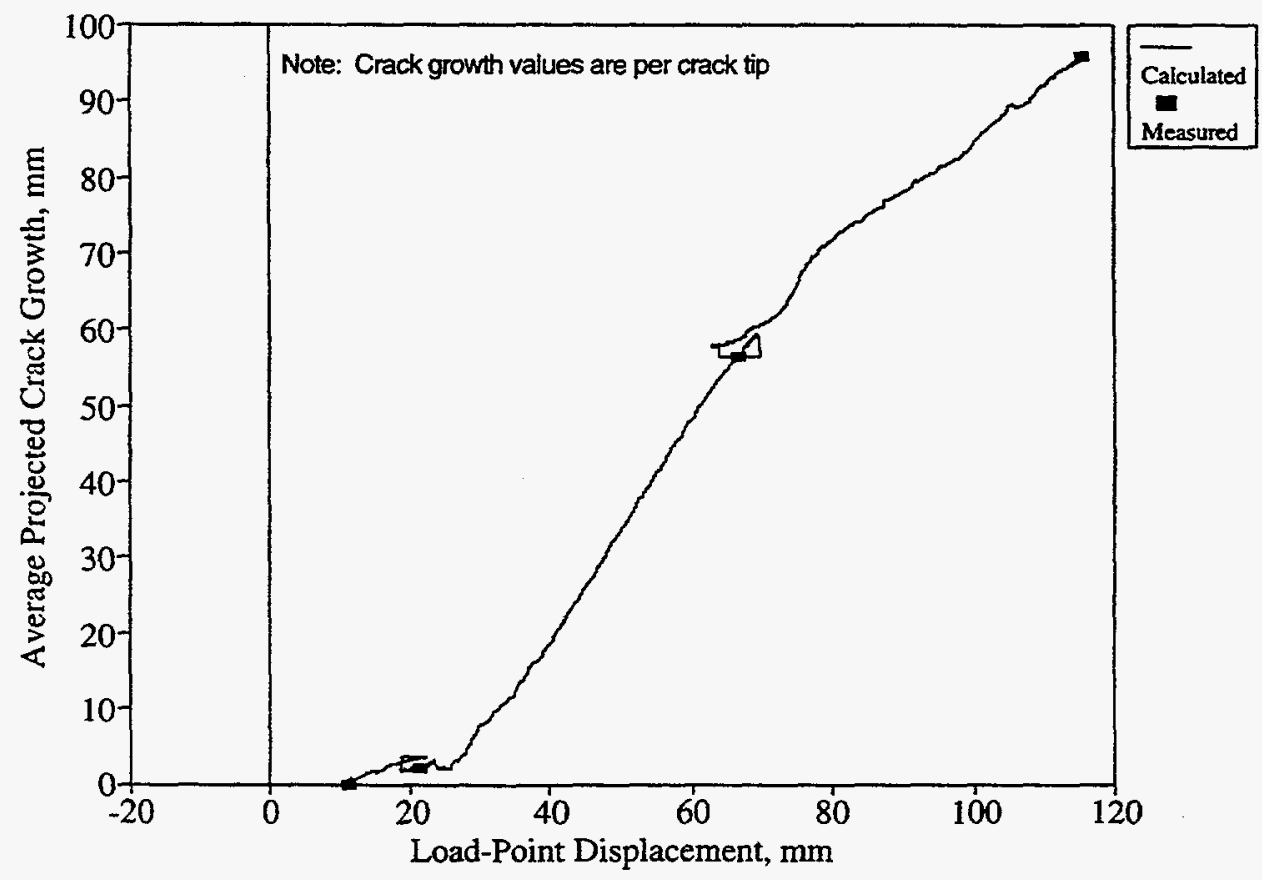

Figure 3.13 Average projected crack growth per crack tip versus the pipe displacement at the load points for Experiment 4.2-1 
throughout this report, represent the average crack growth from the two crack tips projected back onto the circumferential plane. There were no crack instabilities, i.e., unstable crack jumps, during this pipe experiment.

\subsubsection{Experiment 4.2-2}

Figure 3.14 is a plot of the crack section moment as a function of the crack section rotation data for the first two loading blocks of Experiment 4.2-2.

Figures 3.15 and 3.16 are plots of the upper envelope of the normalized EP at the east and west crack tips, respectively, (normalized to the base metal electric potential data), as a function of the CMOD at their respective crack tips. (Note, only the data corresponding to the upper envelope of the loaddisplacement record are shown in these figures.) From Figure 3.15, it can be seen that there is an increase in slope of the EP-CMOD curve at a CMOD level of approximately $1.7 \mathrm{~mm}(0.067 \mathrm{inch})$ during Cycle 8 at the east crack tip. From Figure 3.16, an increase in slope at a CMOD level of approximately $2.25 \mathrm{~mm}$ ( $0.09 \mathrm{inch})$ during Cycle 9 at the west crack tip can be seen. This increase in slope of the EP versus CMOD data is indicative of crack initiation. From these upper envelope figures, it appears that crack initiation occurred between Cycles 7 and 9 at both the east and west crack tips.

Figures 3.17 and 3.18 are plots of the normalized electric potential at the east and west crack tips, respectively, (normalized to the base metal electric potential data), as a function of the crack-mouthopening displacements at their respective crack tips. Only the data corresponding to positive increasing moments are shown in these figures. A change in slope during Cycle 8 is shown in both of these figures. Therefore, it was concluded that the east crack tip initiated at a CMOD level of approximately $1.0 \mathrm{~mm}$ ( 0.04 inch) during the eighth cycle, while the west crack tip initiated at a CMOD level of approximately $0.78 \mathrm{~mm}(0.03 \mathrm{inch})$ during the eighth cycle. The conclusion that the crack initiated during the eighth loading cycle is supported by observation of the video for this experiment which indicates that the east crack tip initiated on the eighth loading cycle.

Figure 3.19 is a plot of the crack-mouth-opening displacement at the crack centerline and both crack tips versus the pipe displacement at the load points for this experiment. Only data corresponding to increasing positive moment values for Cycle 8 are shown in this figure. From this figure, the crack center CMOD value associated with the west crack tip initiation is $1.0 \mathrm{~mm}(0.04$ inch), while the crack center CMOD value associated with the east crack tip initiation is $1.25 \mathrm{~mm}(0.05 \mathrm{inch})$.

Figure 3.20 is a plot of the crack section moment data as a function of the crack-mouth-opening displacement at the crack centerline $e^{(*)}$. Using Figure 3.20, the applied moment when the west crack tip initiated is found to be $62.2 \mathrm{kN}-\mathrm{m}$ (550,500 in-lbs), while the applied moment when the east crack tip initiated is found to be $64.8 \mathrm{kN}-\mathrm{m}(573,600 \mathrm{in}-\mathrm{lbs})$. The average moment at crack initiation for this experiment is $63.5 \mathrm{kN}-\mathrm{m}(562,000 \mathrm{in}-\mathrm{lbs})$. This is 81.0 percent of the maximum moment for this experiment, i.e., $78.44 \mathrm{kN}-\mathrm{m}(694,282 \mathrm{in}-\mathrm{lbs})$.

(*) Only data corresponding to the upper envelope of the load-displacement record are shown in this figure. 


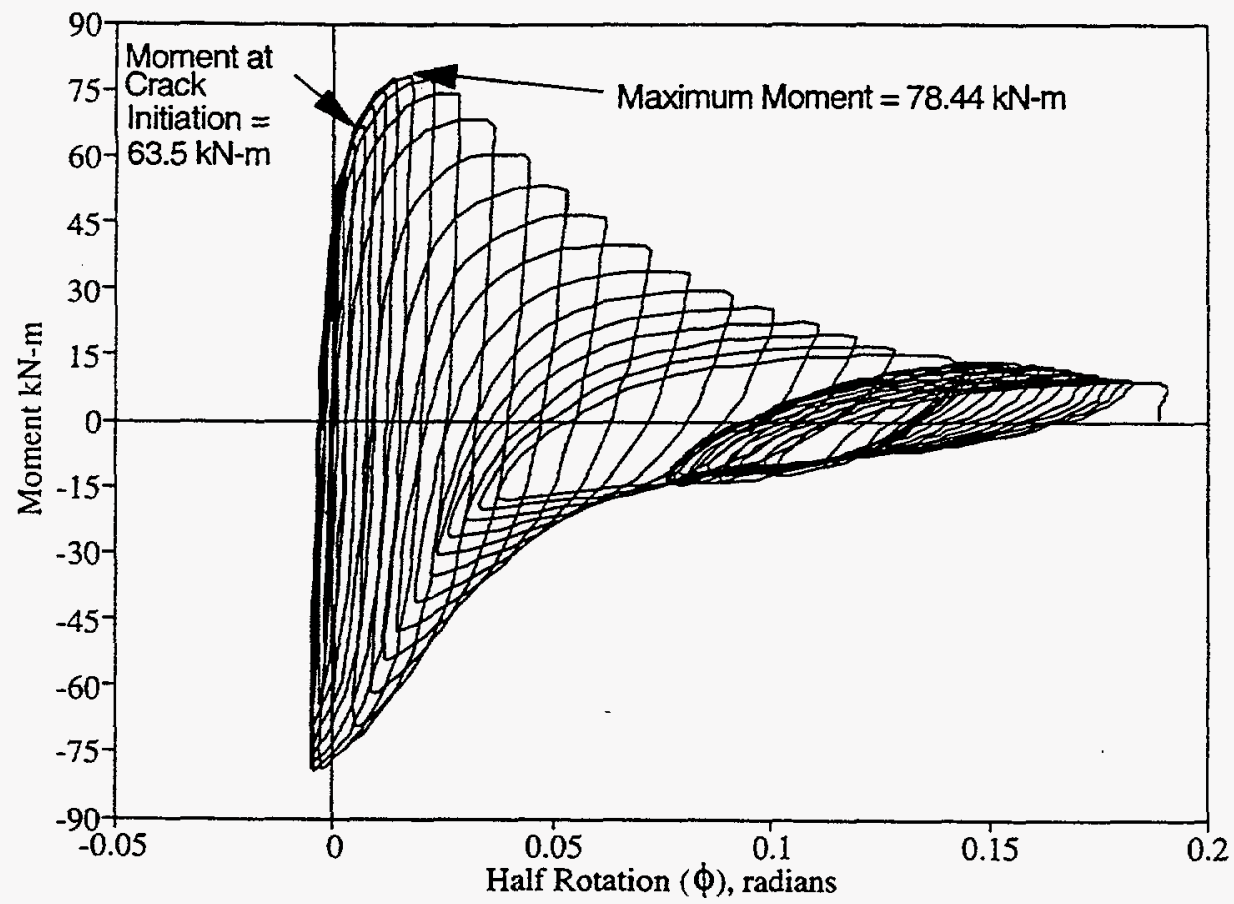

Figure 3.14 Moment versus half rotation for Experiment 4.2-2 (first and second loadings shown)

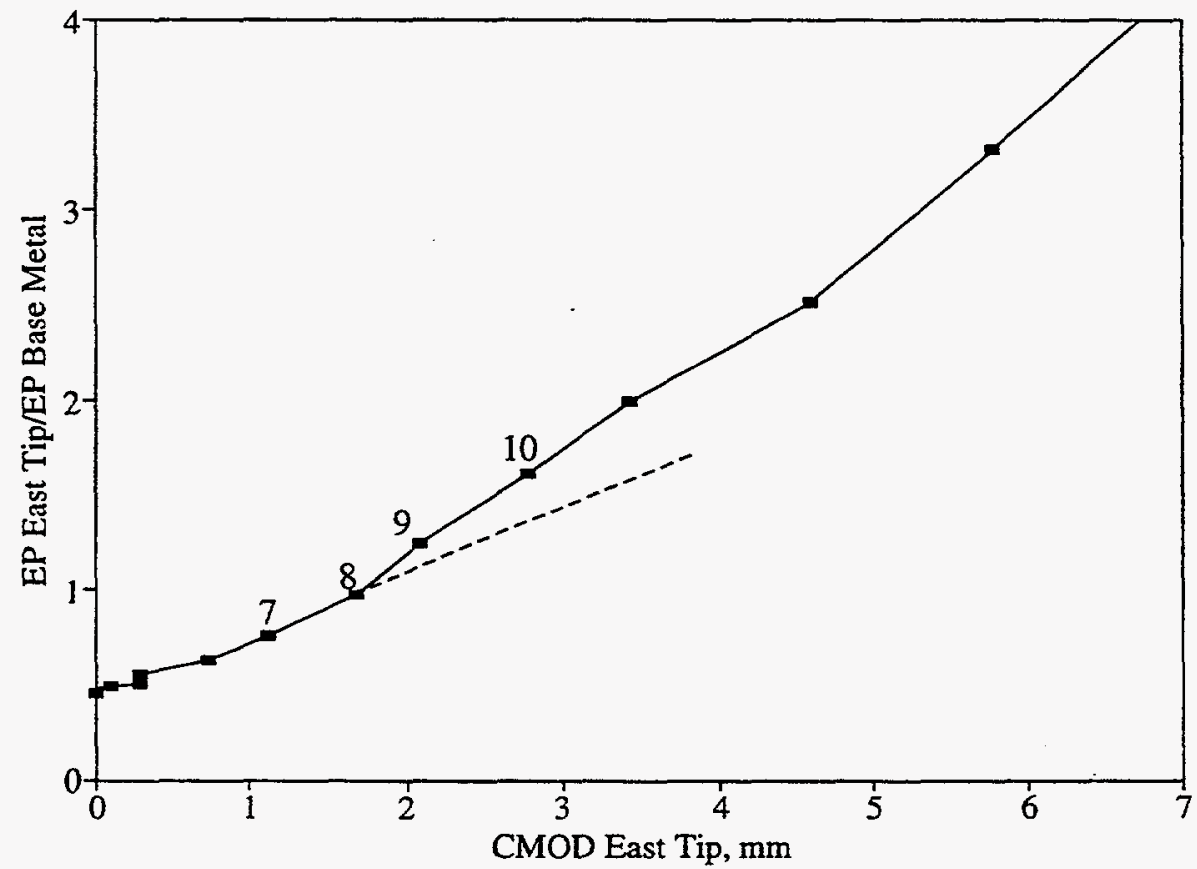

Figure 3.15 Upper envelope of the normalized east crack tip electric-potential data versus east crack tip crack-mouth-opening displacement data for Experiment 4.2-2 


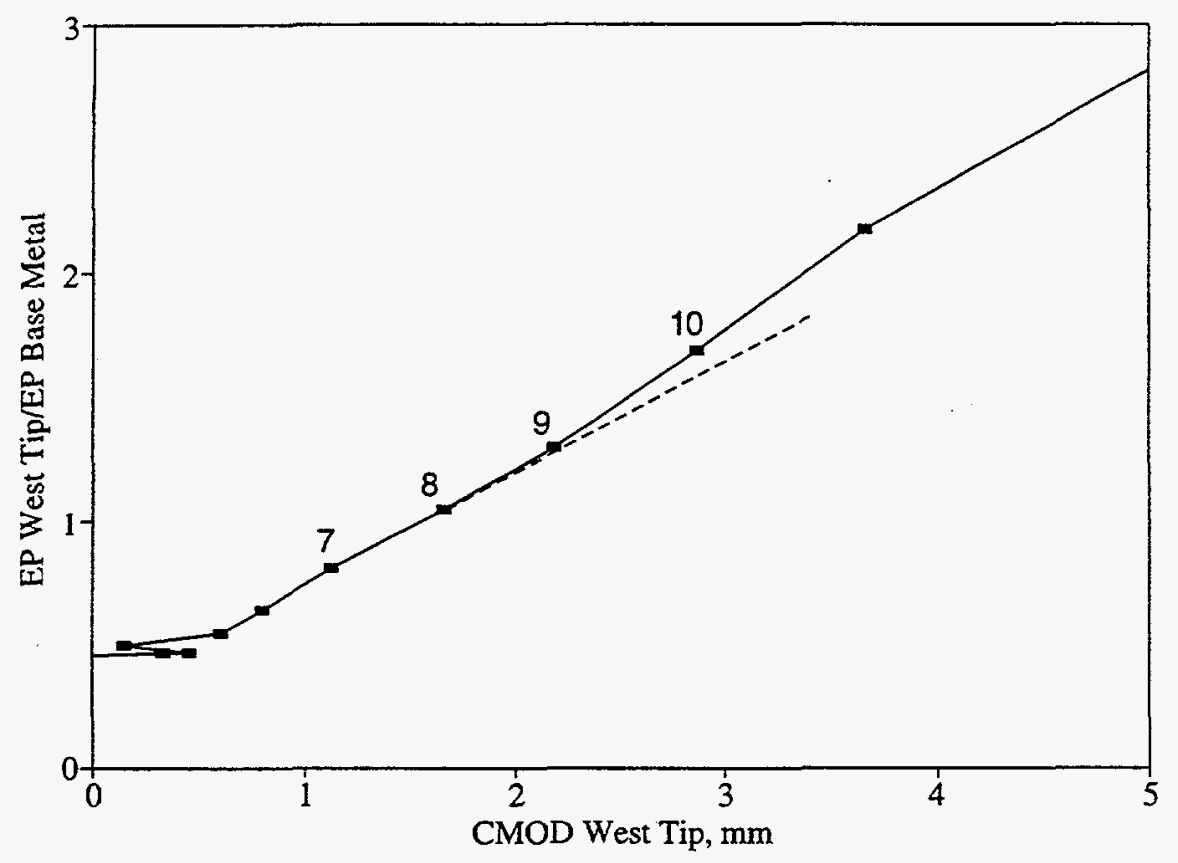

Figure 3.16 Upper envelope of the normalized west crack tip electric-potential data versus west crack tip crack-mouth-opening displacement data for Experiment 4.2-2

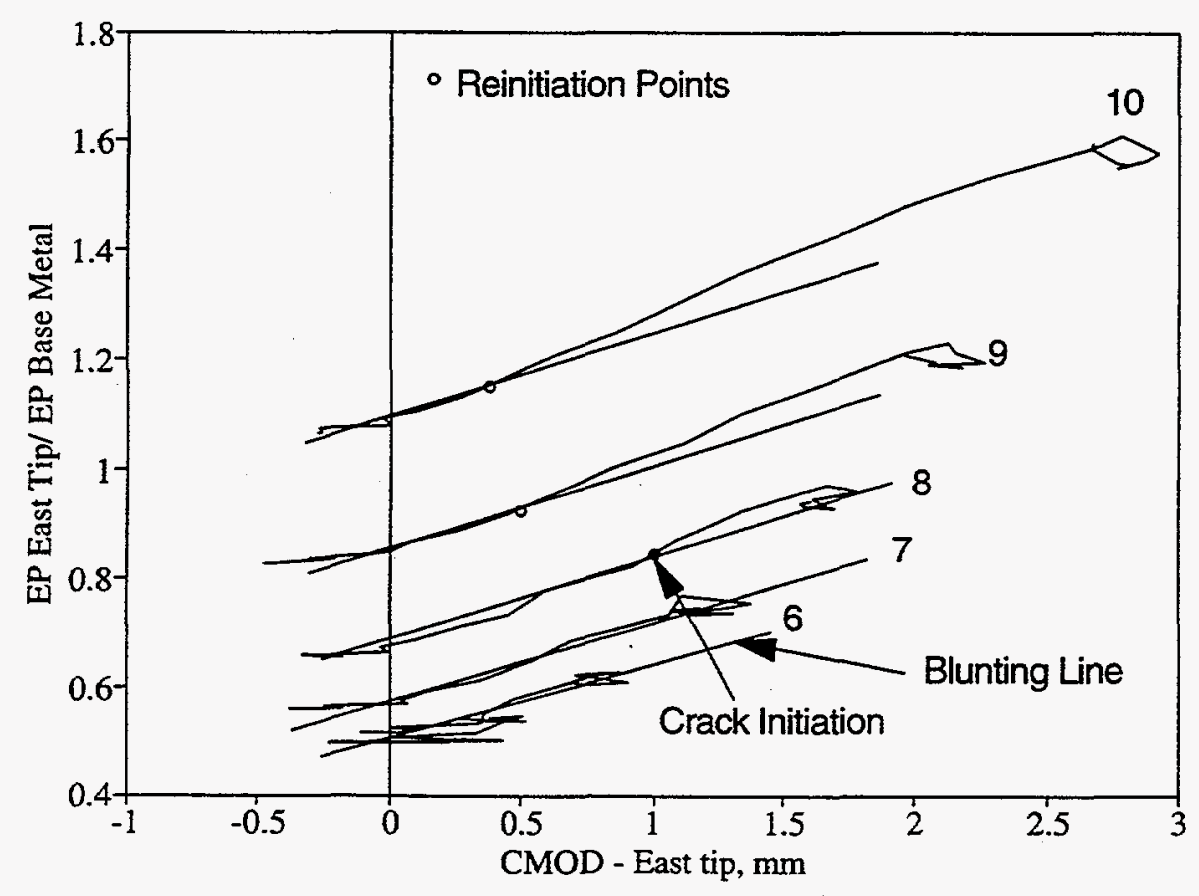

Figure 3.17 Normalized east crack tip electric-potential versus east crack tip crack-mouth-opening displacement for Experiment 4.2-2 (only data corresponding to positive increasing moments are shown) 


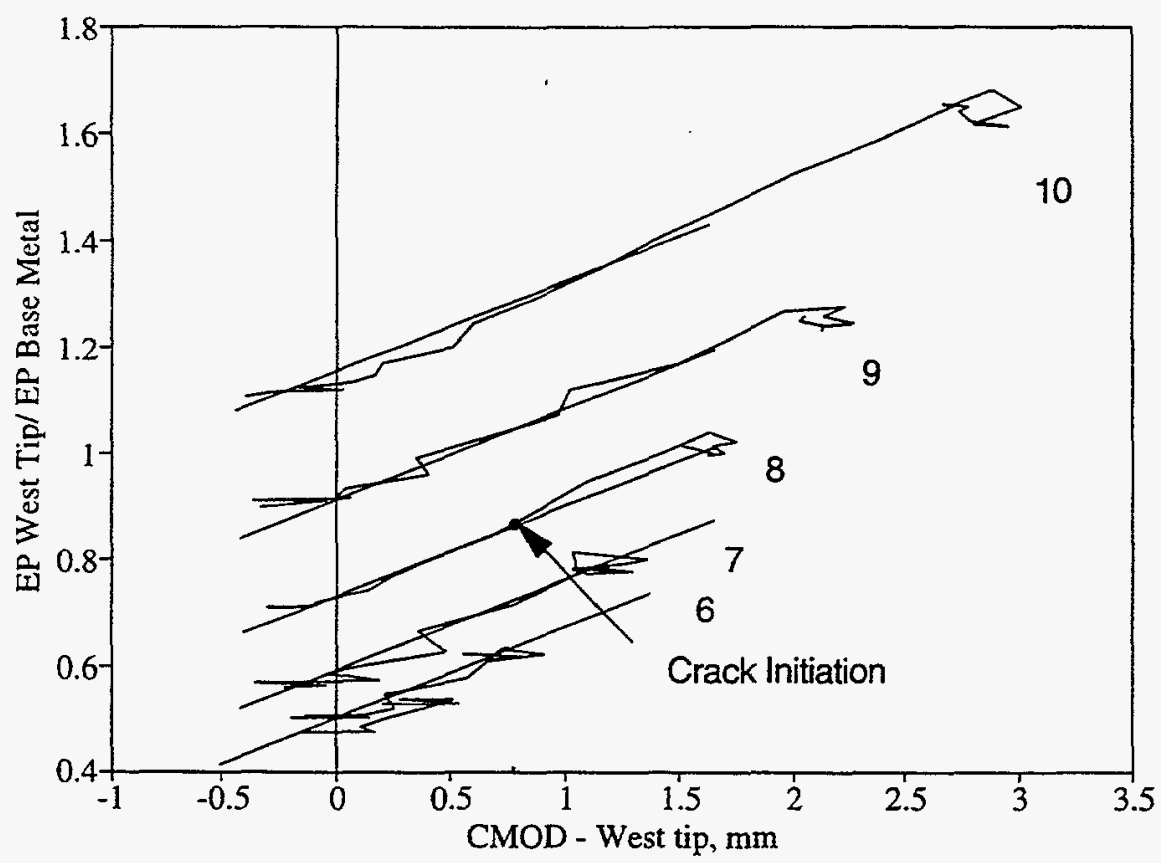

Figure 3.18 Normalized west crack tip electric-potential versus west crack tip crack-mouthopening displacement for Experiment 4.2-2 (only data corresponding to positive increasing moments are shown)

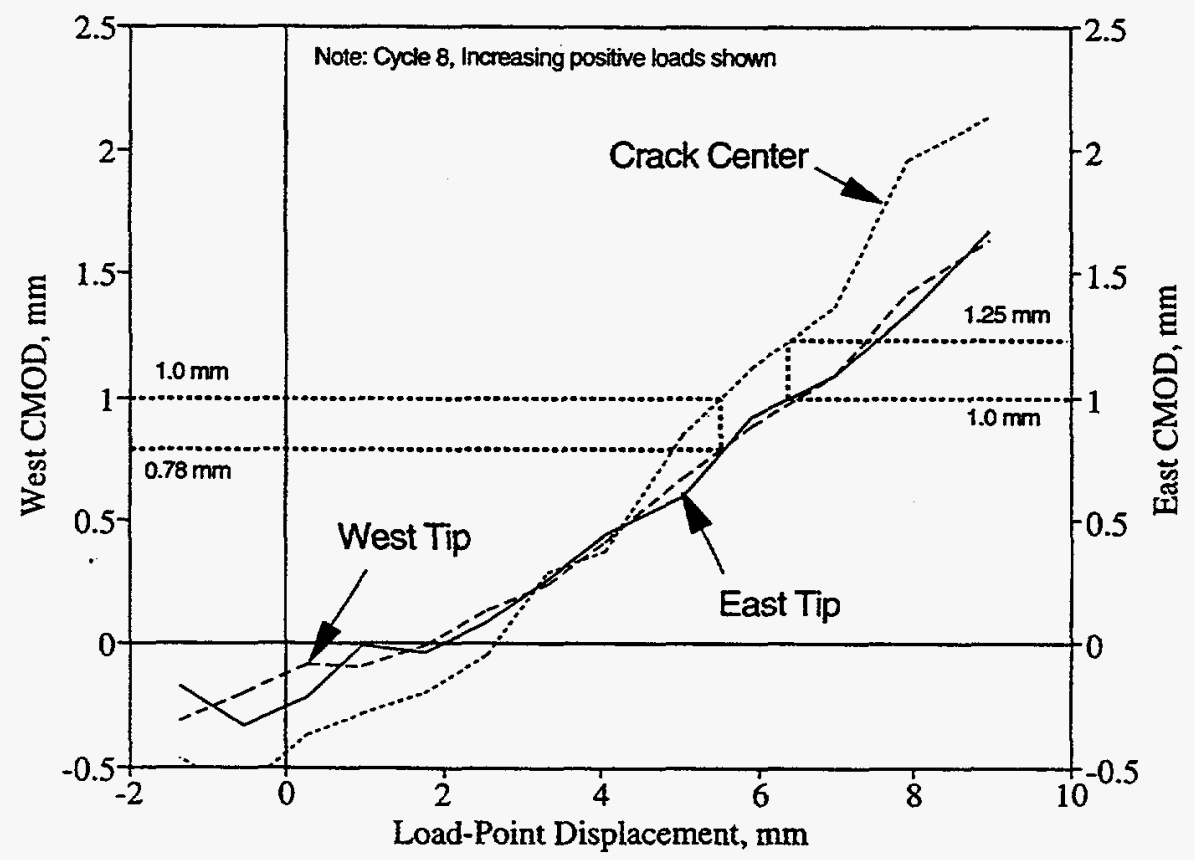

Figure 3.19 Crack-mouth-opening displacements versus the pipe displacement at the load points for Experiment 4.2-2 (only data corresponding to increasing positive moment values for Cycle 8 are shown) 


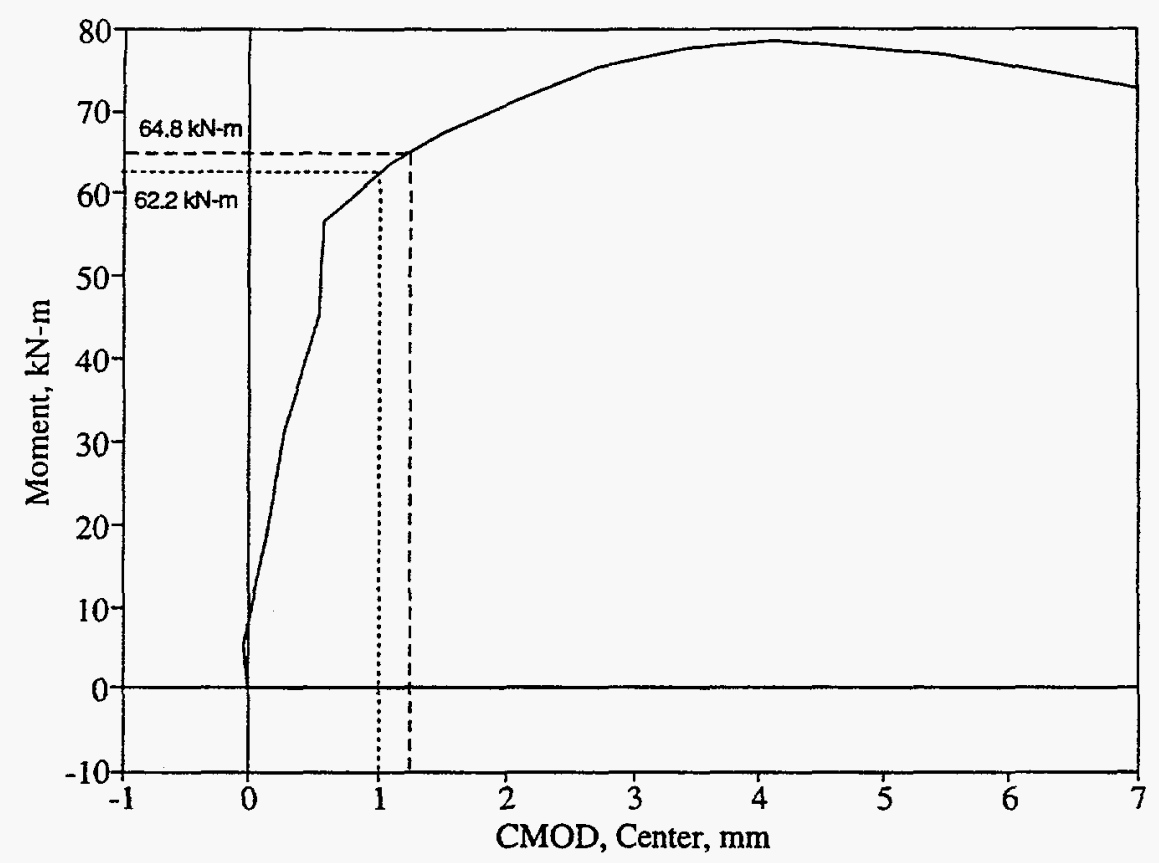

Figure 3.20 Moment versus crack center crack-mouth-opening displacement for Experiment 4.2-2 (only data corresponding to the upper envelope are shown)

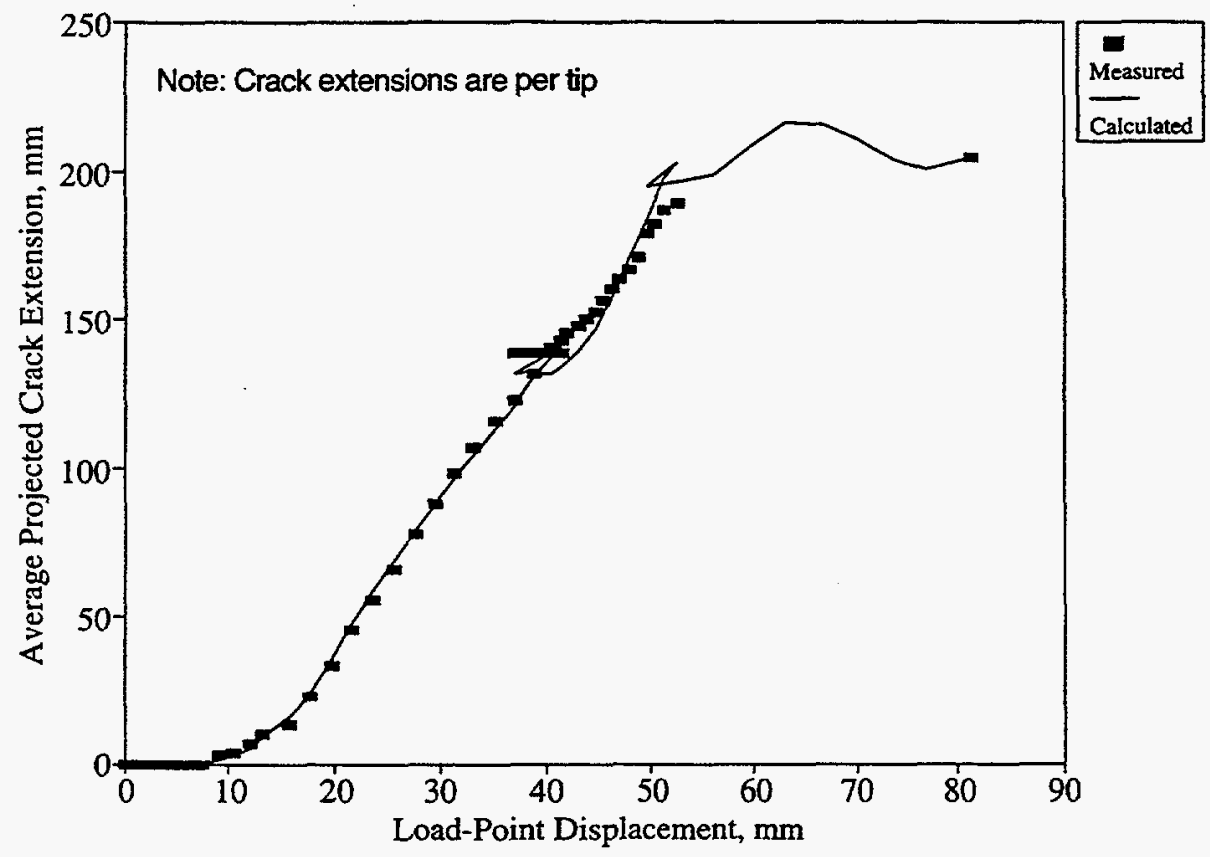

Figure 3.21 Average projected crack growth per crack tip versus the pipe displacement at the load points for Experiment 4.2-2 
Figure 3.21 is a plot of the through-wall-crack growth as a function of the pipe displacement of the load points for Experiment 4.2-2. The through-wall-crack growth data represent the average crack growth from the two crack tips projected back onto the circumferential plane. There were no crack instabilities, i.e., unstable crack jumps, during the course of this experiment.

\subsubsection{Experiment 4.2-3}

Figure 3.22 is a plot of the crack-section moment as a function of the crack-section rotation data for the first two loading blocks for this experiment.

Figure 3.23 is a plot of the upper envelope of the normalized electric potential at the east crack tip [normalized to a remote reference (base-metal) electric-potential data] as a function of the crack-mouthopening displacement at the east crack tip. (Note, only the data corresponding to the upper envelope of the load-displacement record are shown in this figure.) Figure 3.24 is a plot of the normalized EP at the west crack tip (normalized to the base metal electric potential data) as a function of the pipe displacement at the load points. The CMOD at the west tip was not used because the west crack tip CMOD data were noisy at the point of crack initiation. (Note, only the data corresponding to the upper envelope of the load-displacement record are shown in these figures.) From Figure 3.23, it can be seen that there is an increase in slope at an east crack tip CMOD level of approximately $4 \mathrm{~mm}(0.16 \mathrm{inch})$ on the 12th loading cycle. From Figure 3.24, it can be seen that there is an increase in slope at a pipe displacement at the load point of approximately $17 \mathrm{~mm}(0.67 \mathrm{inch})$ during the 12 th loading cycle. This increase in slope of the EP versus displacement data is indicative of crack initiation. From these upper envelope figures, it appears that crack initiation occurred near Cycle 12 at both the east and west crack tips.

Figure 3.25 is a plot of the normalized electric potential at the east crack tip [normalized to the remote reference (base-metal) electric-potential data] as a function of the CMOD at the east crack tip. Figure 3.26 is a plot of the normalized EP at the west crack tip [normalized to the remote reference (base-metal) electric-potential data] as a function of the pipe displacement at the load points. Only the data corresponding to positive increasing loads are shown in these figures. A distinct change in slope during Cycle 13 is shown in both of these figures. From Figure 3.25 it was concluded that the east crack tip initiated at a CMOD level of approximately $2.95 \mathrm{~mm}(0.12$ inch) during Cycle 13 . From Figure 3.26, it was concluded that the west crack tip initiated at a pipe displacement at the load point of approximately $11.7 \mathrm{~mm}$ ( $0.46 \mathrm{inch})$ during Cycle 13 . This conclusion that the crack initiated during the 13th loading cycle is supported by observation of the video for this experiment which indicates that the east crack tip initiated on the 13th loading cycle.

Figure 3.27 is a plot of crack-mouth-opening displacement at the crack centerline and east crack tip versus the pipe displacement at the load points for this experiment. Only the data corresponding to increasing positive loads for Cycle 13 are shown in this figure. From this figure, the centerline CMOD values associated with the east and west crack tip initiations are $2.95 \mathrm{~mm}(0.12 \mathrm{inch})$ at the east crack tip and $3.46 \mathrm{~mm}(0.14 \mathrm{inch})$ at the west crack tip. 


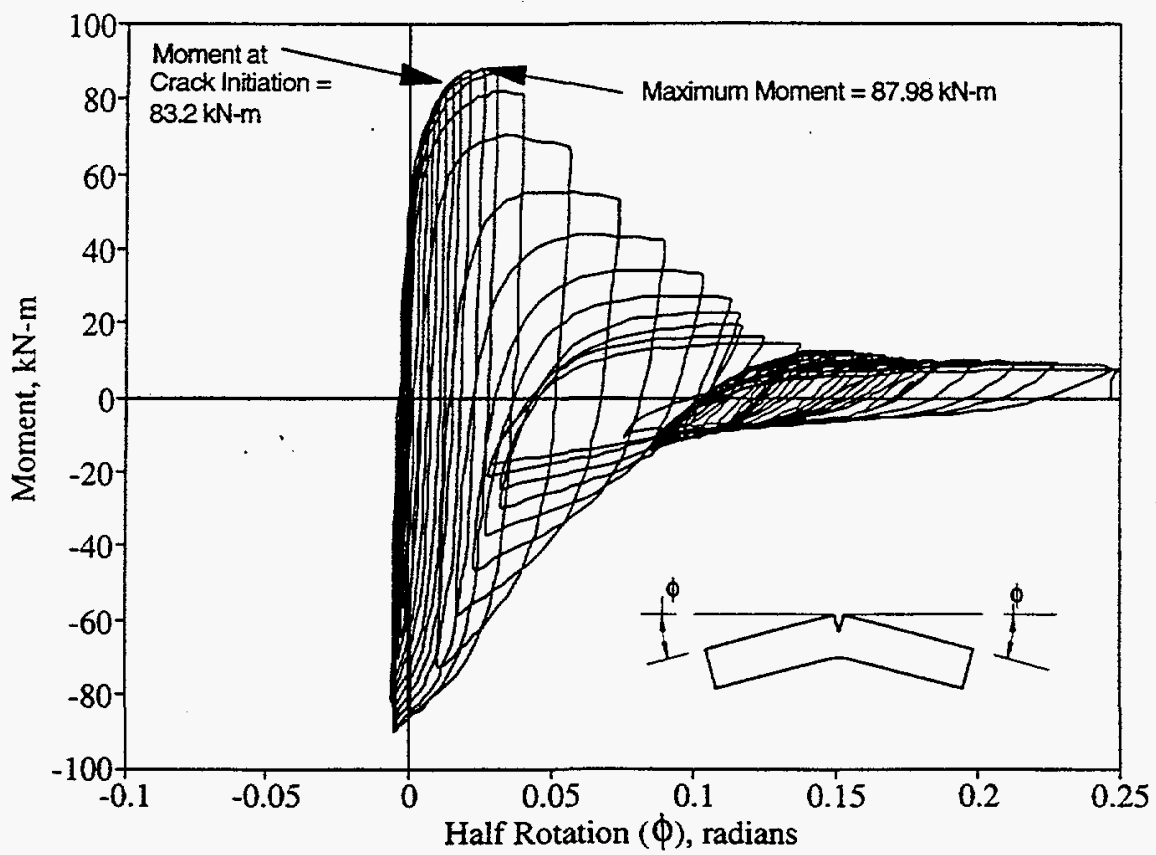

Figure 3.22 Moment versus half rotation for Experiment 4.2-3 (first and second loading blocks shown)

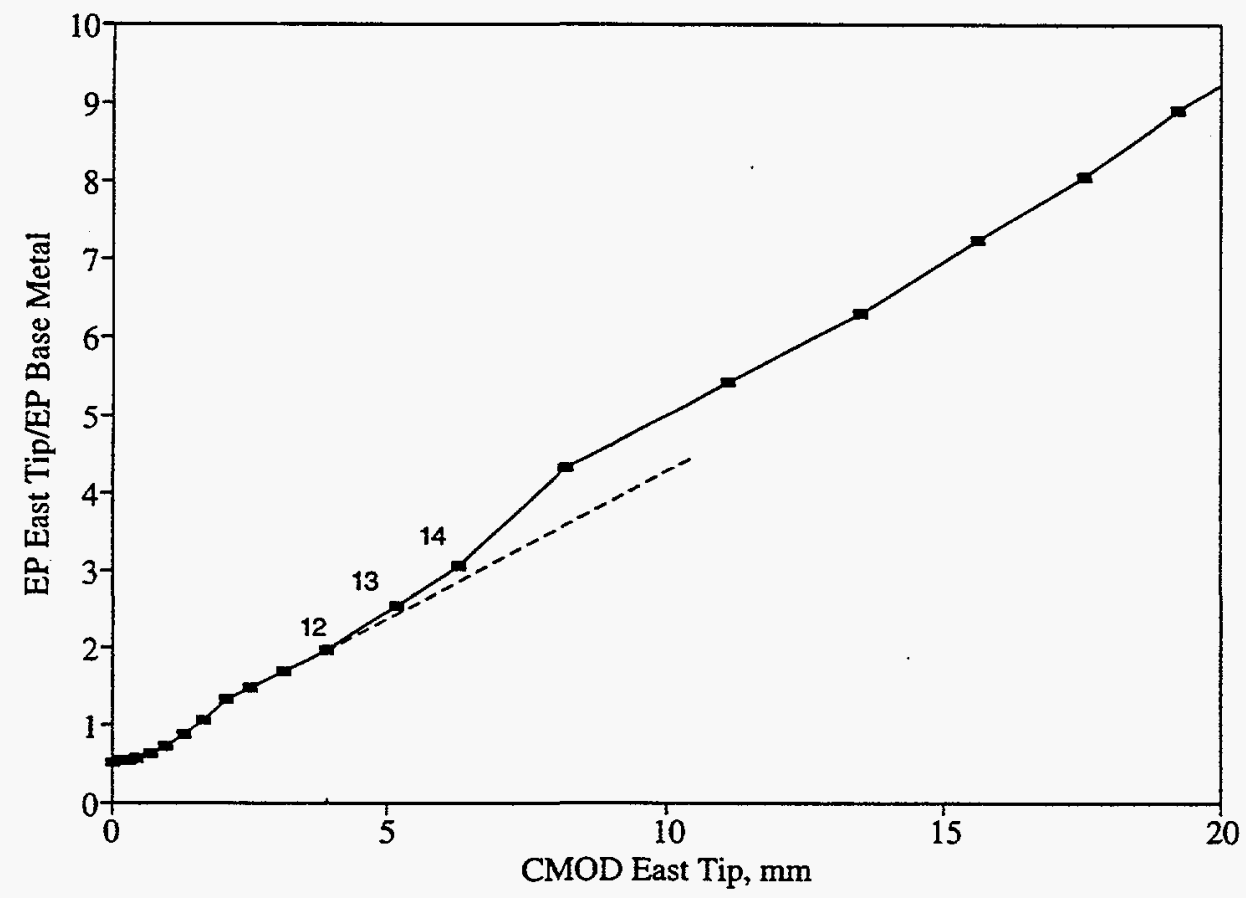

Figure 3.23 Upper envelope of the normalized east crack tip electric-potential data versus east crack tip crack-mouth-opening displacement for Experiment 4.2-3 


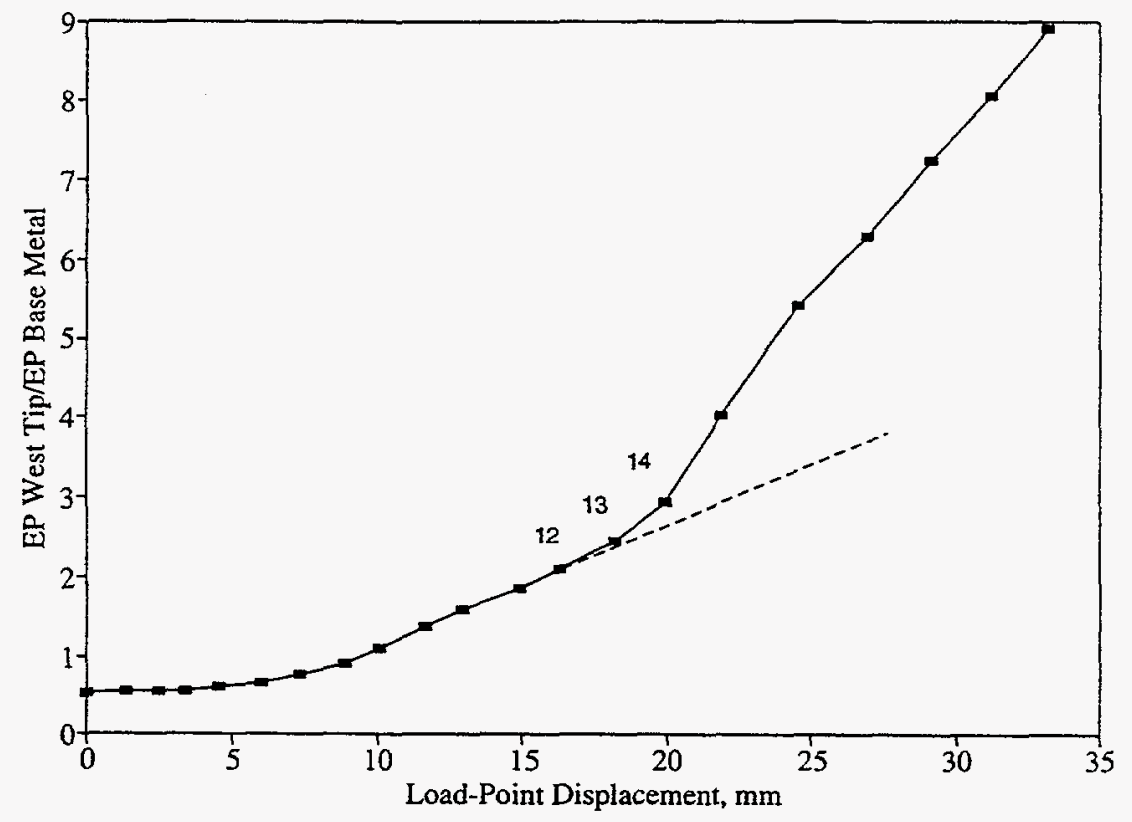

Figure 3.24 Upper envelope of the normalized west crack tip electric-potential data versus pipe displacement at the load points for Experiment 4.2-3

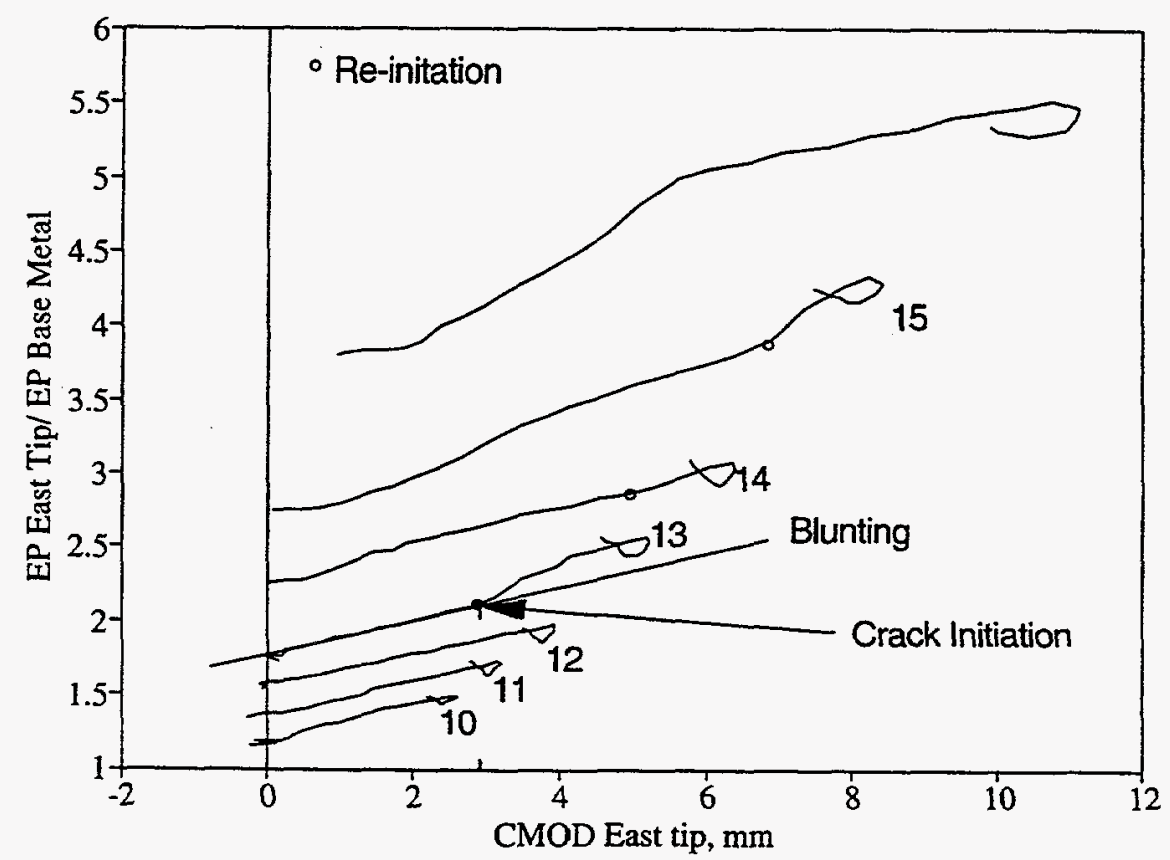

Figure 3.25 Normalized east crack tip electric-potential versus east crack tip crack-mouth-opening displacement for Experiment 4.2-3 (only data corresponding to positive increasing moments are shown) 


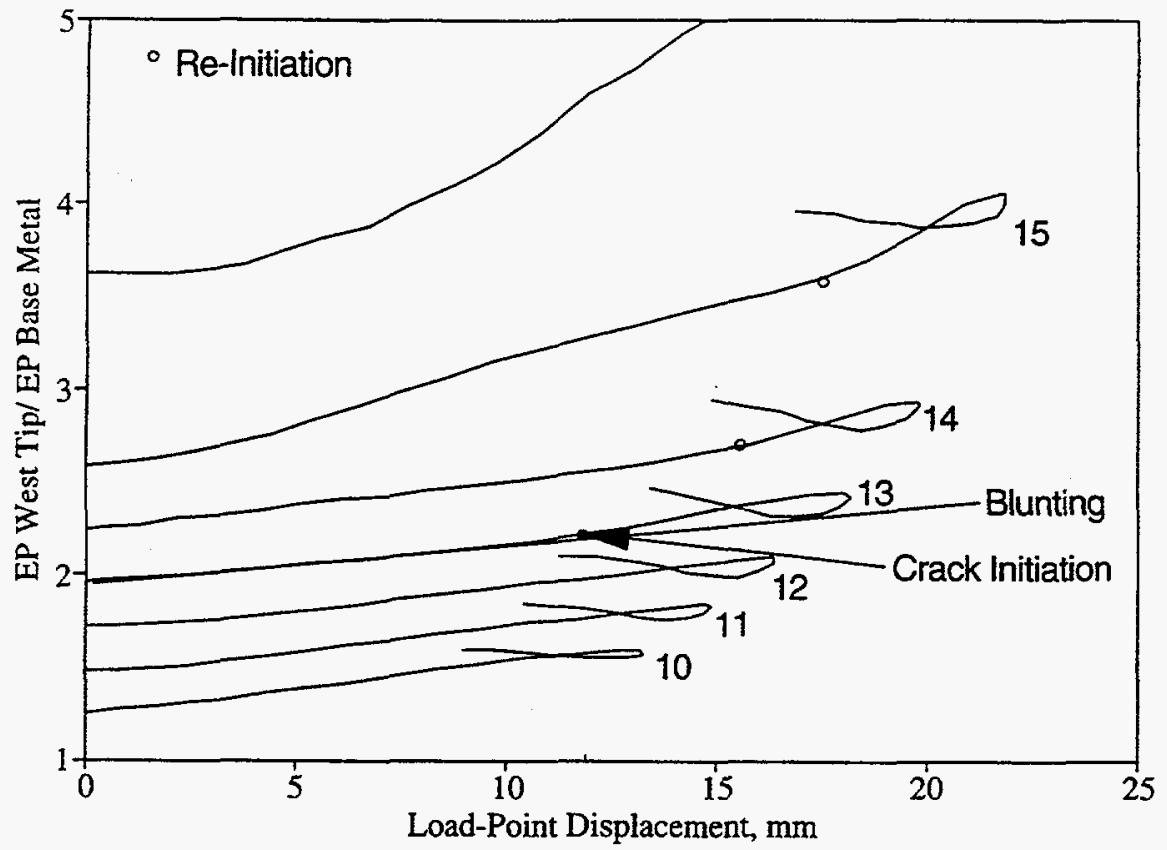

Figure 3.26 Normalized west crack tip electric-potential versus load-point displacement for Experiment 4.2-3 (only data corresponding to positive increasing moments are shown

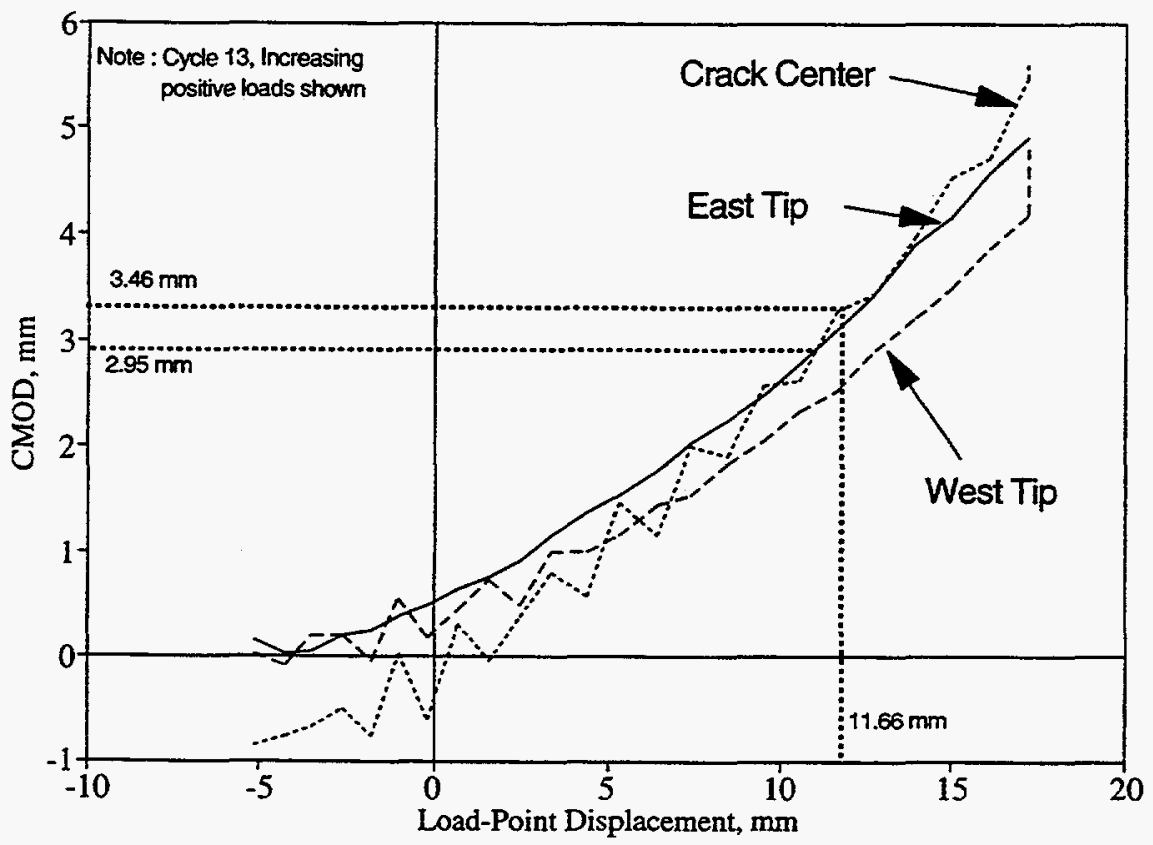

Figure 3.27 Crack-mouth-opening displacement versus load-point displacement for Cycle 13 of Experiment 4.2-3 (only data corresponding to positive increasing moment values for Cycle 13 are shown) 
Figure 3.28 is a plot of the crack section moment data as a function of the crack-mouth-opening displacement at the crack centerline. Using Figure 3.28, the applied moments when the west and east crack tips initiated are found to be $83.5 \mathrm{kN}-\mathrm{m}(739,200 \mathrm{in}-\mathrm{lbs})$ and $82.9 \mathrm{kN}-\mathrm{m}(733,800 \mathrm{in}-\mathrm{lbs})$, respectively. The average moment value at crack initiation for the two crack tips is 83.2 $\mathrm{kN}-\mathrm{m}(736,400 \mathrm{in}-\mathrm{lbs})$. This is 94.5 percent of the maximum moment for this experiment, i.e., 87.98 $\mathrm{kN}-\mathrm{m}(778,700$ in-lbs $)$.

Figure 3.29 is a plot of the through-wall crack growth as a function of pipe displacement at the load points for Experiment 4.2-3. The through-wall-crack growth data shown in Figure 3.29 represent the average crack growth from the two crack tips projected back into the circumferential plane. For this experiment, as for the others, there were no unstable crack jumps.

\subsubsection{Experiment 3.3-1}

Figure 3.30 is a plot of the crack-section moment data as a function of the crack-section rotation data for Experiment 3.3-1 The moment data shown in this figure have been kinematically corrected to account for the relatively large displacements and short moment-arm lengths. The rotation data shown in this figure are the half rotation angle $(\phi)$, i.e., the average rotation of the pipe with respect to its initial horizontal position, see Figure 3.30. From Figure 3.30, the maximum moment for this experiment was $92.76 \mathrm{kN}-\mathrm{m}(821,000 \mathrm{in}-\mathrm{lbs})$.

Figures 3.31 and 3.32 are plots of the normalized electric potential data at Crack Tip A and Crack Tip B, respectively, (normalized to the base metal electric potential data), as a function of the crack-mouthopening displacements at their respective crack tips. From Figures 3.31 and 3.32, it can be seen that there is a distinct increase in slope for both of these figures at a CMOD level of $2.69 \mathrm{~mm}(0.11 \mathrm{inch})$ for Crack Tip A and $2.95 \mathrm{~mm}$ ( 0.12 inch) for Crack Tip B. This increase in slope of the EP versus CMOD data is indicative of crack initiation. Knowing that the CMOD at crack initiation at Crack Tip A was $2.69 \mathrm{~mm}$ (0.11 inch), the CMOD at the crack centerline at crack initiation was found to be approximately $3.99 \mathrm{~mm}$ (0.16 inch), see Figure 3.33. With that piece of data, the crack section moment versus crack centerline CMOD data plot, see Figure 3.34, can be used to establish the moment value at crack initiation as being $71.32 \mathrm{kN}-\mathrm{m}(631,300 \mathrm{in}-\mathrm{lbs})$. This is 76.9 percent of the maximum moment for the experiment, i.e., $92.76 \mathrm{kN}-\mathrm{m}(821,000 \mathrm{in}-\mathrm{lbs})$.

Figure 3.35 is a plot of the through-wall-crack growth as a function of the pipe displacement at the load points for Experiment 3.3-1. The through-wall-crack growth data shown in Figure 3.35 represent the average crack growth from the two crack tips projected back onto the circumferential plane. There were no crack instabilities, i.e., unstable crack jumps, during this pipe experiment. 


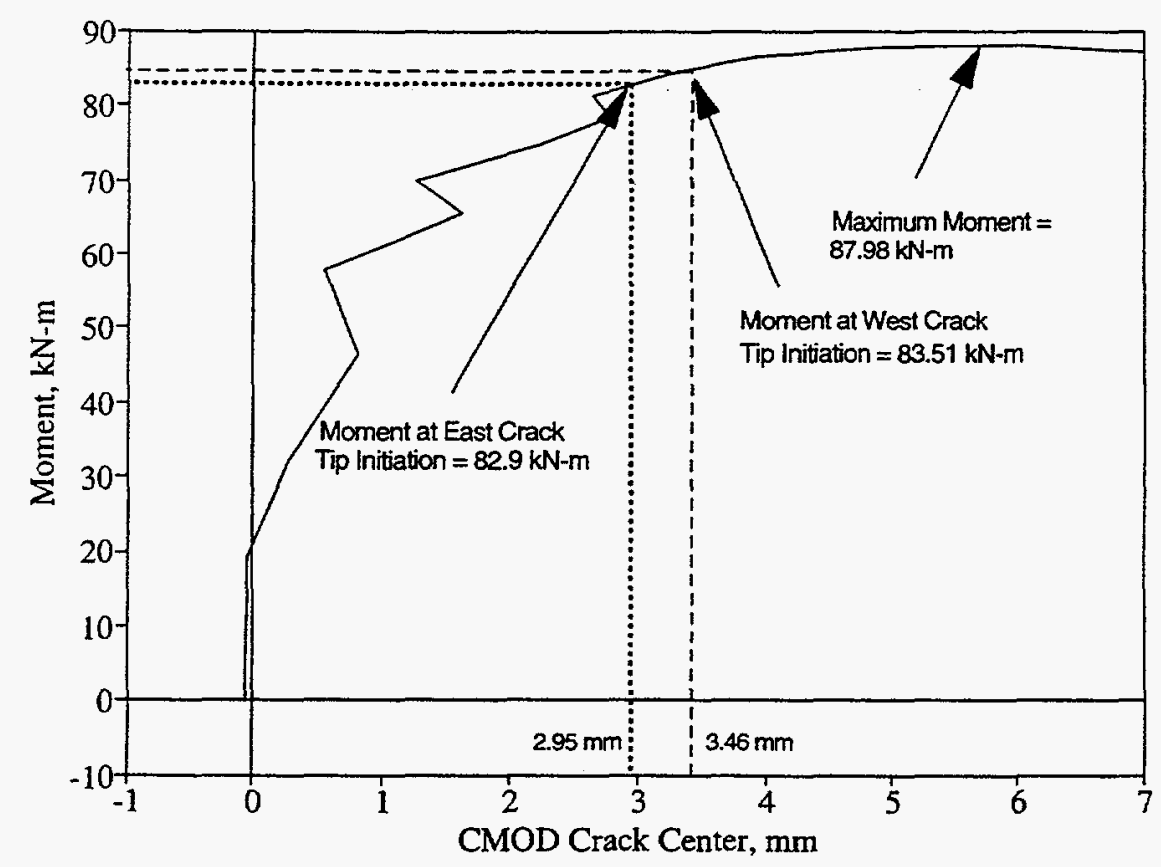

Figure 3.28 Crack section moment versus crack center crack-mouth-opening displacement for Experiment 4.2-3 (only data corresponding to the upper envelope are shown)

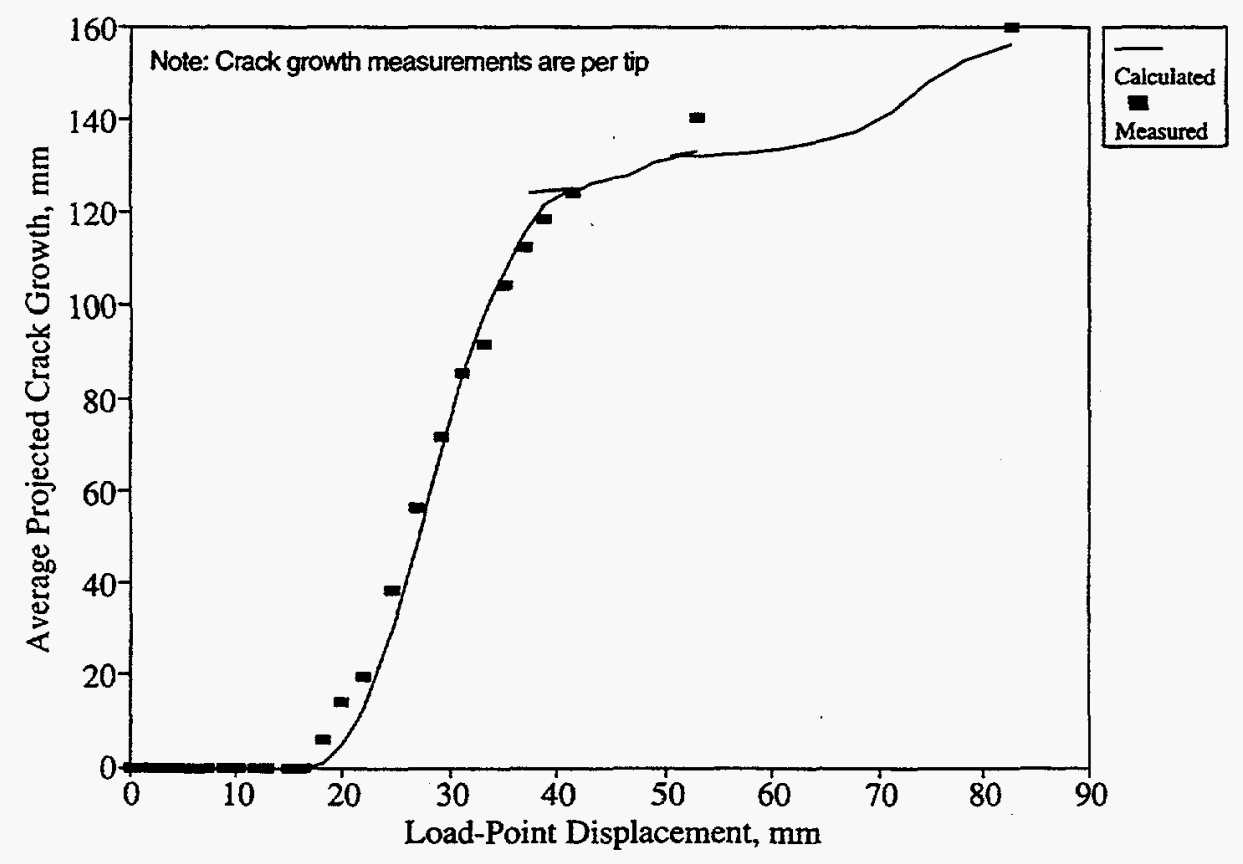

Figure 3.29 Average projected crack growth per crack tip versus the pipe displacement at the load points for Experiment $4.2-3$ 


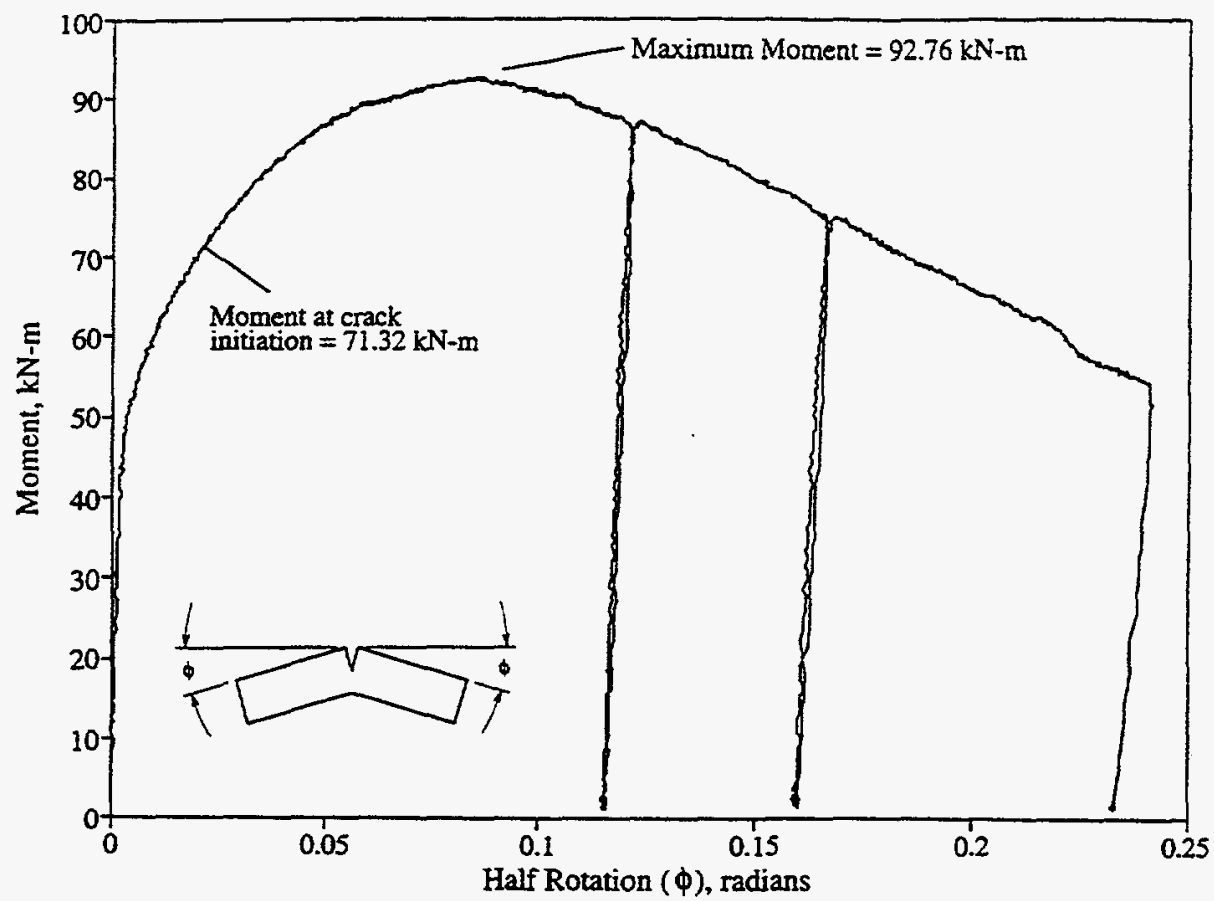

Figure 3.30 Crack section moment versus half rotation for Experiment 3.3-1

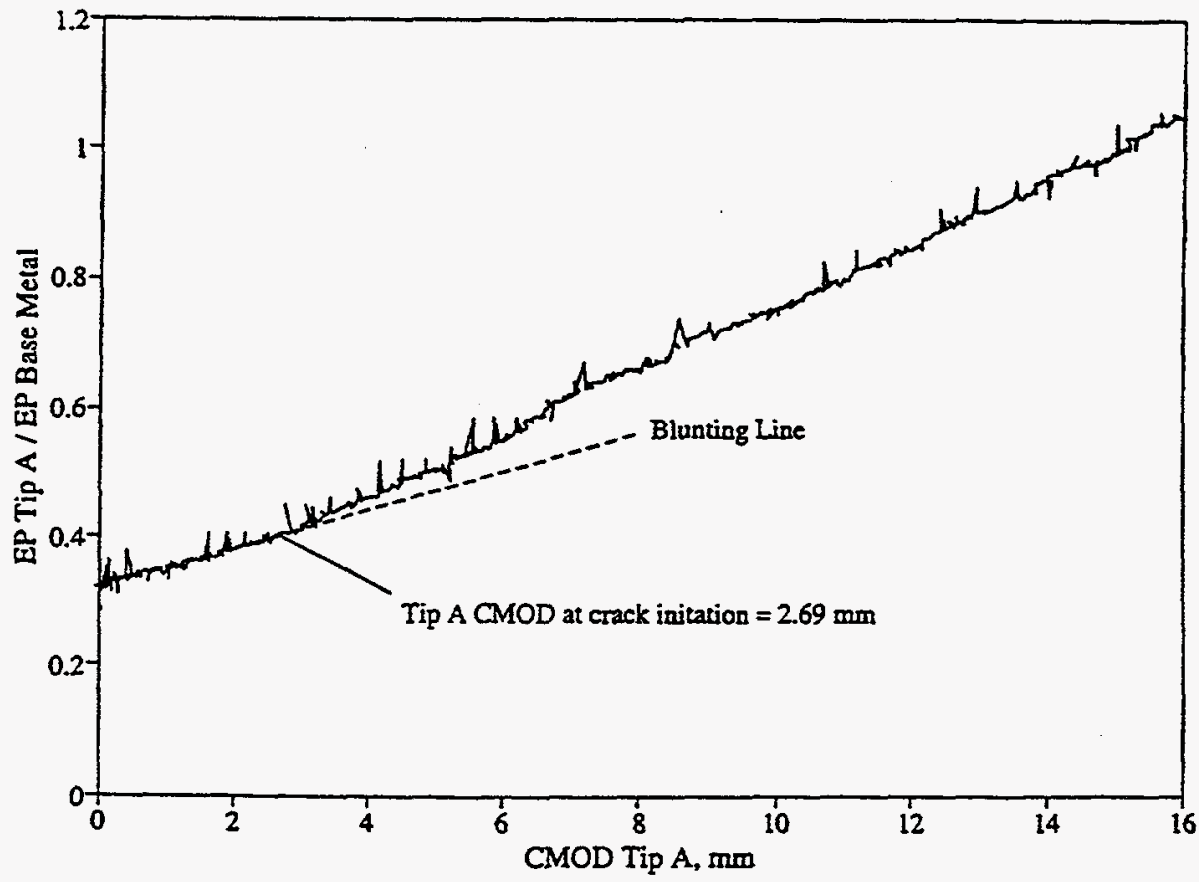

Figure 3.31 Normalized d-c electric potential at Crack Tip A versus crack-mouth-opening displacement at Crack Tip A for Experiment 3.3-1 


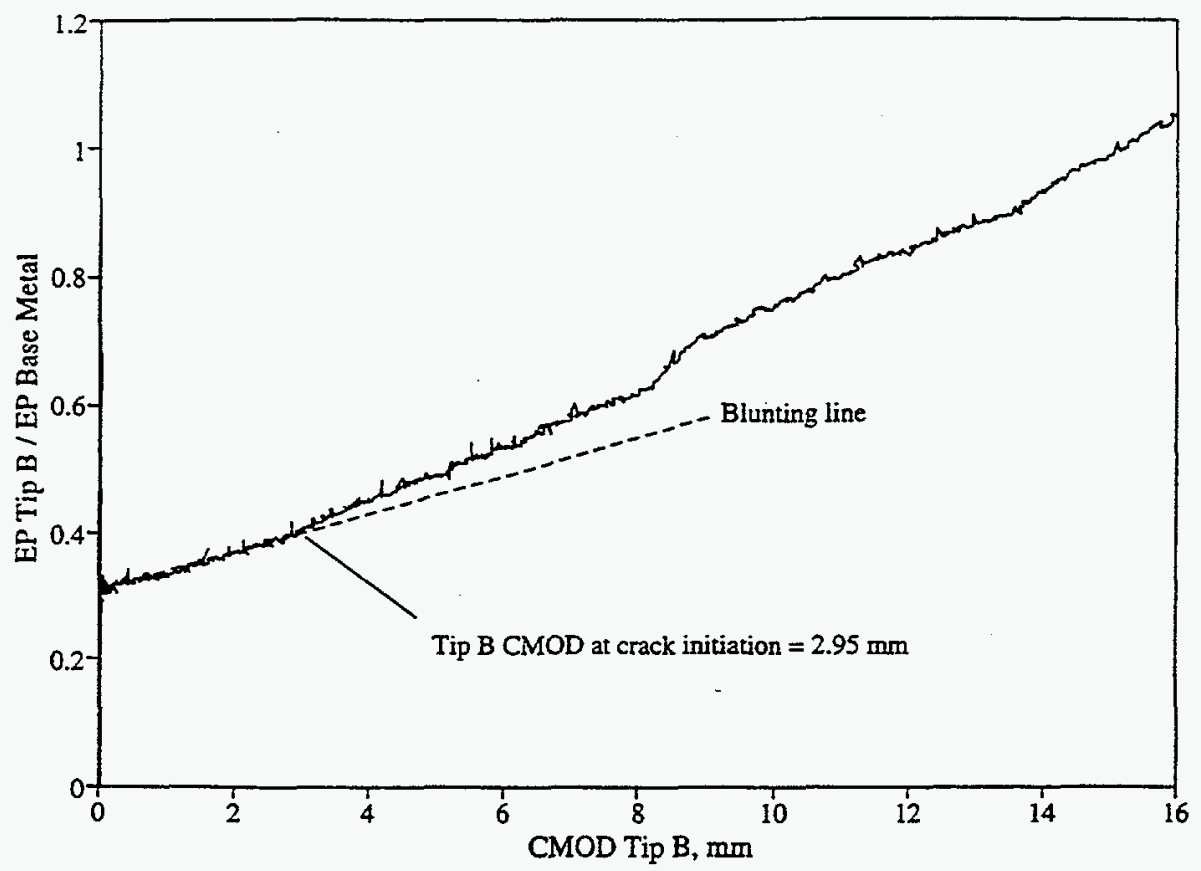

Figure 3.32 Normalized d-c electric potential at Crack Tip B versus crack-mouth-opening displacement at Crack Tip B for Experiment 3.3-1

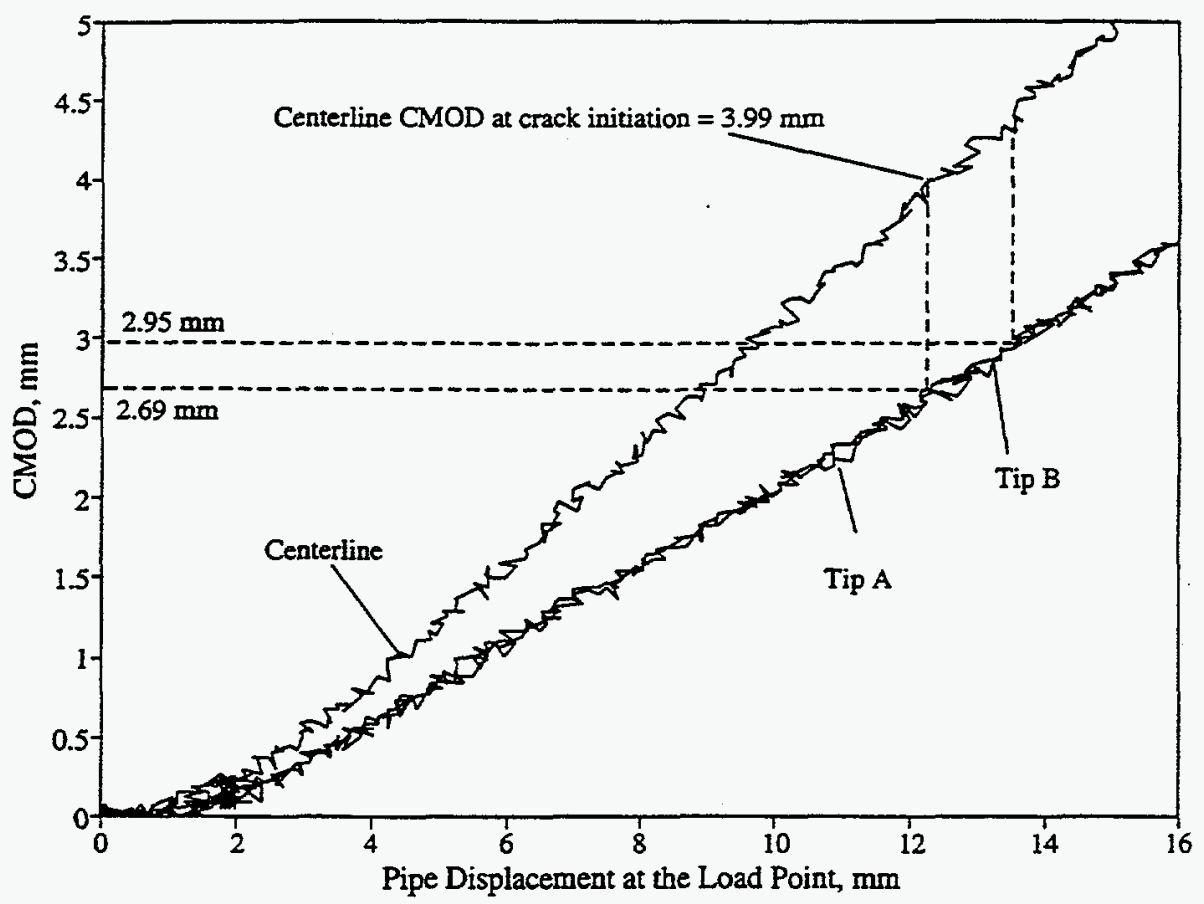

Figure 3.33 CMOD versus pipe displacement at the load point for Experiment 3.3-1 


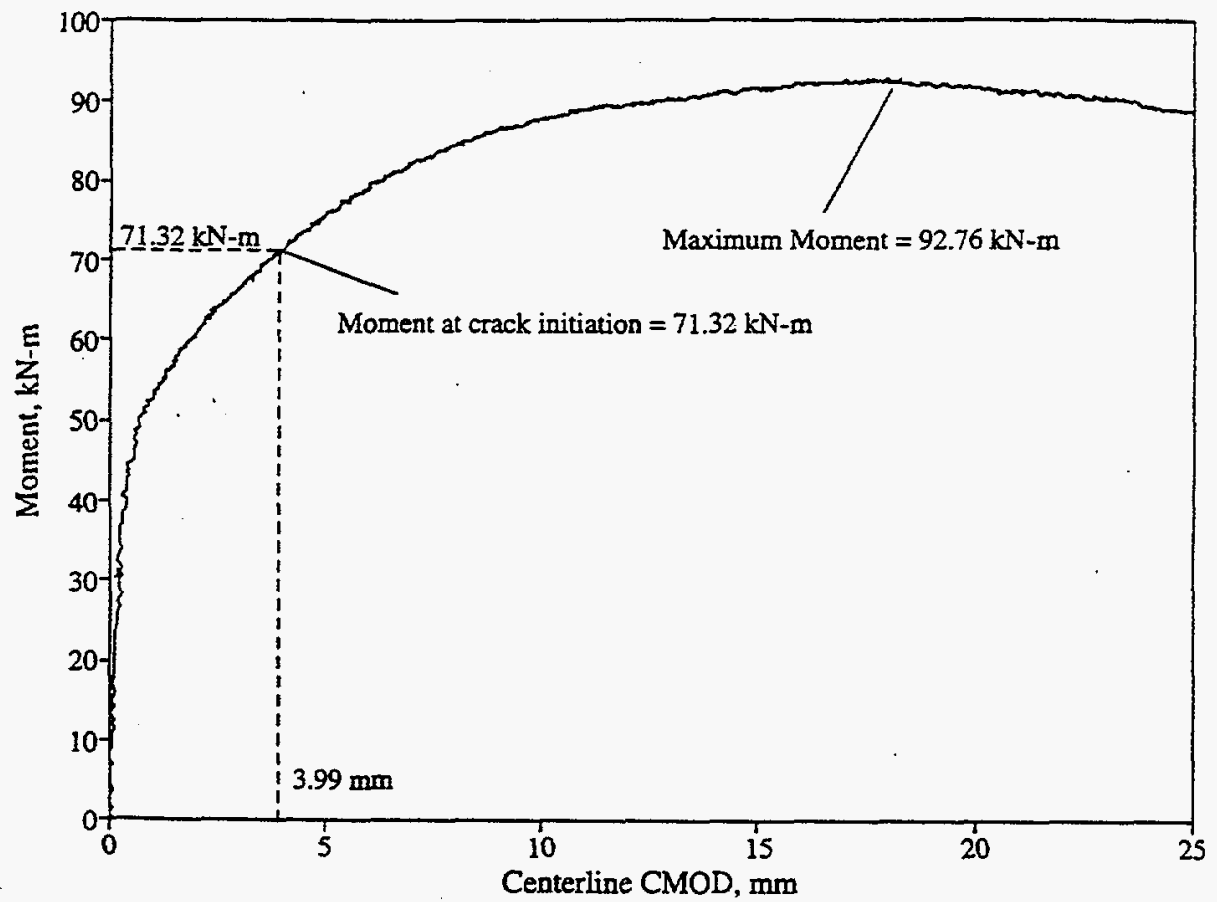

Figure 3.34 Crack section moment versus centerline CMOD for Experiment 3.3-1

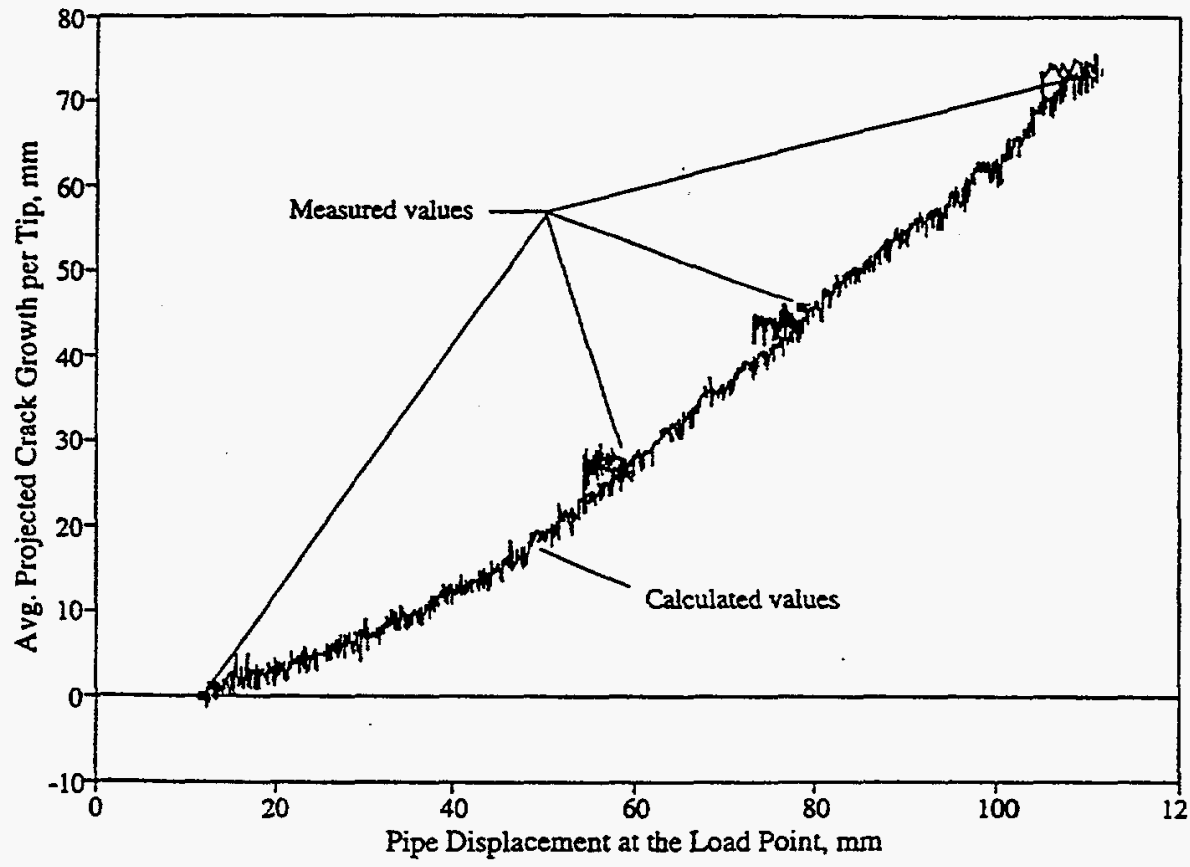

Figure 3.35 Average projected crack growth per crack tip versus pipe displacement at the load point for Experiment 3.3-1 


\subsection{References}

3.1 Wilkowski, G., Kramer, G., Vieth, P., Francini, R., and Scott, P., "The Effect of Cyclic Loading During Ductile Tearing on Circumferentially Cracked Pipe -- Analytical Results," ASME PVP Vol. 280, pp 221-240, June 1994.

3.2 Sanders, J. L. Jr., "Circumferential Through-Crack in a Cylindrical Shell Under Combined Bending and Tension," Journal of Applied Mechanics, Vol. 50, pp 221, 1983.

3.3 Wilkowski, G. M., "Anisotropic Fracture Toughness Effects on Failure Modes of Piping," Journal of Pressure Vessel Technology, Vol. 113, pp 154-158, May 1991. 


\subsection{ANALYSIS OF PIPE FRACTURE EXPERIMENTS}

In this section of the report, the results of a limited series of analyses of the pipe fracture experiments conducted as part of this effort will be presented. The analysis efforts consisted of: (1) comparing the experimental crack initiation moments and maximum moments with predictions based on available fracture prediction models, and (2) calculating J-R curves for the pipe experiments using the $\eta$-factor method.

\subsection{Comparison of Results with Fracture Prediction Analyses}

The crack initiation moments and maximum moments from the four pipe fracture experiments will be compared with predictions of initiation and maximum moments using a number of fracture prediction models. The experimental moments at crack initiation will be compared with predictions from the:

GE/EPRI method, Ref. 4.1,

LBB.ENG2 method, Ref. 4.2, and

R6 Revision 3 Option 1 method, Refs. 4.3, 4.4, and 4.5.

The experimental maximum moments will be compared with predictions based on the:

Net-Section-Collapse (NSC) analysis, Refs. 4.6 and 4.7,

Dimensionless-Plastic-Zone-Parameter (DPZP) analysis, Ref. 4.8,

GE/EPRI method, Ref. 4.1,

LBB.ENG2 method, Ref. 4.2, and

R6 Revision 3 Option 1 method, Refs. 4.3, 4.4, and 4.5.

In making predictions for the three base-metal crack pipe experiments (Experiments 4.2.1, 4.2.2 and 3.3-1), quasi-static base metal tensile and J-R curve data were used. In making predictions for the weld metal experiment (Experiment 4.2-3), quasi-static tensile properties for the base metal and quasi-static $\mathrm{J}-\mathrm{R}$ curves for the weld metal were used. Dynamic material property data were not used in any of these analyses. Rarely would such data be available for an actual plant piping analysis. Throughout this assessment, the flow stress has been defined as the average of the yield and ultimate strengths. For the J-estimation schemes, i.e., GE/EPRI and LBB.ENG2, and R6 predictions, the material stress-strain behavior was modeled using a Ramberg-Osgood relationship where the fit of the data was chosen as that segment of the stress-strain curve which would result in the highest correlation constant. The fit of the stress-strain data to the Ramberg-Osgood equation was made using a Battelle-written computer program, ROFIT. The equation was fit to data in the range from 1-percent strain to the strain corresponding to 80 percent of the ultimate strength. Table 4.1 shows the quasi-static tensile properties, i.e., yield strength, 
ultimate strength, flow stress, and Ramberg-Osgood coefficients, for the base metal used in these fracture prediction analyses. Figure 4.1 shows the actual quasi-static base metal tensile data, with the RambergOsgood representation of the data superimposed on the figure.

Table 4.1 Quasi-static STS410 carbon steel base metal tensile properties used in fracture analyses

\begin{tabular}{|c|c|c|c|c|c|c|}
\hline $\begin{array}{c}\text { Yield } \\
\text { Strength, } \\
\text { MPa } \\
\end{array}$ & $\begin{array}{c}\text { Ultimate } \\
\text { Strength, } \\
\mathbf{M P a} \\
\end{array}$ & $\begin{array}{c}\text { Flow } \\
\text { Stress }^{(a)} \text {, } \\
\text { MPa }\end{array}$ & $\begin{array}{c}\text { Reference } \\
\text { Stress }\left(\sigma_{0}\right), \\
\mathbf{M P a}\end{array}$ & $\begin{array}{c}\text { Reference } \\
\text { Strain } \\
\left(\epsilon_{0}\right) \\
\end{array}$ & $\alpha$ & n \\
\hline 215.8 & 493 & 354.4 & 215.8 & 0.001138 & 3.20 & 3.717 \\
\hline
\end{tabular}

(a) Flow stress defined as the average of the yield and ultimate strengths.

The $J-R$ curves used in these analyses were based on modified $J$ resistance curves, i.e., $J_{M}-R$ curves, where the $J_{M}-R$ curves for $0.5 T C(T)$ specimens were linearly extrapolated over the last few data points in order to get the large amounts of crack growth needed for these analyses. Figures 4.2 and 4.3 show the extrapolated $\mathrm{J}_{\mathrm{M}}-\mathrm{R}$ curves for the quasi-static base metal and weld metal data, respectively, with the actual $C(T)$ specimen data superimposed.

\subsubsection{Comparison of Experimental Moments at Crack Initiation with Fracture Analysis Predictions}

Comparisons were made between the experimental moments at crack initiation and the predicted crack initiation moments using the GE/EPRI (Ref. 4.1), LBB.ENG2 (Ref. 4.2), and R6 Revision 3 Option 1 (Refs. 4.3 through 4.5) methods. Details of each of these methods can be found in the appropriate references. The predictions were made with the aid of a Battelle-written computer code, NRCPIPE. (Note, the GE/EPRI method used in this analysis was the original GE/EPRI method, with the plasticzone correction.) The results of those comparisons are shown in Tables 4.2 and 4.3 as well as in Figure 4.4.

In examining Tables 4.2 and 4.3 and Figure 4.4, it can be seen that the GE/EPRI and R6 methods underpredicted (i.e., conservatively predicted) the experimental loads at crack initiation. The extent of the underprediction was approximately 1 to 12 percent for the GE/EPRI method, and 7 to 30 percent for the R6 method. This trend is somewhat contrary to what was observed in Subtask 1.2 of the IPIRG-1 program (Ref. 4.9) in which the GE/EPRI and R6 methods often overpredicted the initiation moments, see Table 4.3. The LBB.ENG2 method overpredicted the initiation moments for all the three dynamic experiments but slightly underpredicted the initiation moment for the quasi-static experiment. The extent of the overprediction was as much as 10 percent for Experiment 4.2-2. This overprediction was somewhat less than what was observed for the A106 Grade B pipe experiments in Subtask 1.2 of the IPIRG program. In that program, the LBB.ENG2 method overpredicted the initiation moments by 
Section 4

ANALYSIS OF PIPE FRACTURE EXPERIMENTS

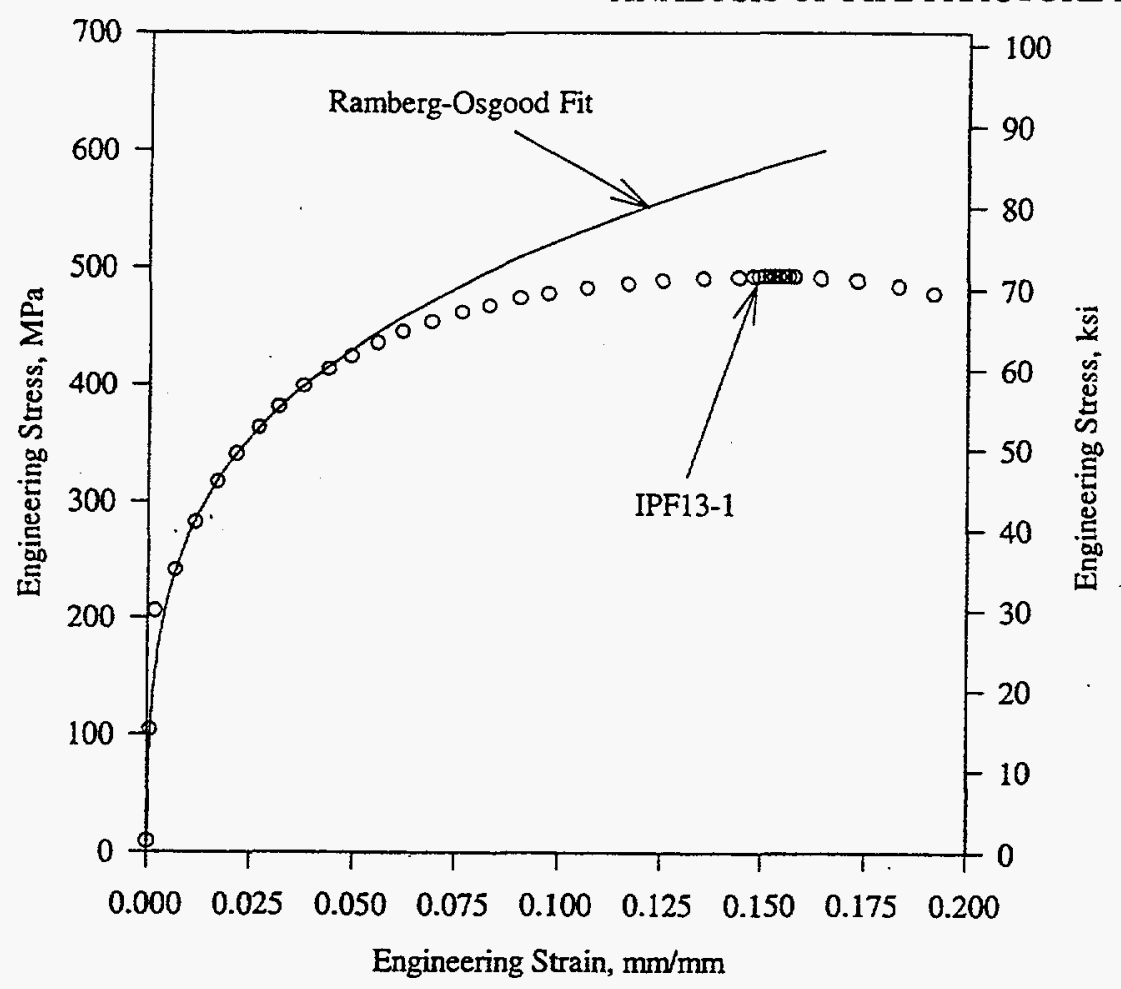

Figure 4.1 Quasi-static base metal stress-strain curve with Ramberg-Osgood representation of the data superimposed

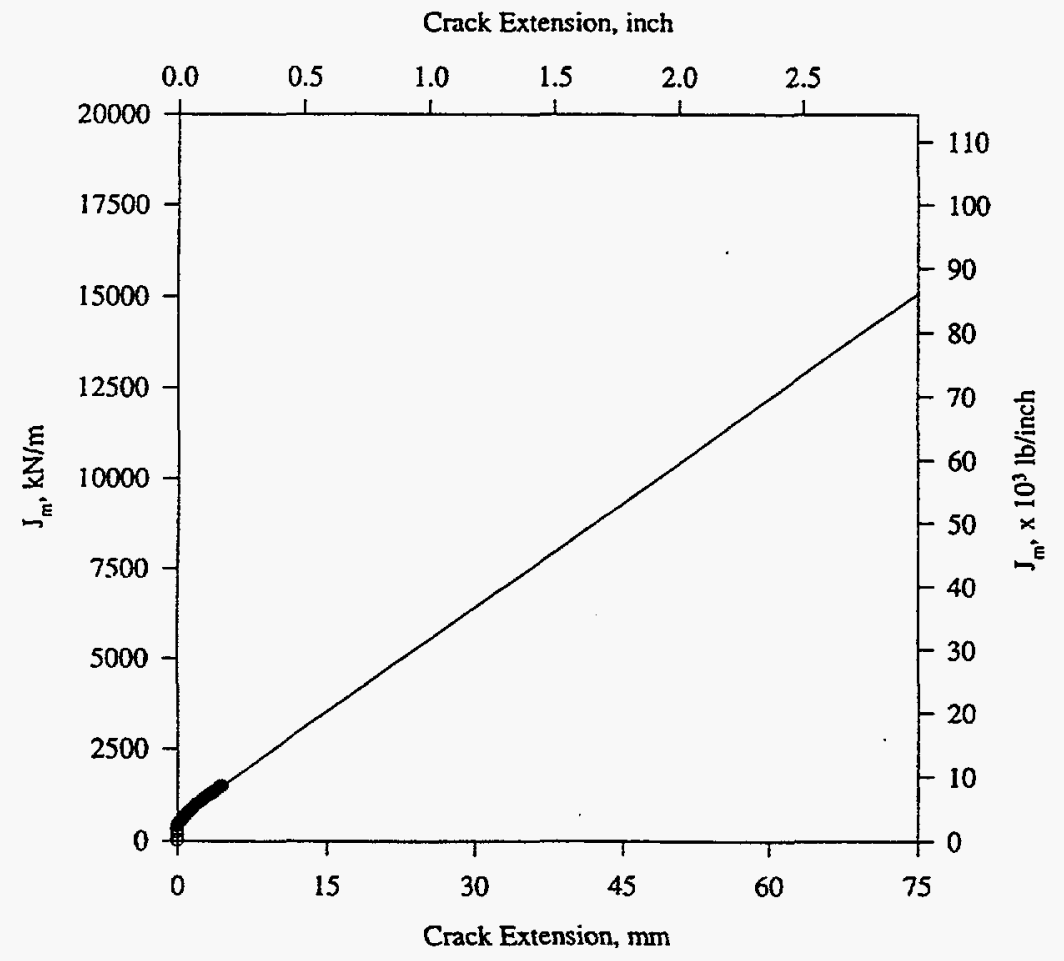

Figure 4.2 Extrapolated quasi-static base metal $J_{M}-R$ curve with actual $C(T)$ specimen data superimposed 
Crack Extension, inch

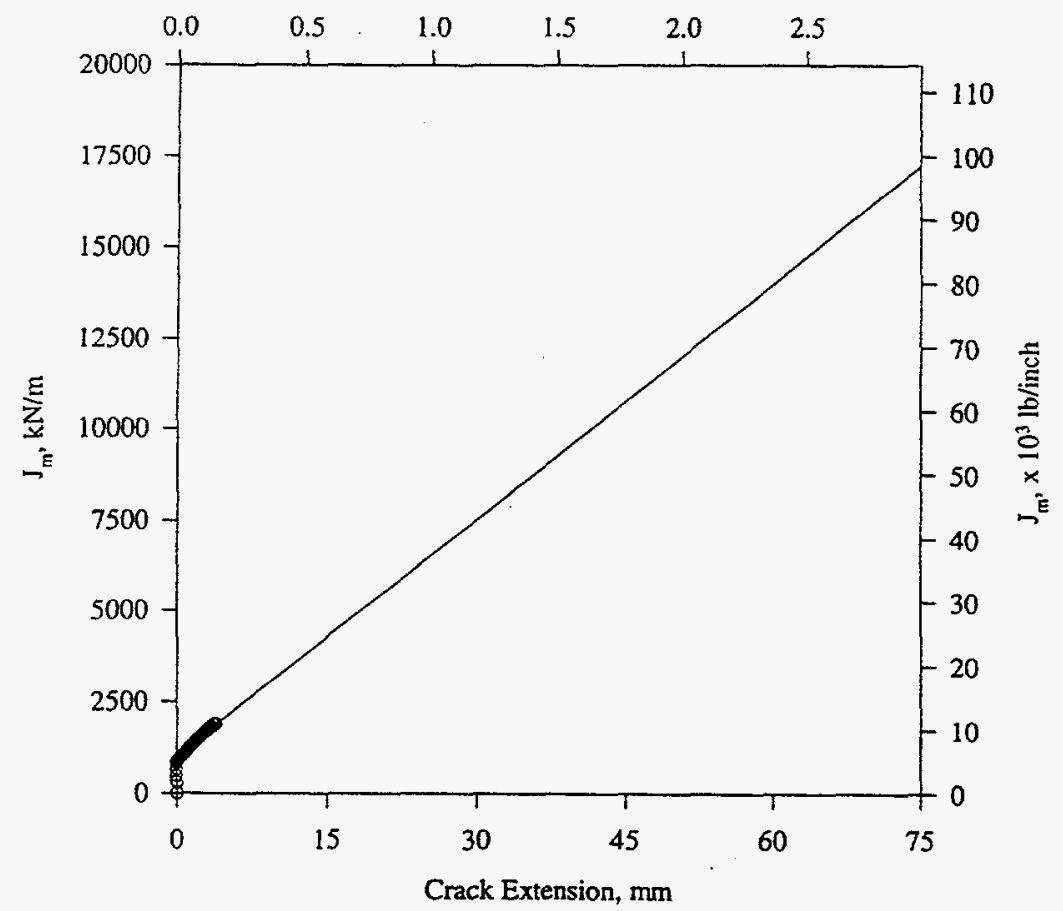

Figure 4.3 Extrapolated quasi-static weld metal $J_{M}-R$ curve with actual $C(T)$ specimen data superimposed

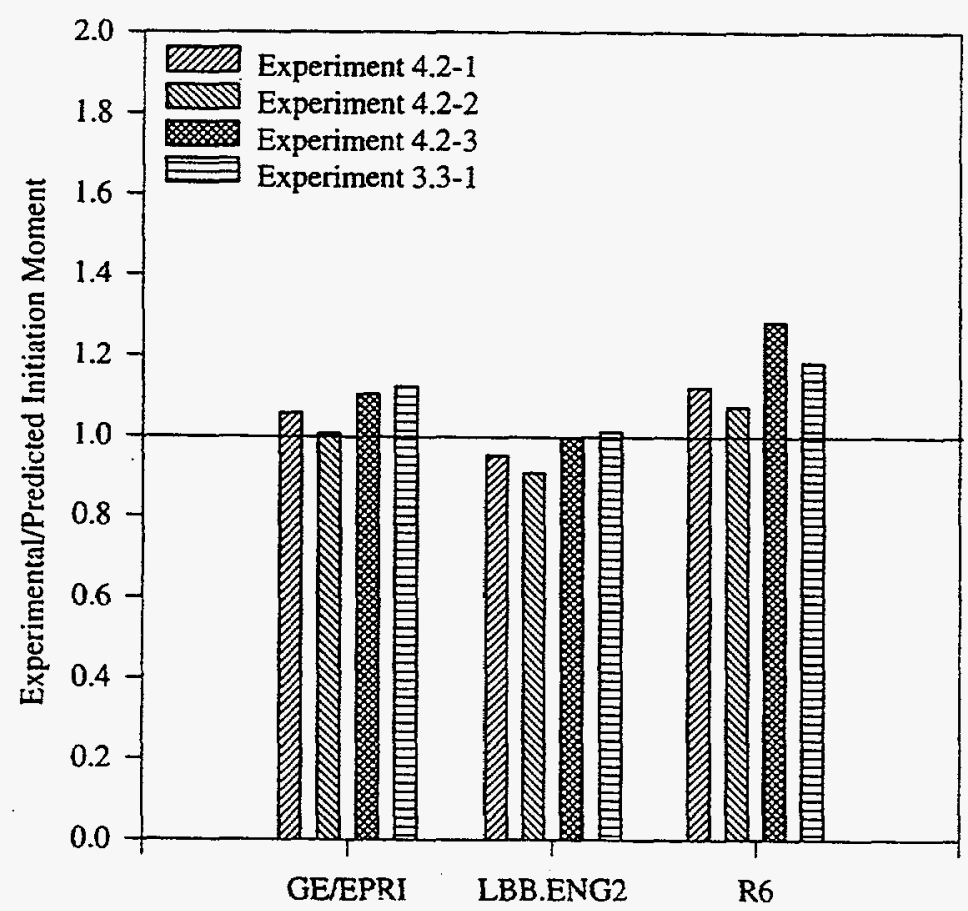

Figure 4.4 Comparison of experimental moments at crack initiation with predicted moments at crack initiation based on the GE/EPRI, LBB.ENG2, and R6 Revision 3 Option 1 analyses 
Table 4.2 Comparison of experimental moments at crack initiation with GE/EPRI, LBB.ENG2, and R6 Revision 3 Option 1 predictions

\begin{tabular}{|c|c|c|c|c|c|c|c|}
\hline \multirow{2}{*}{$\begin{array}{l}\text { Experiment } \\
\text { Number }\end{array}$} & \multirow{2}{*}{$\begin{array}{l}\text { Experimental } \\
\text { Moment at } \\
\text { Crack } \\
\text { Initiation, } \\
\mathrm{kN}-\mathrm{m}\end{array}$} & \multicolumn{3}{|c|}{ Predicted Moments ${ }^{\left({ }^{\prime \prime}\right.}, \mathrm{kN}-\mathrm{m}$} & \multicolumn{3}{|c|}{$\begin{array}{c}\text { Experimental Moment/Predicted } \\
\text { Moment }\end{array}$} \\
\hline & & GE/EPRI & LBB.ENG2 & R6 & GE/EPRI & LBB.ENG2 & R6 \\
\hline $4.2-1$ & 68.7 & 65.0 & 72.1 & 61.2 & 1.057 & 0.952 & 1.122 \\
\hline $4.2-2$ & 63.5 & 63.1 & 70.0 & 59.2 & 1.006 & 0.907 & 1.073 \\
\hline $4.2-3$ & 83.2 & 75.4 & 83.4 & 64.7 & 1.104 & 0.997 . & 1.285 \\
\hline $3.3-1$ & 71.3 & 63.5 & 70.5 & 60.2 & 1.123 & 1.011 & 1.184 \\
\hline
\end{tabular}

(a) For the base metal tests, quasi-static base metal stress-strain curves and J-R curve data were used; for the weld test, quasi-static base metal stress-strain curves and quasi-static weld metal J-R curve data were used.

as much as 28 percent. The potential significance of this finding will be discussed in detail in Section 5 of this report.

In comparing the quasi-static and dynamic monotonic experiments, it can be seen that the dynamic loading rate slightly lowered the initiation moment ratios. The analysis underpredicted the quasi-static initiation load approximately 6 percent more than it did the dynamic initiation moments.

In comparing the results for the two dynamic, base metal experiments (Experiments 4.2-1 and 4.2-2), it can be seen that the cyclic loading history only lowered the normalized crack initiation moments (experimental-to-predicted moments) by about 5 percent, which is within the experimental scatter band we have previously observed for this type of experiment.

\subsubsection{Comparison of Maximum Experimental Moments with Fracture Analysis Predictions}

Comparisons were made between the maximum experimental moments and the predicted maximum moments using the Net-Section-Collapse (Refs. 4.6 and 4.7), Dimensionless-Plastic-Zone-Parameter (Ref. 4.8), GE/EPRI (Ref. 4.1), LBB.ENG2 (Ref. 4.2), and R6 Revision 3 Option 1 (Refs. 4.3 through 4.5) methods. Details of each of these analysis methods can be found in the appropriate references. The predictions were made with the aid of a Battelle-written computer code, NRCPIPE Version 1.4g. (Note, the GE/EPRI method used in this analysis was the original GE/EPRI method, with the plastic-zone correction.) The results of those comparisons are shown in Tables 4.3 and 4.4 and Figure 4.5 .

In examining Tables 4.3 and 4.4 and Figure 4.5, the NSC, DPZP, GE/EPRI, and LBB.ENG2 methods overpredicted the maximum moment for Experiments 4.2-1 and 4.2-2 by as much as 15 percent. The NSC and DPZP methods tended to underpredict the Experiment 4.2-3 maximum moment by about 4 percent. All analysis methods underpredicted the maximum moment for Experiment 3.3-1, from 4 
Table 4.3 Comparison of ratios of experimental-to-predicted moments at crack initiation and maximum moment for experiments conducted in this program and IPIRG-1 Subtask 1.2 (Ref. 4.9)

\begin{tabular}{|c|c|c|c|c|c|c|c|c|}
\hline \multirow{2}{*}{$\begin{array}{c}\text { Experiment } \\
\text { Number }\end{array}$} & \multirow[b]{2}{*}{ Program } & \multirow{2}{*}{$\begin{array}{c}\text { Loading } \\
\text { Condition } \\
\end{array}$} & \multirow[b]{2}{*}{ Materials } & \multicolumn{4}{|c|}{ Experimental Moment/Predicted Moments } & \multirow[b]{2}{*}{$\mathbf{R 6}$} \\
\hline & & & & NSC & DPZP & GE/EPRI & LBB.ENG2 & \\
\hline & Crack Initiation & & & & & & & \\
\hline $4.2-1$ & IPIRG-2, Task 4 & Dyn, Mono & STS410 & - & - & 1.057 & 0.952 & 1.122 \\
\hline $4.2-2$ & IPIRG-2, Task 4 & Dyn, $R=1$ & STS410 & - & - & 1.006 & 0.907 & 1.073 \\
\hline $4.2-3$ & IPIRG-2, Task 4 & Dyn, $R=1$ & STS410(a) & - & - & 1.104 & 0.997 & 1.285 \\
\hline $3.3-1$ & IPIRG-2, Task 3 & QS, Mono & STS410 & - & - & 1.123 & 1.011 & 1.184 \\
\hline $1.2-8$ & IPIRG-1, Subtask 1.2 & Dyn, Mono & $\mathrm{A} 106 \mathrm{~B}$ & - & - & 1.010 & 0.900 & 1.050 \\
\hline $1.2-11$ & IPIRG-1, Subtask 1.2 & Dyn, Mono & A106B & - & - & 0.825 & 0.735 & 0.858 \\
\hline $1.2-12$ & IPIRG-1, Subtask 1.2 & Dyn, Mono & A106B & - & - & 1.049 & 0.935 & 1.091 \\
\hline $1.2-6$ & IPIRG-1, Subtask 1.2 & Dyn, $R=1$ & $\mathrm{~A} 106 \mathrm{~B}$ & - & - & 0.811 & 0.723 & 0.844 \\
\hline \multirow[t]{2}{*}{$1.2-7$} & IPIRG-1, Subtask 1.2 & QS, Mono & A106B & - & - & 1.231 & 1.098 & 1.281 \\
\hline & Maximum Moment & & & & & & & \\
\hline $4.2-1$ & IPIRG-2, Task 4 & Dyn, Mono & STS410 & 0.961 & 0.961 & 0.935 & 0.888 & 1.151 \\
\hline $4.2-2$ & IPIRG-2, Task 4 & Dyn, $R=1$ & STS410 & 0.928 & 0.928 & 0.884 & 0.844 & 1.095 \\
\hline $4.2-3$ & IPIRG-2, Task 4 & Dyn, $R=1$ & STS410(a) & 1.039 & 1.039 & 0.968 & 0.914 & 1.186 \\
\hline $3.3-1$ & IPIRG-2, Task 3 & QS, Mono & ST\$410 & 1.093 & 1.093 & 1.136 & 1.043 & 1.383 \\
\hline $1.2-8$ & IPIRG-1, Subtask 1.2 & Dyn, Mono & A106B & 0.727 & 1.38 & 0.947 & 0.879 & 1.116 \\
\hline $1.2-11$ & IPIRG-1, Subtask 1.2 & Dyn, Mono & A106B & 0.833 & 1.58 & 1.171 & 1.090 & 1.328 \\
\hline $1.2-12$ & IPIRG-1, Subtask 1.2 & Dyn, Mono & A106B & 0.825 & 1.56 & 1.153 & 1.071 & 1.359 \\
\hline $1.2-6$ & IPIRG-1, Subtask 1.2 & Dyn, $R=1$ & A106B & 0.825 & 1.56 & 1.153 & 1.071 & 1.359 \\
\hline $1.2-7$ & IPIRG-1, Subtask 1.2 & QS, Mono & A106B & 0.844 & 1.61 & 1.175 & 1.090 & 1.384 \\
\hline
\end{tabular}

(a) Crack in a TIG weld. 
Table 4.4 Comparison of maximum experimental moments with Net-Section-Collapse, Dimensionless-Plastic-Zone Parameter, GE/EPRI, LBB.ENG2, and R6 predictions

\begin{tabular}{|c|c|c|c|c|c|c|c|c|c|c|c|}
\hline \multirow[b]{2}{*}{$\begin{array}{c}\text { Experiment } \\
\text { No. }\end{array}$} & \multirow[b]{2}{*}{$\begin{array}{c}\text { Experimental } \\
\text { Moment, } \\
\text { kN-m } \\
\end{array}$} & \multicolumn{5}{|c|}{ Predicted Maximum Moments, kN-m } & \multicolumn{5}{|c|}{ ExperimentalPredicted Maximum Moment } \\
\hline & & NSC & DPZP & $\begin{array}{c}\text { GE/ } / \\
\text { EPRI }\end{array}$ & $\begin{array}{l}\text { LBB. } \\
\text { ENG2 }\end{array}$ & $\mathbf{R} 6$ & NSC & DPZP & $\begin{array}{c}\text { GE } / \\
\text { EPRI } \\
\end{array}$ & $\begin{array}{l}\text { LBB. } \\
\text { ENG2 }\end{array}$ & R6 \\
\hline $4.2-1$ & 84.1 & 87.5 & 87.5 & 89.9 & 94.7 & $73.1^{\circ}$ & 0.961 & 0.961 & 0.935 & 0.888 & 1.151 \\
\hline $4.2-2$ & 77.3 & 84.5 & 84.5 & 86.9 & 91.6 & 70.6 & 0.928 & 0.928 & 0.884 & 0.844 & 1.095 \\
\hline $4.2-3$ & 87.9 & 84.6 & 84.6 & 90.8 & 96.2 & 74.1 & 1.039 & 1.039 & 0.968 & 0.914 & 1.186 \\
\hline $3.3-1$ & 92.8 & 84.9 & 84.9 & 81.7 & 89.0 & 67.1 & 1.093 & 1.093 & 1.136 & 1.043 & 1.383 \\
\hline
\end{tabular}

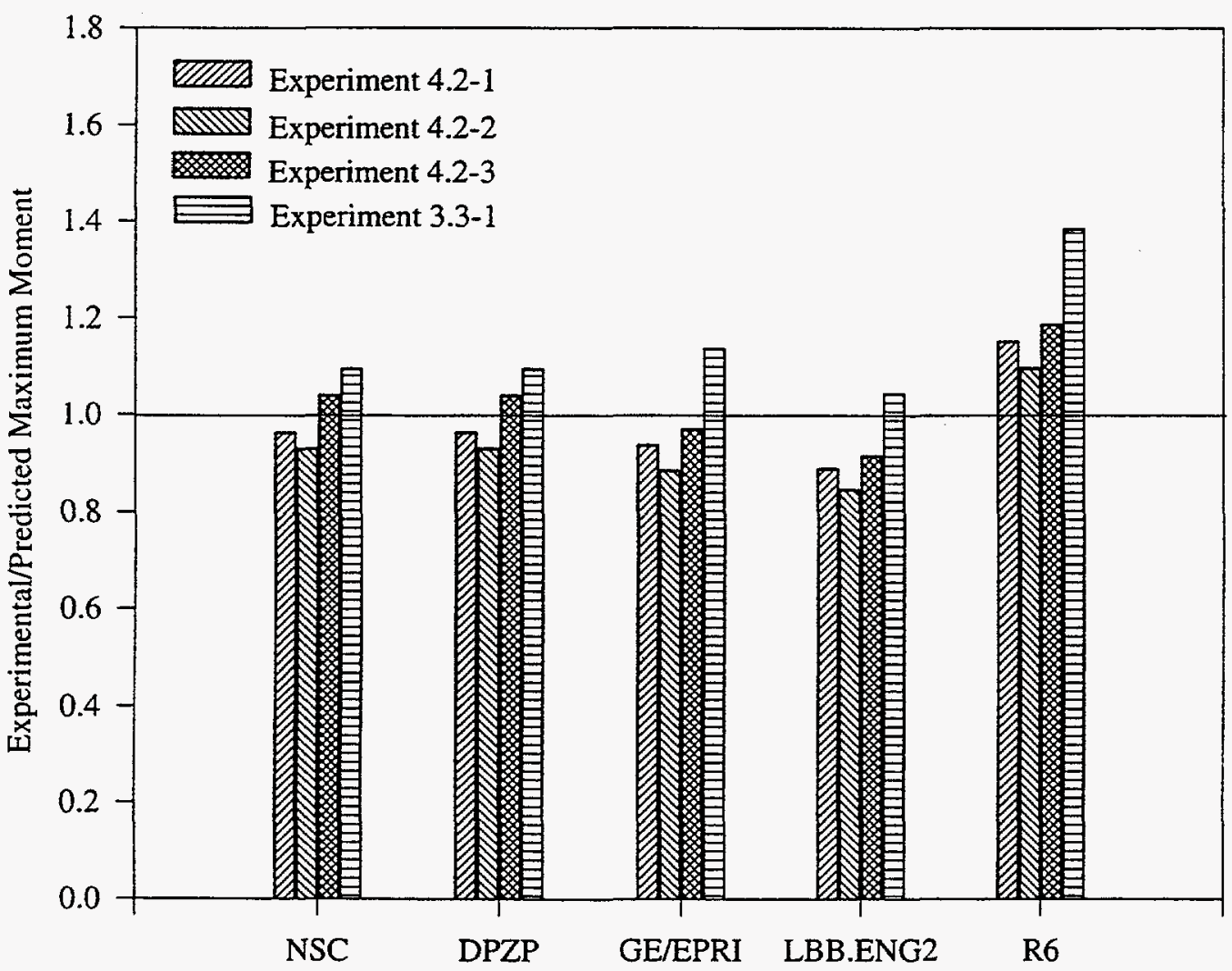

Figure 4.5 Comparison of maximum experimental moments with maximum predicted moments based on the NSC, DPZP, GE/EPRI, LBB.ENG2, and R6 Revision 3 Option 1 analyses 
percent for the LBB.ENG2 method to 38 percent for the R6 Revision 3 Option 1 analysis. The fracture ratios for the R6 Revision 3 Option 1 analysis are slightly higher than the others, indicative of the fact that the R6 Revision 3 Option 1 method is more conservative than the other analysis methods considered. This is not surprising since the R6 method is a fracture prevention method, with some built-in conservatisms, while the other methods are more nearly true fracture prediction methods. It can also be seen that the Net-Section-Collapse and Dimensionless-Plastic-Zone-Parameter analyses both had the exact same fracture ratios for all four experiments. This is the result of the fact that the toughness of this carbon steel pipe material (STS410) was great enough, and the pipe diameter was small enough [152-mm (6- inches)], that fully plastic conditions were easily satisfied and the pipes should have failed under limit-load conditions. This was not the case for the A106B pipe material evaluated in IPIRG-1. The toughness of that 152-mm (6-inch) diameter pipe was low enough that the Dimensionless-Plastic-ZoneParameter analysis predicted maximum moments were only 53 percent of the Net-Section-Collapse predicted maximum moments.

Also of note from Table 4.3 is the fact that for each of the analysis methods, the fracture ratios (i.e., experimental moment/predicted moment) at the maximum moment for the dynamic cyclic, base metal experiment (4.2-2) is only about 5 percent less than the fracture ratio at maximum moment for the dynamic monotonic, base metal experiment (4.2-1). Conversely, the fracture ratios at maximum moment, for each of the analysis methods for the IPIRG-1 Subtask 1.2 dynamic cyclic experiment (1.2-6) was about 20 percent less than the average fracture ratio for the three IPIRG-1 Subtask 1.2 dynamic monotonic experiments (1.2-8, 1.2-11, and 1.2-12). The significance of this finding will be discussed in detail in Section 5 of this report.

\subsection{Calculation of J-R Curves from Pipe Experiments}

The calculation of the J-R curves from the four pipe experiments was possible using the $\eta$-factor J-estimation scheme method (Refs. 4.10 and 4.11). The $\eta$-factor analysis is a method used to estimate the J-R curve for a pipe material from experimental data. It is a simple method used in lieu of threedimensional finite element analysis. The energy absorbed during the test, i.e., the area under the moment-rotation or load-displacement curve, is proportional to the fracture resistance through a geometric term, i.e., the $\eta$-factor. In this method, $\mathrm{J}$ is separated into an elastic and plastic component.

$$
\mathrm{J}_{\text {toot }}=\mathrm{J}_{\text {Elassic }}+\mathrm{J}_{\text {plasic }}
$$

The elastic component of $\mathrm{J}$ is derived from an elastic solution in the GE/EPRI J-estimation scheme handbook (Ref. 4.1).

$$
J_{\text {Elastic }}=\frac{R_{m}^{2} \pi c F^{2}\left(c / b, R_{m} / t\right) M^{2}}{E I^{2}}
$$


where

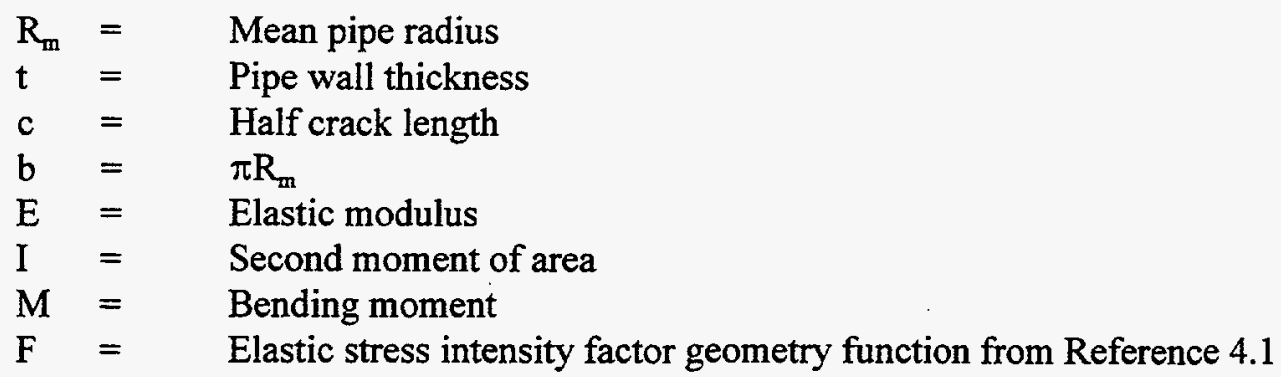

The plastic component of $J$ can be calculated from Equation 4-3.

$$
\mathrm{J}_{\text {Plastic }}=2 \int_{0}^{\Delta_{\mathrm{PI}}} \eta(\theta) \mathrm{Pd} \Delta_{\mathrm{PL}}+\frac{2}{\mathrm{R}_{\mathrm{m}}} \int_{c_{0}}^{c} \gamma(\theta) \mathrm{J}_{\mathrm{Plastic}} \mathrm{dc}
$$

where

$$
\begin{aligned}
& \Delta_{\mathrm{PL}}=\quad \text { Plastic displacement } \\
& \mathrm{P}=\quad \text { Half of the total applied load in a four-point bend test } \\
& \mathrm{c}_{\mathrm{o}}=\quad \text { Initial half crack length } \\
& \theta=\text { Half crack angle } \\
& \eta(\theta)=\frac{-h^{\prime}(\theta)}{R_{m} t h(\theta)} \\
& \gamma(\theta)=\frac{h^{\prime \prime}(\theta)}{h^{\prime}(\theta)}
\end{aligned}
$$

$h^{\prime}(\theta), h^{\prime \prime}(\theta)=$ first and second derivatives of $h(\theta)$ with respect to $\theta$, respectively.

The plastic component of the displacement, $\Delta_{\mathrm{PL}}$, can be obtained by subtracting the elastic component of the uncracked pipe displacement $\left(\Delta_{\mathrm{EL}, \mathrm{NC}}\right)$, the elastic component of displacement due to the crack $\left(\Delta_{\mathrm{EL}, \mathrm{C}}\right)$, and the elastic component of the displacement due to the machine compliance $\left(\Delta_{\mathrm{EL}, \mathrm{M}}\right)$ from the measured load-line displacements $(\Delta)$. 


$$
\Delta_{\mathrm{PL}}=\Delta-\Delta_{\mathrm{EL}, \mathrm{NC}}-\Delta_{\mathrm{EL}, \mathrm{C}}-\Delta_{\mathrm{EL}, \mathrm{M}}
$$

where

$$
\begin{gathered}
\Delta_{E L, N C}=\frac{(Z-L)^{2}(Z+2 L) P}{24 E I} \\
\Delta_{E L, C}=\frac{4 R_{m} c V_{2}\left(c / b, R_{m} / t\right) M}{E I} \\
\Delta_{E L, M}=2 C_{M} P
\end{gathered}
$$

where
$\mathrm{Z}=$ Outer span in a four-point bend test
$\mathrm{L}=$ Inner span in a four-point bend test
$\mathrm{V}_{2}=$ Compliance function from Reference 4.1
$\mathrm{C}_{\mathrm{M}}=$ Test machine compliance

The second term on the right side of Equation 4-3 represents a contribution to J due to crack growth, which is equal to zero until crack initiation. The plastic component of $\mathrm{J}$, $\mathrm{J}_{\text {plastic }}$, after crack initiation can be derived on the basis of Equation 4-3 by repeating the calculations until $\mathrm{J}_{\text {plastic }}$ converges.

The results of these $\eta$-factor calculations are shown in Table 4.5 and Figures 4.6 through 4.8. Table 4.5 shows a comparison of the calculated $\mathrm{J}_{\mathrm{i}}$ values from the pipe experiments to the $\mathrm{J}_{\mathrm{i}}$ values obtained from the $C(T)$ specimens. Figure 4.6 shows the full J-R curves for the four pipe experiments. Figure 4.7 shows the initial portion of the J-R curves for the three base metal experiments along with the base metal $C(T)$ specimen data at both quasi-static and dynamic rates. Figure 4.8 shows the initial portion of the J-R curve for the single weld metal experiment along with the weld metal $C(T)$ specimen data at both quasistatic and dynamic rates.

Figure 4.6 shows that the quasi-static and dynamic monotonic experiments had approximately the same resistance until about $4 \mathrm{~mm}$ of crack extension. At this point, the quasi-static resistance became much higher than the dynamic resistance. A portion of this difference could be due to dynamic strain aging, but a major portion is probably due to the difference in crack extension angle. This effect is discussed in Section 5 .

Table 4.5 and Figure 4.6 show that the value of $J$ at crack initiation $\left(J_{i}\right)$ for the pipe experiment with a crack in the weld was quite a bit higher than the $\mathrm{J}_{\mathrm{i}}$ values for the three base metal experiments. 
Table 4.5 Comparison of $J_{i}$ values from pipe experiments with $J_{i}$ values from $C(T)$ specimens

\begin{tabular}{ccccc}
\hline $\begin{array}{c}\text { Experiment } \\
\text { Number }\end{array}$ & $\begin{array}{c}\text { Crack } \\
\text { Location }\end{array}$ & $\begin{array}{c}\text { Load } \\
\text { History }\end{array}$ & $\begin{array}{c}\mathbf{J}_{\mathbf{i}} \text { Values } \\
\text { From Pipe } \\
\text { Experiments, } \\
\mathbf{k J} / \mathbf{m}^{2}\end{array}$ & $\begin{array}{c}\text { Average } \\
\mathbf{J}_{\mathbf{i}} \text { Values From } \\
\mathbf{C}(\mathbf{T}) \text { Specimens, } \\
\mathbf{k J} / \mathbf{m}^{2}\end{array}$ \\
\hline $4.2-1$ & Base metal & Dyn. mono. & 750.1 & $476.5^{(1)}$ \\
$4.2-2$ & Base metal & Dyn. cyc. & 258.1 & $476.5^{(1)}$ \\
$4.2-3$ & Weld & Dyn. cyc. & 1261.4 & $536.3^{(1)}$ \\
$3.3-1$ & Base Metal & QS, Mono & 807.0 & $378.7^{(2)}$ \\
\hline
\end{tabular}

(1) Monotonically loaded specimens with approximate time to crack initiation of 0.2 seconds.

(2) Monotonically loaded specimens with approximate time to crack Initiation of 600 seconds.

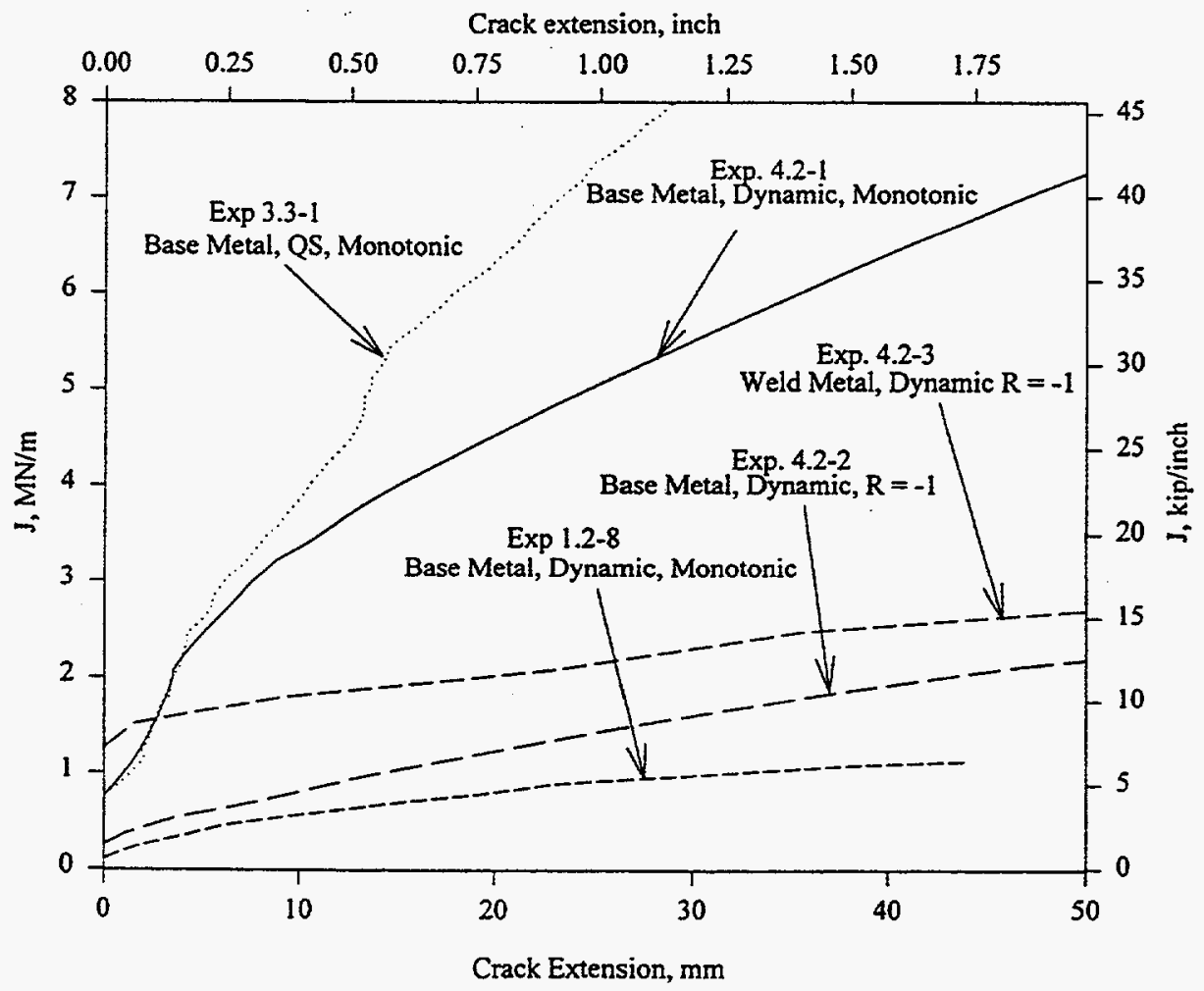

Figure 4.6 $J_{D}$-Resistance curves for Experiments 4.2-1, 4.2-2, 4.2-3 and 3.3-1 
Crack extension, inch

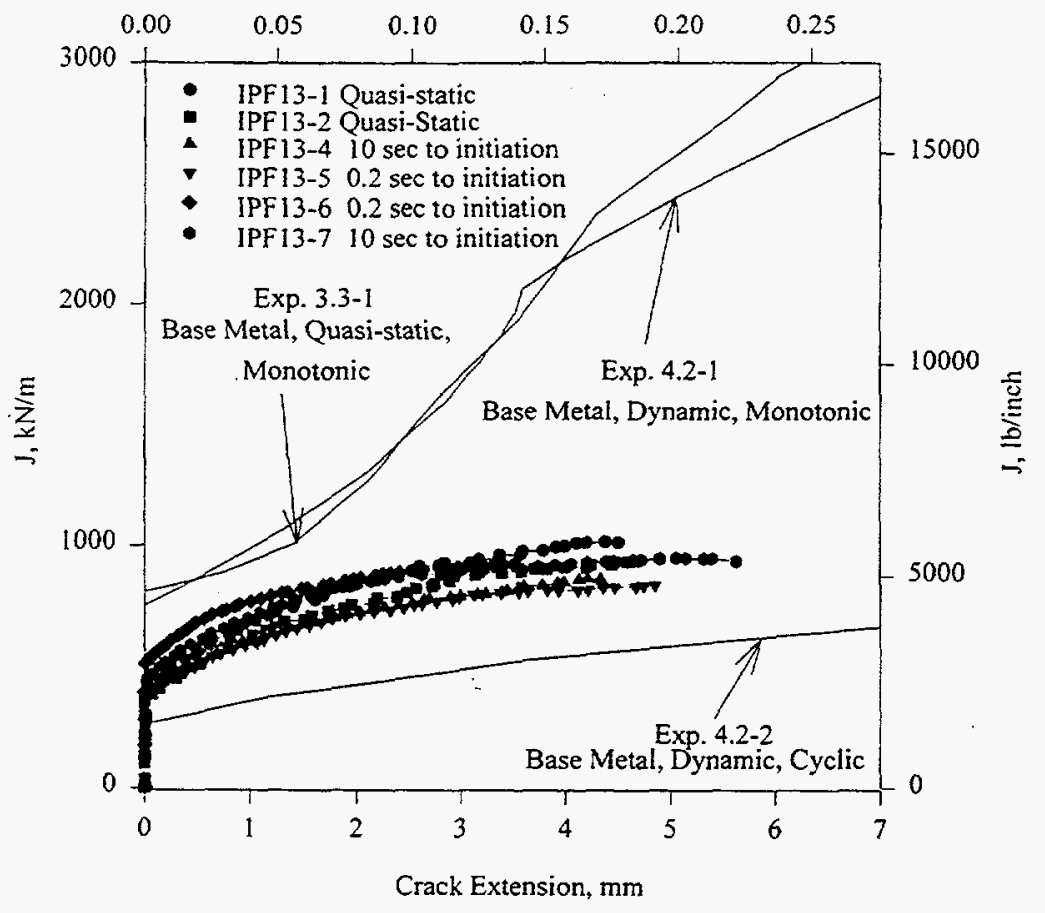

Figure 4.7 Comparison of STS410 pipe and C(T) specimen J-R curves

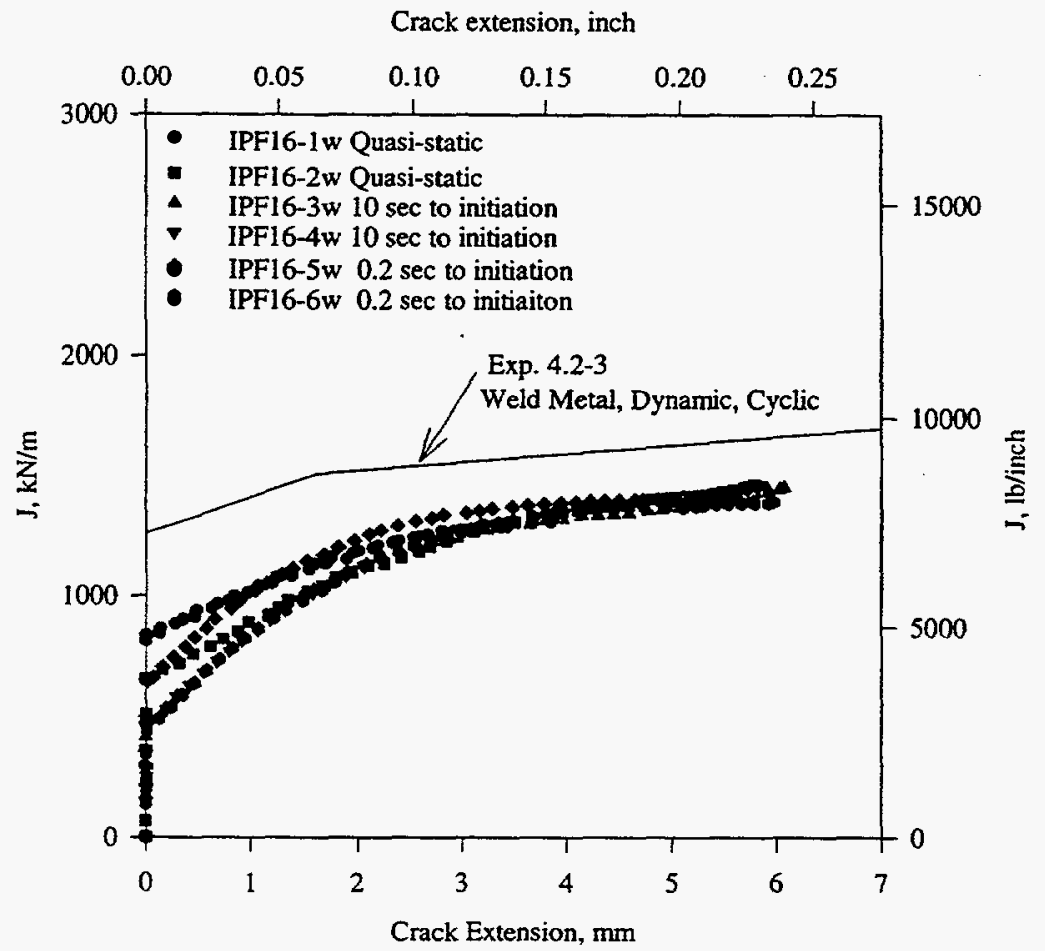

Figure 4.8 Comparison of STS410 TIG welded pipe and welded C(T) specimen J-R curves 
However, once the crack in the cyclic weld metal experiment initiated, the J-R curve leveled off and tended to mirror the cyclic base metal experiment J-R curve. This is not surprising in that once the crack in the weld metal experiment initiated, it turned out of the weld and grew in the base metal. As a result, one would expect the fracture resistance for this experiment to be similar to that of the cyclic base metal experiment once the crack started to grow. The fact that the weld metal pipe experiment exhibited a higher $J$ value at crack initiation than did the three base metal experiments is consistent with what was observed for the $C(T)$ specimens for which the $J_{i}$ value for the weld metal was found to be higher than that for the base metal, see Table 2.4. This higher toughness for the weld metal, as well as the higher strength of the weld metal when compared with the base metal (see Table 2.3), perhaps explains why the crack in the weld metal experiment turned and grew out of the weld metal into the base metal. It also explains why the crack in the cyclic weld experiment (4.2-3) did not initiate until Cycle 13 while the crack in the cyclic base metal experiment initiated during Cycle 8 for the exact same cyclic load history. Also of note from Figure 4.6 is the fact that the J-R curves for the two cyclic experiments were both significantly below the J-R curves for the dynamic, monotonic, base metal experiment. For this stress ratio $(R=-1$ ), this reduction in the J-R curve is consistent with past IPIRG-1 test data. This lowering of the J-R curves for the cyclic experiments was observed previously for the IPIRG-1 Subtask 1.2 cyclic through-wall-cracked pipe experiments (Ref. 4.9).

In examining Figure 4.7, it can be seen that there is little difference in the quasi-static and dynamic, monotonic-loaded base metal $C(T)$ specimen data. It can also be seen in Figure 4.7 that the $C(T)$ specimen quasi-static and dynamic J-R curve data, which were generated under monotonic loading conditions, are quite a bit lower than the dynamic, monotonic pipe J-R curve data. This is probably due to the fact that the $C(T)$ specimens were sidegrooved, which would decrease the apparent resistance. On the other hand, the monotonic $C(T)$ specimen J-R curve data are above the J-R curve for the dynamic, cyclic pipe experiment. This is opposite to the trend observed for the weld metal case, where the monotonic $C(T)$ specimen J-R curve data are below the J-R curve for the weld metal, dynamic, cyclic pipe experiment, see Figure 4.8.

\subsection{References}

4.1 Kumar, V., and German, M., "Elastic-Plastic Fracture Analysis of Through-Wall and Surface Flaws in Cylinders," EPRI Report NP-5596, January 1988.

4.2 Brust, F. W., "Approximate Methods for Fracture Analyses of Through-Wall-Cracked Pipes," NUREG/CR-4853, February 1987.

4.3 Harrison, R. P., Loosmore, K., Milne, I., and Dowling, A. R., "Assessment of the Integrity of Structures Containing Defects," CEGB Report R/H/R6, 1976: R/H/R6-Rev. 1, 1977.

4.4 Milne, I., "Failure Assessment Diagrams and J Estimates: A Comparison for Ferritic and Austenitic Steels," CEGB Report RD/L/2208N81, 1982. 
4.5 Milne, I., Ainsworth, R. A., Dowling, A. R., and Stewart, A. T., "Assessment of the Integrity of Structures Containing Defects," R/H/R6-Rev. 3, Published by Central Electric Generating Board, England, May 1986.

4.6 Kanninen, M. F., and others, "Mechanical Fracture Predictions for Sensitized Stainless Steel Piping with Circumferential Cracks," Final Report, EPRI NP-192, September 1976.

4.7 Kanninen, M. F., and others, "Instability Predictions for Circumferentially Cracked Type 304 Stainless Steel Pipes Under Dynamic Loadings," Final Report on EPRI Project T118-2, by Battelle Columbus Laboratories, EPRI Report No. NP-2347, April 1982.

4.8 Wilkowski, G. M. and Scott, P. M., "A Statistical Based Circumferentially Cracked Pipe Fracture Mechanics Analysis for Design or Code Implementation," Nuclear Engineering and Design, Vol. $111, \mathrm{pp}$ 173-187, 1989.

4.9 Wilkowski, G., Kramer, G., Vieth, P., Francini, R., and Scott, P.., "The Effect of Cyclic Loading During Ductile Tearing on Circumferentially Cracked Pipe -- Analytical Results," ASME PVP Vol. 280, pp 221-240, June 1994.

4.10 Zahoor, A. and Kanninen, M. F., "A Plastic Fracture Mechanics Prediction for Fracture Instability in a Circumferentially Cracked Pipe in Bending - Part I. J-Integral Analysis," Journal of Pressure Vessel Technology, Vol. 103, pp 352-358, 1981.

4.11 Pan, J., Ahmad, J. A., Kanninen, M. F., and Popelar, C. H., "Application of a Tearing Instability Analysis for Strain Hardening Materials to a Circumferentially Cracked Pipe in Bending," in ASTM STP 833, pp 721-748, 1984. 


\subsection{DISCUSSION OF RESULTS}

In this section of the report, the results from the material characterization studies, the pipe fracture experiments, and the analysis of those experiments will be discussed. First, the results pertinent to the question of the effect of loading rate on the fracture behavior of this STS410 carbon steel pipe material and associated TIG weld will be discussed. This is followed by a discussion of the effects of cyclic loading on the fracture behavior of this STS410 pipe material.

\subsection{Effect of Loading Rate on the Fracture Behavior of STS410 Carbon Steel and an Associated TIG Weld}

The effects of loading rate on the fracture behavior of this carbon steel can be investigated by studying both the pipe experiments as well as the material property data. Due to the fact that there were no quasistatic pipe fracture experiments on the TIG weld conducted as part of this effort, this discussion of the effect of loading rate on the fracture behavior of the TIG weld associated with the 152-mm (6-inch) diameter STS410 carbon steel pipe material will have to be limited to a discussion of the effects of loading rate on the STS410 weld metal material property specimen data.

Material property results. Based on the tensile tests conducted as part of this effort, it appears that the base metal ultimate tensile strength decreased approximately 15 percent as the strain rate was increased from approximately $10^{-4} / \mathrm{sec}$ to approximately $10 / \mathrm{sec}$. Also, the yield strength increased 15 percent as the strain rate was increased from $10^{-4} / \mathrm{sec}$ to $10 / \mathrm{sec}$. In addition, the elongation at the higher strain rates was 60 percent higher than the elongation at the quasi-static testing rates.

Similarly, the weld metal evaluated as part of this program also exhibited a reduction in tensile strength at the higher strain rates. The tensile strength at a strain rate of $10 / \mathrm{sec}$ was 24 percent lower than the tensile strength at $10^{-4} / \mathrm{sec}$. However, whereas the base metal tensile strength was nearly the same at both the 1 and $10 / \mathrm{sec}$ strain rates, the weld metal tensile strength at the $10 / \mathrm{sec}$ strain rate was 13 percent lower than the tensile strength at $1 / \mathrm{sec}$ strain rate. Also, contrary to the results for the base metal, the elongation of the weld metal at the higher strain rates decreased approximately 8 percent when compared with the elongation for the quasi-static tests, and the yield strength decreased by approximately 20 percent when the strain rate was increased to $10 / \mathrm{sec}$. In addition, the stress-strain curves for some of the high speed tests for this weld metal (particularly for Specimens IPF14-T2w and IPF16-T4w) showed evidences of serrated stress-strain curves. The serrations on the stress-strain curves are indicative of a material susceptible to dynamic strain aging effects. Such serrations were not evident on the base-metal stress-strain curves.

Both the base metal and weld metal J-R curves showed little evidence of degradation as the strain rate was increased approximately 3000 times. There was little difference in the J-R curves for either material between the quasi-static case, with an approximate time to crack initiation of 600 seconds, and the J-R curves for the fastest dynamic tests, with an approximate time to initiation of 0.2 seconds. The only difference of significance is that the average value of $J$ at crack initiation $\left(\mathrm{J}_{\mathrm{i}}\right)$ for the base metal $\mathrm{C}(\mathrm{T})$ specimens which were loaded at the fastest rate, i.e., 0.2 seconds to crack initiation, was approximately 25 percent higher than the $J_{i}$ value for the quasi-static $C(T)$ specimens or the dynamic $C(T)$ specimens 
whose cracks initiated in approximately 10 seconds. Conversely, the average $\mathrm{J}_{\mathrm{i}}$ value for the quasi-static weld metal $C(T)$ specimens was approximately 55 percent higher than the average $J_{i}$ value for the dynamic weld metal $C(T)$ specimens. However, once the cracks began to grow, the J-R curves for the quasi-static and dynamic, base metal and weld metal specimens began to converge.

Although these results, especially the tensile test results, suggest that this pipe material and the associated TIG weld may be susceptible to dynamic strain aging effects, the effect of higher strain rates on both materials was not as great as had been observed in other carbon steel materials tested in the IPIRG-1 program (Ref. 5.1). For Pipe DP2-F30, a 152-mm (6-inch) diameter, A106B carbon steel, the tensile strength decreased approximately 25 percent as the strain rate was increased from approximately $10^{-4}$ /second to 10/second. Similarly for Pipe DP2-F29, a 406-mm (16-inch) diameter, A106B carbon steel, the tensile strength decreased approximately 30 percent as the strain rate was increased from approximately $10^{-4} /$ second to 10 /second. Finally, for the low-toughness submerged-arc weld (SAW) in Pipe DP2-F29, the tensile strength decreased approximately 20 percent at the higher strain rate. This compares to a 15 percent reduction for the STS410 base metal and a 20 percent reduction for the TIG weld evaluated in this program. As far as toughness is concerned, the value of $J$ at crack initiation $\left(J_{i}\right)$ for Pipes DP2-F30 and DP2-F29 decreased approximately 15 and 35 percent, respectively, at the higher loading rates when compared with the quasi-static loading rates. Conversely, the value of $\mathrm{J}$ at crack initiation for the submerged-arc weld in Pipe DP2-F29 increased 55 percent as the loading rate was increased. The toughness of the STS 410 base metal evaluated in this program was essentially unchanged by increasing the loading rate by a factor of approximately 3,000 . Conversely, the value of $\mathrm{J}$ at crack initiation $\left(\mathrm{J}_{\mathrm{i}}\right)$ for the TIG weld evaluated in this program decreased approximately 35 percent at the higher loading rates when compared with the quasi-static loading rates.

Furthermore, the serrations on the stress-strain curves for the base metal and weld metal materials evaluated as part of this effort were not as pronounced as they were on some of the carbon steel materials evaluated in the IPIRG-1 program. Figure 5.1 compares the stress-strain curves for the $152-\mathrm{mm}$ (6-inch) nominal diameter, STS410 base metal evaluated in this program with the stress-strain curves for the 152$\mathrm{mm}$ (6-inch) nominal diameter, A106B pipe material evaluated in the IPIRG-1 program. Figure 5.2 is a similar comparison for the two ferritic welds, i.e., the TIG weld evaluated in this program and the submerged-arc weld evaluated in the IPIRG-1 program.

Pipe Experiments. Figure 5.3 shows the load-displacement record for the quasi-static, monotonic (Experiment 3.3-1) and dynamic, monotonic (Experiment 4.2-1) base metal TWC pipe tests. The maximum load for the quasi-static experiment was approximately 10 percent higher than the maximum load for the dynamic experiment. This difference in load could be attributed to the difference in crack growth angle. For Experiment 4.2-1, the crack grew at a 38-degree angle from the circumferential plane while the crack in Experiment 3.3-1 grew at a 48-degree angle from the circumferential plane. This difference in angle would cause a difference in the load-displacement response. Past studies (Ref. 5.2) have shown that as the angle from the circumferential plane is increased, the loads are increased. Figure 5.4 shows the load-displacement record for these experiments only up to the point of crack initiation. This figure shows that the load-displacement records for these two tests do not differ greatly up to the point of crack initiation, indicating that the effect of dynamic loading on the fracture toughness of this material is minimal. 


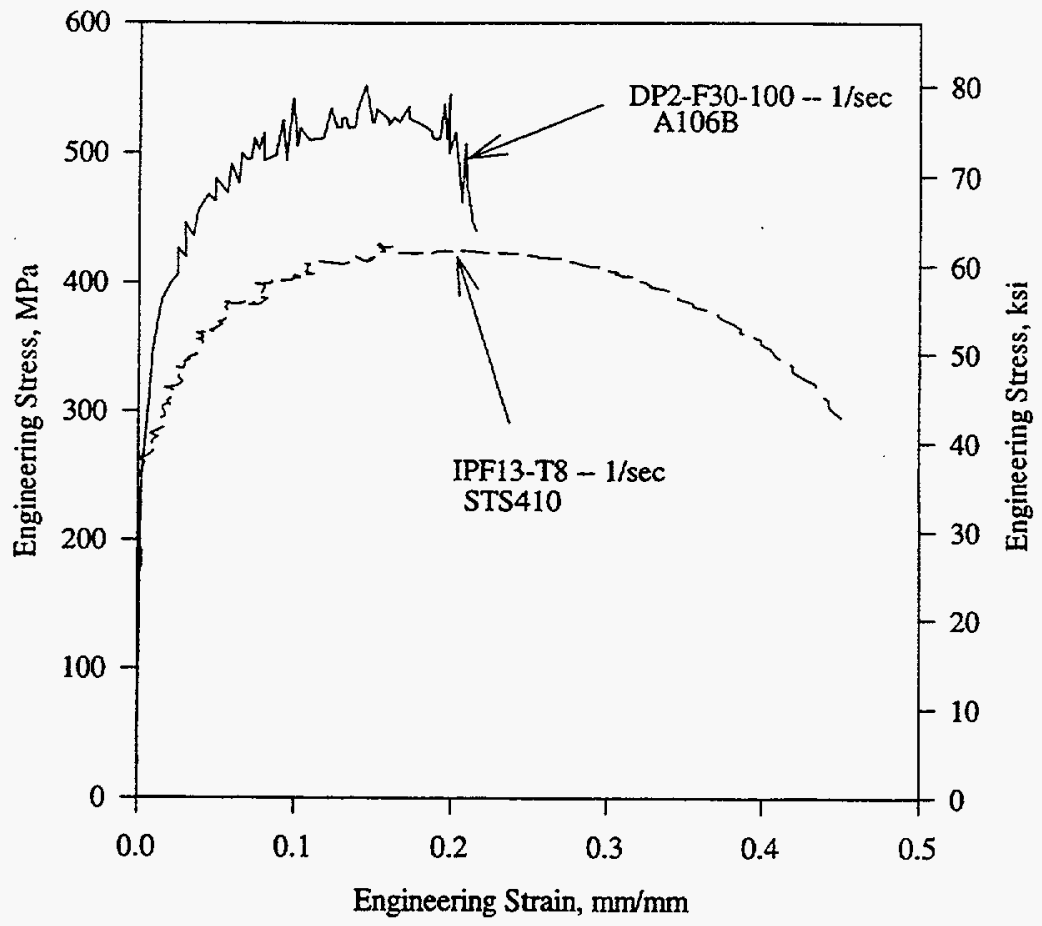

Figure 5.1 Comparison of stress-strain curve for the A106 Grade B pipe material used in Subtask 1.2 of IPIRG-1 (DP2-F30) with the stress-strain curve for the STS410 pipe material evaluated as part of this effort (IP-F13)

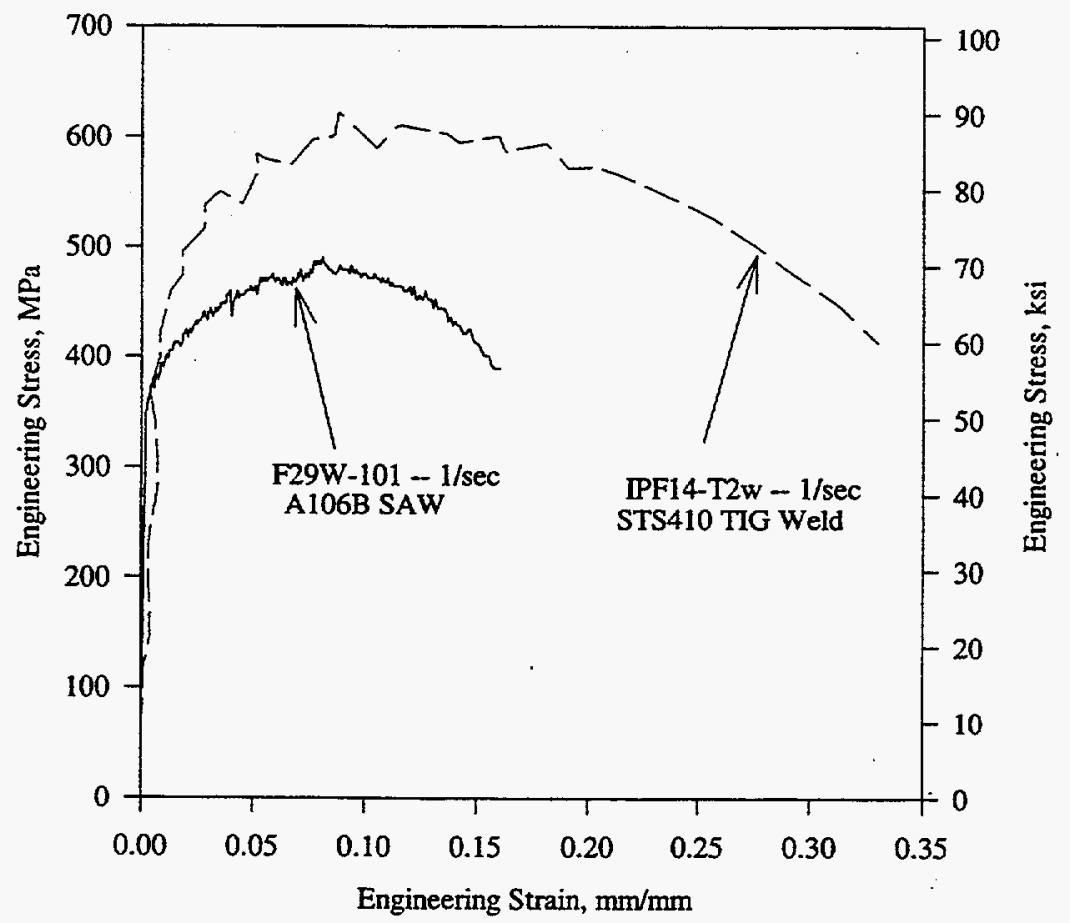

Figure 5.2 Comparison of stress-strain curve for the A106B SAW used in IPIRG-1 (DP2-F29W) with the stress-strain curve for the TIG weld in STS410 evaluated in this program 


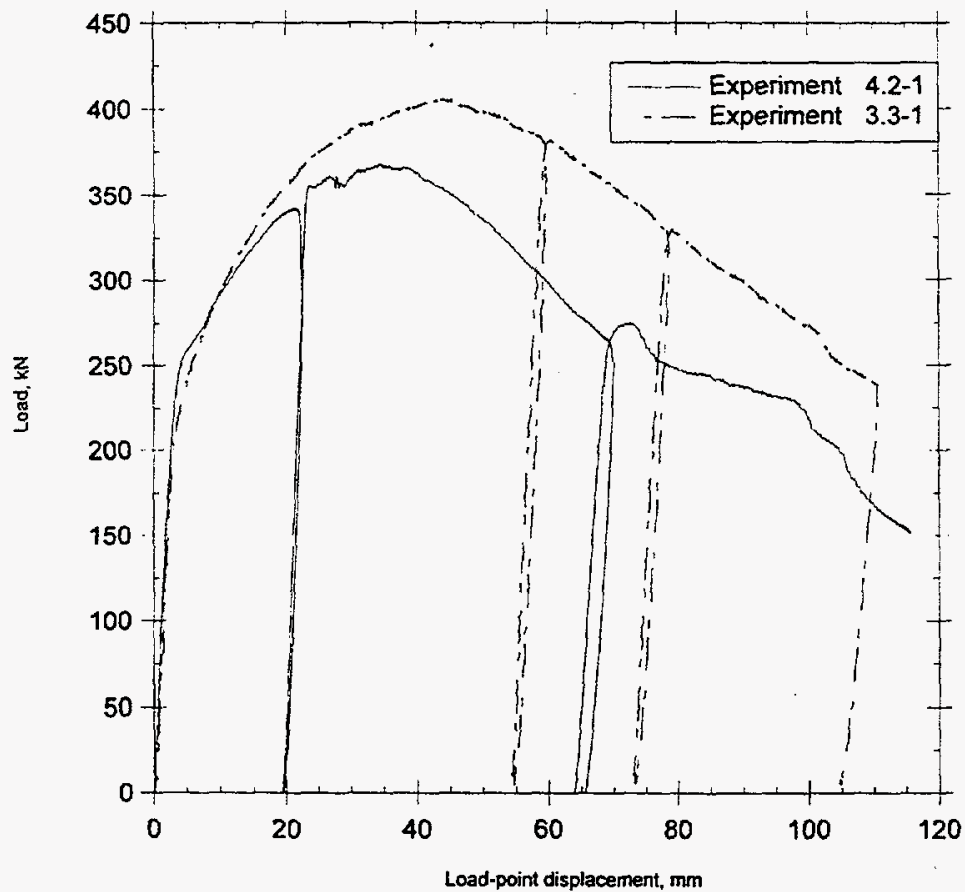

Figure 5.3 Comparison of load-displacement curves for Experiments 4.2-1 and 3.3-1

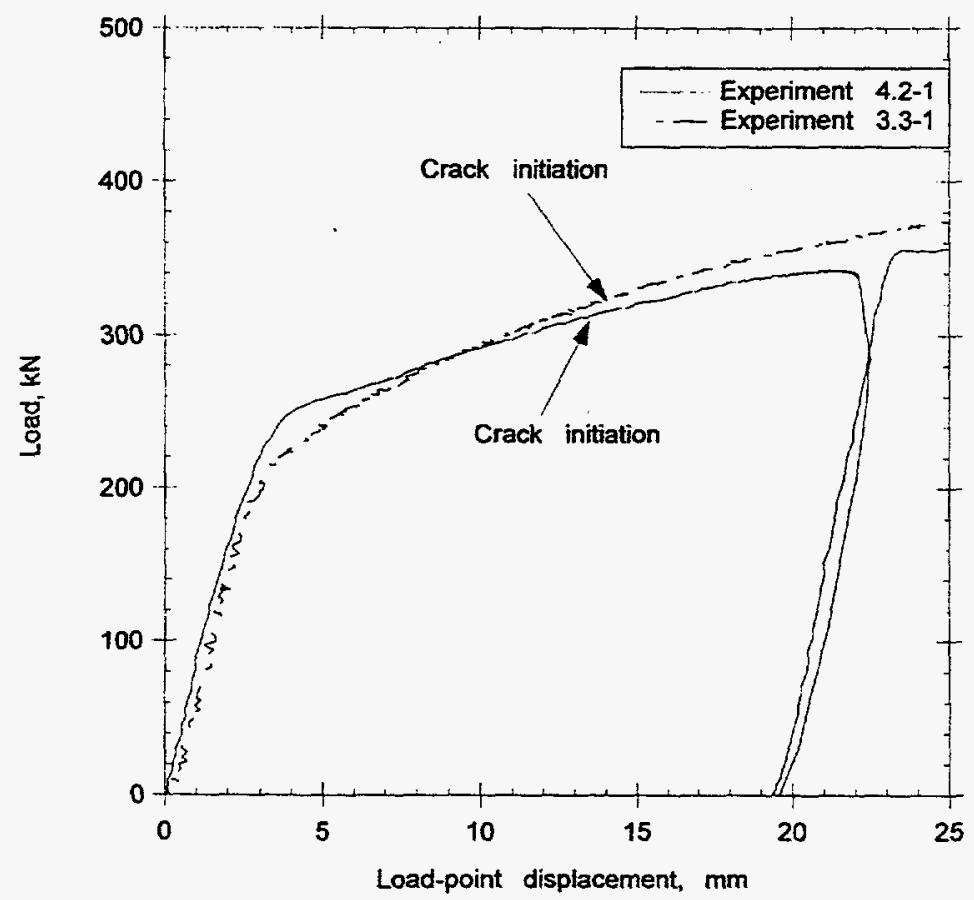

Figure 5.4 Comparison of load-displacement curves for Experiments 4.2-1 and 3.3-1 up to the point of crack initiation 
When the fracture ratios at crack initiation for the GE/EPRI, LBB.ENG2, and R6 methods for the STS410 base metal experiments are compared with the fracture ratios at crack initiation for these same analysis methods for the corresponding IPIRG-1 Subtask 1.2 A106 Grade B experiments, the fracture ratios at crack initiation for the STS410 experiments conducted as part of this effort are higher (approximately 10 percent higher for the monotonic experiments and 25 percent higher for the cyclic experiments) than they are for the corresponding Subtask 1.2 A106 Grade B base metal experiments. This may partially be an artifact of using quasi-static material property data in the analyses of both sets of experiments. If dynamic data were used in the analysis of the STS410 experiments conducted as part of this effort, the fracture ratios at crack initiation (i.e., the ratio of the experimental moments at crack initiation to the predicted moments at crack initiation) would not change much because the base-metal ultimate strength is reduced slightly, and the base-metal $J_{i}$ value is increased slightly at the higher loading rates. However, if dynamic data were used in the analysis of the A106 Grade B experiments conducted as part of Subtask 1.2 of the IPIRG-1 program, the fracture ratios at crack initiation would increase significantly due to the greater reduction in the ultimate strength and the reduction in the $J$ value at crack initiation. As a result of this greater increase in the fracture ratios for the A106 Grade B pipe experiments when dynamic material data are used in the analyses, the fracture ratios for the two sets of experiments would be more in line with each other. This idea that the fracture ratios for the STS410 material are less sensitive to the choice of quasi-static or dynamic material property data than the fracture ratios for the A106 Grade B material, supports the contention that the STS410 material may be less sensitive to dynamic strain aging effects than the A106 Grade B material evaluated in Subtask 1.2 of the IPIRG-1 program. Based on these findings, it appears that this STS410 carbon steel, and its associated TIG weld, may be susceptible to dynamic strain aging effects, but not to the extent as some of the carbon steel pipe materials evaluated earlier in the IPIRG-1 program. This finding is supported by the observation that there were no crack instabilities, i.e., unstable crack jumps, during the course of any of these pipe experiments. In the past, crack jumps in through-wall-cracked pipe experiments have been attributed to the material's sensitivity to dynamic strain aging.

\subsection{Effect of Cyclic Load Histories on the Fracture Behavior of STS410 Carbon Steel}

Two dynamic base metal (STS410) pipe experiments were conducted as part of this effort. One was a dynamic, monotonic pipe experiment. The other was a dynamic, cyclic experiment with a stress ratio (R) of -1 . Based on the results of these two experiments, an assessment of the effect of cyclic loading on the fracture behavior of the STS 410 base metal can be made. However, due to the lack of baseline monotonic data for the weld metal pipe experiment, it will not be possible to make such an assessment for the TIG weld case.

When the fracture ratios (i.e., the ratio of the experimental-to-predicted moments) using the GE/EPRI and LBB.ENG2 analysis methods for the dynamic, monotonic and dynamic, cyclic, base metal experiments are compared (see Table 4.3), the fracture ratio at crack initiation for the dynamic, cyclic ( $R$ $=-1$ ) experiment $(4.2-2)$ was only 5 percent less than the fracture ratio at crack initiation for the dynamic, monotonic experiment (4.2-1). Similarly, the fracture ratio at maximum moment for the cyclic experiment (4.2-2) was only 5 percent less than the fracture ratio for the monotonic experiment (4.2-1). Conversely, for the IPIRG-1 Subtask 1.2 experiments, the fracture ratios at crack initiation and 
maximum moment (using these same two analysis methods), for the dynamic, cyclic experiment (1.2-6) were 16 and 23 percent less, respectively, than the corresponding average fracture ratios for the three dynamic, monotonic experiments (1.2-8, 1.2-11, and 1.2-12). It appears that there is a greater effect of cyclic loading for the particular A106 Grade B carbon steel tested in IPIRG-1 than there is for this STS 410 carbon steel.

However, when the J-R curves calculated from the pipe experiments are examined, a different trend is observed. The J-R curve for the dynamic, monotonic base metal experiment (4.2-1) is quite a bit higher than the J-R curve for the dynamic, cyclic base metal experiment (4.2-2), see Figure 4.6. The reason for this is obvious when one examines the moment-rotation curves for the two experiments, see Figure 3.8 for Experiment 4.2-1 and Figure 3.14 for Experiment 4.2-2. In examining these figures, it can be seen that the maximum moments for the two experiments are comparable (explaining the reasonable agreement in fracture ratios for the two experiments), but the rotations for the dynamic, monotonic experiment are significantly greater than they are for the dynamic, cyclic experiment (explaining the higher J-R curve for the monotonic experiment). Based on these two observations, (1) the comparable fracture ratios at crack initiation and maximum moment for the monotonic and cyclic experiments, and (2) the significantly higher J-R curve for the monotonic experiment, one could conclude that the cyclic load history had a more significant effect on the crack growth portion of the experiment than it did on the crack initiation portion of the experiment.

Figure 5.5 shows a comparison of the STS- 410 pipe J-R curves with the A106 Grade B pipe J-R curves from IPIRG-1. Clearly, the STS-410 material is much tougher than the A106B material. The quasistatic monotonic J-R curve for the STS-410 material is not shown since it was nearly identical to the dynamic monotonic J-R curve up to $5 \mathrm{~mm}$ of crack growth, see Figure 4.6. Even when cycled at a stress ratio of -1 , the STS -410 material is tougher than the A106B material tested monotonically. However, the cyclic degradation during stable crack growth in the STS-410 is greater than in the A106 material. Figure 5.5 shows that at $30 \mathrm{~mm}$ of crack growth, the STS 410 material shows an approximately 80 percent decrease in $\mathrm{J}$ when the pipe undergoes fully reversed loading. However, the A106B material only shows a 50 percent decrease in $J$ at the same crack growth when the pipe undergoes fully reversed loading. This supports the conclusion that the cyclic load history has a more significant effect on the crack growth portion of the STS-410 experiments than the same history has on the A106B experiments.

Another point to be made regarding the results from the cyclic pipe experiments is that when the J-R curves for the base metal and weld metal, dynamic, cyclic pipe experiments are compared (see Figure 4.6), the value of $J$ at crack initiation for the weld metal experiment is much higher than that for the base metal experiment. However, once the crack starts to grow, the two J-R curves begin to converge. This is the result of the fact that the strength and toughness of the weld metal are higher than they are for the base metal. Consequently, after the crack initiated it turned and grew into the softer, weaker base metal. As a result, the weld metal J-R curve converged to the base metal J-R curve at large amounts of crack growth.

Finally, if one compares the ratio of the cyclic $(R=1)$ to monotonic fracture toughness from the pipe $\eta$ factor analysis for the 152-mm (6-inch) nominal diameter STS410 pipe experiments conducted as part of this effort with the ratio of the cyclic $(\mathrm{R}=-1)$ to monotonic fracture toughness for the $152-\mathrm{mm}$ (6-inch) nominal diameter A106B carbon steel and Type 304 stainless pipe experiments conducted as part 


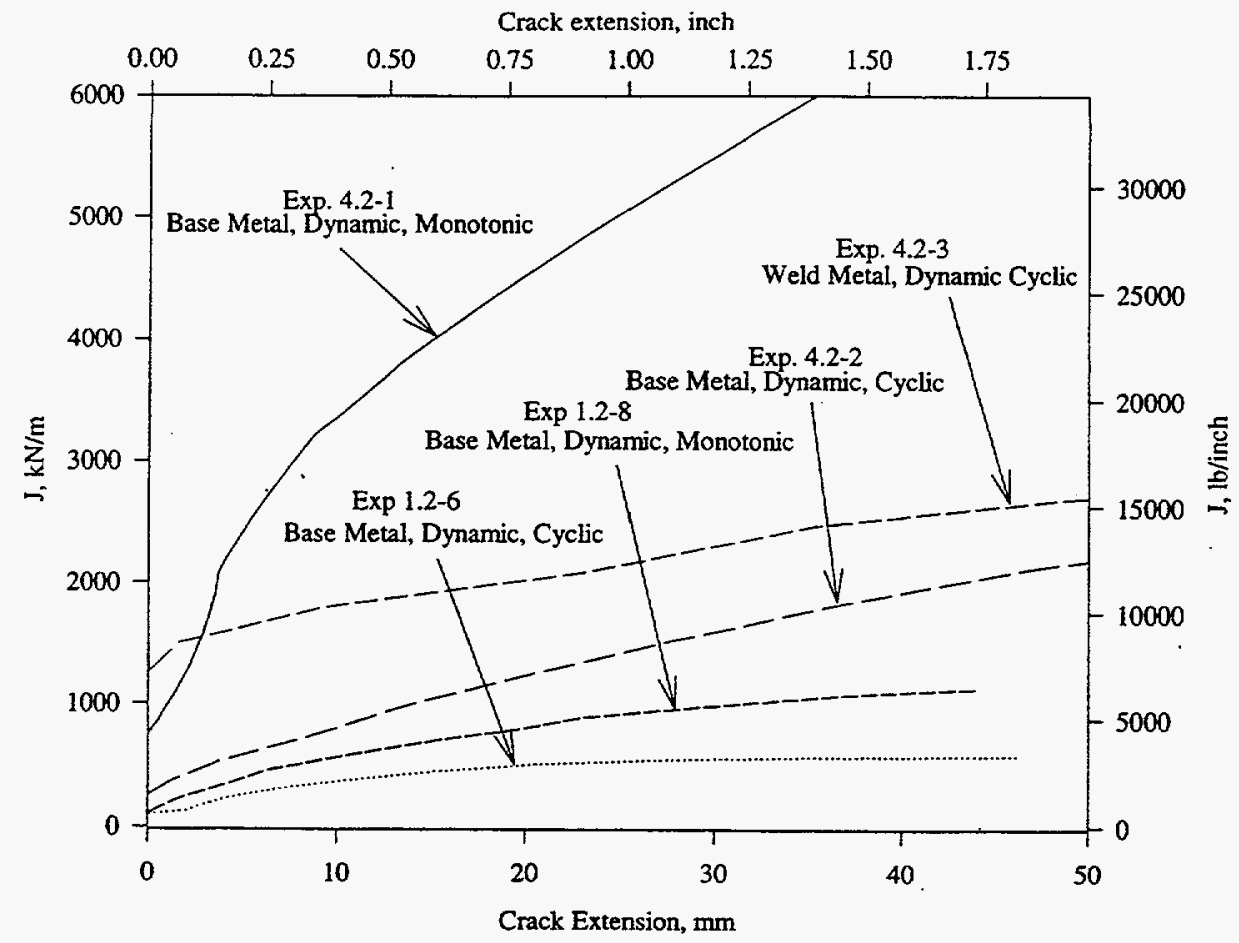

Figure 5.5 STS-410 and A106 Grade B J-R curve comparison

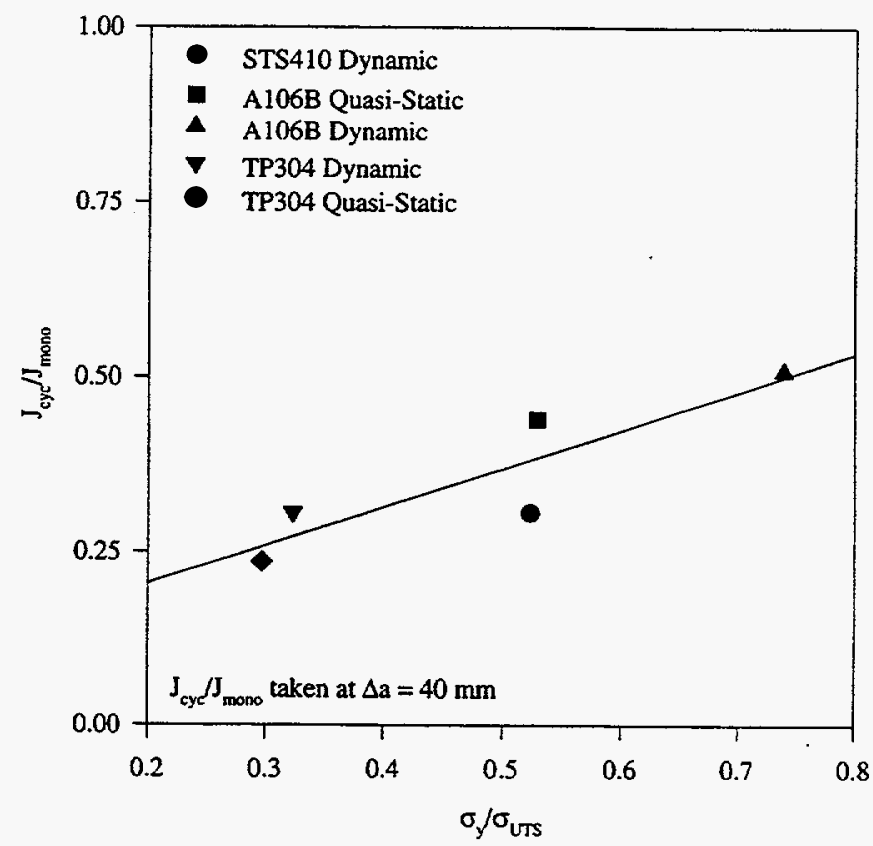

Figure 5.6 Plot of the ratio of cyclic $(R=1)$ to monotonic fracture toughness from the pipe $\eta$-factor analysis as a function of the yield-to-ultimate strength ratio for the $152-\mathrm{mm}$ (6-inch) nominal diameter through-wall-cracked pipe experiments conducted as part of this program and Subtask 1.2 of the IPIRG-1 program 
of IPIRG-1, one sees that these ratios are consistent with each other, especially when plotted against the yield-to-ultimate strength ratios for the specific materials, see Figure 5.6. The implication of Figure 5.6 is that for this pipe size and flaw geometry, that the higher the yield-to-ultimate strength ratio, the less degradation in toughness due to cyclic $(\mathrm{R}=-1)$ loading one might expect to occur. This is important since welds typically have higher yield-to-ultimate strength ratios than base metals, so consequently one would expect that the degree of toughness degradation due to cyclic loading would be less for the weld metal case than for the base metal case.

\subsection{Helical Crack Growth}

In the experiments conducted in this program, the crack grew at a helical angle from the initial circumferential crack. This is similar behavior to carbon steel pipes tested in the various USNRC programs conducted at Battelle. The crack in all but one of the quasi-static carbon steel pipe experiments on 102-mm (4-inch) to 914-mm (36-inch) diameter pipe from the Degraded Piping Program (Ref. 5.3) grew at a helical angle from the initial circumferential crack.

In the IPIRG-1 program, helical crack growth was also observed in the cyclic 152-mm (6-inch) nominal diameter carbon steel pipe experiments, as well as in the 406- $\mathrm{mm}$ (16-inch) diameter carbon steel pipe experiments. In the many $152-\mathrm{mm}$ (6-inch) diameter pipe experiments conducted with pipe specimens from the same length of pipe, it was found that the helical crack growth angle varied from 25 to 60 degrees (Ref. 5.4). It was found that a larger angle of crack growth increased the apparent fracture resistance of the pipes tested under bending. Helical crack growth also occurred in the 762-mm (30inch) diameter STS49 pipe used in Experiment 4.3-1 in the IPIRG-1 program.

Crack growth out of the initial circumferential plane of the crack has also occurred in carbon steel pipe fracture programs conducted in other countries and other programs on oil and gas piping (Ref. 5.5). There were many carbon steel pipes tested at the MPA-Stuttgart facility where there was helical crack growth from an initial circumferential crack plane. In Italy, it was also found that helical crack growth occurred in their ferritic steel pipe experiments (Ref. 5.6).

In Japan, the NUPEC program on Proving Test on the Integrity of Carbon Steel Piping in LWR's had circumferentially cracked pipe with helical angle crack growth less than 20 degrees in the room temperature tests (Ref. 5.7). In the JAERI ferritic pipe tests (Ref. 5.8), the cracks grew at large angles from the crack plane. Helical crack growth in the $300 \mathrm{C}(572 \mathrm{~F})$ STS42 pipe tests was not documented in the reports reviewed by Battelle. Also in the recent 102-mm (4-inch) nominal diameter Japanese carbon steel pipe experiments, it was observed that the helical crack growth was very small (Ref. 5.9).

The key factor controlling if helical crack growth occurs or not in all these cases is probably the toughness anisotropy of the material. Virtually all seamless carbon steel pipes made in the world use the Mannesmann process which works the material in the axial direction. If there are soft inclusions in the steel, they will be elongated in the axial direction which then becomes the low toughness direction with the circumferential direction having a much higher toughness. This difference of toughness (or anisotropy) in different orientations is well known from work by many investigators, see discussion in Section 6 of Reference 5.10. Anisotropy of the toughness can be reduced by decreasing the amount of impurities and modifying the chemistry with additions that make inclusions less plastic in the hot 
working process (Ref. 5.11). Such inclusion shape control is frequently used in the steel industry. Another way of controlling the anisotropy is to cross roll the plates used in seam welded pipe, but this method could not be applied for seamless pipe.

Helical crack growth behavior was the focus of a study conducted in the USNRC Short Cracks in Piping and Piping Welds Program at Battelle (Ref. 5.2). In this study, the effects of material anisotropy and combined stresses (hoop, tension, bending and torsion) were examined to determine why cracks frequently grow in a helical direction for carbon steel pipes. In such an analysis, not only is the anisotropy of the toughness of interest, but also the fact that there are several loading modes on the cracked pipe from a fracture mechanics analysis, i.e., Mode I loading is the normal opening mode, Mode II is the in-plane shear loading, and Mode III is the out-of-plane tearing of the material. For a pipe under combined bending, tension, and torsion, all three fracture mechanics loading modes are present. It is believed that the ratio of the toughness to the crack-driving force as a function of the angle from the crack tip will determine if the crack will grow in a helical direction. If there is very little anisotropy, as with stainless steel, then the crack growth would be in the circumferential direction for tension or bending loads.

Hence, the helical crack growth observed in the pipe experiments conducted in this program is very typical for carbon steel pipe, and, in fact, the relatively straight crack growth in Reference 5.9 is unusual, and it is of interest to see why the cracks grew straight in those experiments.

\subsection{Dynamic Strain Aging Sensitivity of Carbon Steels}

The effects of loading rate on the load-carrying capacity of cracked carbon steel pipe at LWR temperatures depends on the material's sensitivity to dynamic strain aging. Dynamic strain aging is the pinning of dislocation movement during plastic deformation. The pinning is caused by atomic carbon or nitrogen in the crystals of the steel. DSA is known to occur in carbon steels in the temperature range of $150 \mathrm{C}(302 \mathrm{~F})$ to $400 \mathrm{C}(752 \mathrm{~F})$. A good summary of the phenomenon is given in a Battelle report to the USNRC on "Dynamic Crack Instabilities in Nuclear Ferritic Piping at LWR Temperatures and the Role of Dynamic Strain Aging" (Ref. 5.11). In this report, several different U.S. ferritic pipe steels were used to develop a screening criterion for predicting the occurrence of unstable crack jumps that occasionally occurred in carbon steel pipes at LWR temperatures. These unstable crack jumps were found to be related to the dynamic strain aging sensitivity of the steels. It was found in Reference 5.11 that there were some U.S. ferritic pipes that were not susceptible to dynamic strain aging, but pipes that were susceptible to dynamic strain aging were found in virtually every grade of U.S. nuclear piping steel, e.g., A106 Grade B, A333 Grade 6, etc. It was also concluded that having a steel highly sensitive to dynamic strain aging is not desirable since large unstable crack jumps might occur. However, pipes slightly sensitive to dynamic strain aging may be desirable since that amount of dynamic strain aging would raise the strength of the material with a minimal loss in toughness. This change in properties would increase the load-carrying capacity of cracked carbon steel pipes.

The effect of dynamic loading on the strength and toughness of carbon steel pipes is also being investigated in Task 3 of the IPIRG-2 program. In Task 3, it was found that several U.S. carbon steel pipes were not affected by dynamic strain aging, and at least one carbon steel weld had a higher 
toughness at the dynamic loading rates than at quasi-static rates. Hence, there is a great degree of variability of properties in the U.S. ferritic steels.

The STS410 pipe used in this program had a much superior toughness than the A106 B pipe used in similar experiments during the IPIRG-1 program. Although there are other U.S. carbon steel pipes that are not sensitive to dynamic strain aging and are just as tough as the STS410 pipe tested, the limited data on Japanese carbon steel pipe we have from this program and the IPIRG-1 program showed that the Japanese pipes tested had better fracture resistance properties than the average of the U.S. pipes tested. Additional tests on pipes from different heats of Japanese carbon steel pipes are needed to make a more statistically valid comparison.

\subsection{References}

5.1 Marschall, C. W., Landow, M. P., and Wilkowski, G. M., "Loading Rate Effects on Strength and Fracture Toughness of Pipe Steels Used in Task 1 of the IPIRG Program," NUREG/CR-6098, BMI-2175, October 1993.

5.2 Mohan, R., and others, "Effects of Toughness Anisotropy and Combined Tension, Torsion, and Bending Loads on Fracture Behavior of Ferritic Nuclear Pipe,"NUREG/CR-6299, April 1995.

5.3 Wilkowski, G. M., and others, "Degraded Piping Program - Phase II, Summary of Technical Results and Their Significance to Leak-Before-Break and In-Service Flaw Acceptance Criteria, March 1984-January 1989," Battelle Columbus Division, NUREG/CR-4082, Vol. 8, March 1989.

5.4 Wilkowski, G. M., Kramer, Vieth, P., Francini, R., and Scott, P., "The Effect of Cyclic Loading During Ductile Tearing on Circumferentially Cracked Pipe - Analytical Results," ASME PVP Vol. 280, pp 221-240, June 1994.

5.5 Wilkowski, G. M., "Anisotropic Fracture Toughness Effects on Failure Modes of Piping," ASME Journal of Pressure Vessel Technology, 25 Year Anniversary Edition, June 1991.

5.6 Maricchiolo C. and Milella, P. P., "Fracture Behavior of Carbon Steel Pipes Containing Circumferential Cracks at Room Temperature and $300 \mathrm{C}$," Nuclear Engineering and Design, 111, pp 35-46, 1989.

5.7 "Proving Test on the Integrity of Carbon Steel Piping in LWRs," A translation of excerpt from Summary Report of "Proving Tests on the Reliability for Nuclear Power Plant," Nuclear Power Engineering Test Center, Tokyo, Japan, 1989.

5.8 Shibata, K., Ohba, T., Kawamura, T., Miyazono, S., Kaneko, T., Yohoyama, N., "Ductile Fracture Behavior of 6-Inch Diameter Type 304 Stainless Steel and STS42 Carbon Steel Piping Containing a Through-Wall or Part-Through Crack," JAERI-M 86-078, April 25, 1986. 
5.9 Fujioka T., Miura, N., Kashima, K., Kanno, S., Miyazaki, K., Ishiwata, M., and Gotoh, N., "A Fracture Strength Evaluation Method for Carbon Steel Pipes Subjected to Dynamic/Cyclic Loadings: Evaluation of Dynamic/Cyclic Pipe Fracture Tests at Elevated Temperature," ASME PVP Vol. 304, pp 191-197, 1995.

5.10 Wilkowski, G. M., and others, "Short Cracks in Piping and Piping Welds," Second Semiannual Report by Battelle, NUREG/CR-4599, Vol. 1, No. 2, April 1992.

5.11 Marschall, C., Mohan, R., Krishnaswamy, P., and Wilkowski, G. M., "Dynamic Crack Instabilities in Nuclear Ferritic Piping at LWR Temperatures and the Role of Dynamic Strain Aging," NUREG/CR-6226, September 1994. 


\subsection{SUMMARY AND CONCLUSIONS}

As part of this program, three dynamic and one quasi-static pipe fracture experiments were conducted on sections of 152-mm (6-inch) nominal diameter, STS410 carbon steel pipe manufactured in Japan. Three of the experiments involved through-wall cracks in the base metal of the STS410 carbon steel material. The fourth involved a through-wall-crack in a TIG weld joining two sections of the same STS 410 carbon steel pipe material. All were loaded in four-point bending. The load histories for the four experiments were: (1) dynamic, monotonic with the crack in the base metal, (2) dynamic, cyclic with a stress ratio (R) of -1 and the crack in the base metal, (3) dynamic, cyclic with a stress ratio (R) of -1 with the crack in the center of a tungsten-inert-gas (TIG) weld, and (4) quasi-static, monotonic with the crack in the base metal. The test temperature for each experiment was $300 \mathrm{C}(572 \mathrm{~F})$. Each test specimen was unpressurized.

In addition to the pipe experiments, quasi-static and dynamic, tensile and fracture toughness properties for both the base metal and weld metal were evaluated. Also, a number of analyses were conducted for each pipe experiment. The moments at crack initiation were predicted using the GE/EPRI and LBB.ENG2 J-estimation schemes and the R6 Revision 3 Option 1 method and were compared with the experimental values. The maximum moments for each experiment were predicted using the Net-Section-Collapse, Dimensionless-Plastic-Zone-Parameter, GE/EPRI, LBB.ENG2, and R6 Revision 3 Option 1 methods and were compared with the maximum moments from the experiments. Finally, the J-R curves from the pipe experiments were calculated using the $\eta$-factor method and the load-displacement test record from each of the pipe experiments.

As a result of these efforts, the following conclusions can be drawn:

(1) The STS410 carbon steel pipe material and the associated TIG weld studied in this program may be slightly susceptible to dynamic strain aging effects, although the extent of their susceptibility is probably less than some of the U.S. manufactured carbon steel base metal materials evaluated in the Degraded Piping, IPIRG-1, and Short Cracks in Piping and Piping Welds programs previously conducted at Battelle. The absence of any crack instabilities, i.e., crack jumps, in any of the pipe fracture experiments also shows that the pipe material tested was not highly sensitive to dynamic strain aging effects.

(2) Based on a comparison of maximum loads for the three base metal experiments, the STS410 carbon steel pipe material appears to be less sensitive to cyclic loading effects than the A106 Grade B pipe material evaluated in Subtask 1.2 of the IPIRG-1 program. However, when one compares the J-R curves for the pipe experiments from the $\eta$-factor analysis, one sees a dramatic reduction in toughness due to cyclic loading, see Figure 4.6. This material seems to be more sensitive to cyclic loading after some amount of crack growth than at crack initiation. This may explain why the maximum load predictions for the three base metal experiments agree so closely. The maximum load may have been attained before significant crack growth occurred. 
(3) The through-wall cracks in the STS410 carbon steel pipe experiments all grew out of the circumferential crack plane, much in the same manner as the through-wall cracks tested in the U.S. manufactured carbon steel pipe materials evaluated in the Degraded Piping, IPIRG-1, and Short Cracks programs. Such behavior is typically attributed to toughness anisotropy effects. All information to date suggests that the angular crack growth increases the load-carrying capacity and overall ductility (global displacements and pipe rotation), and hence is desirable. 


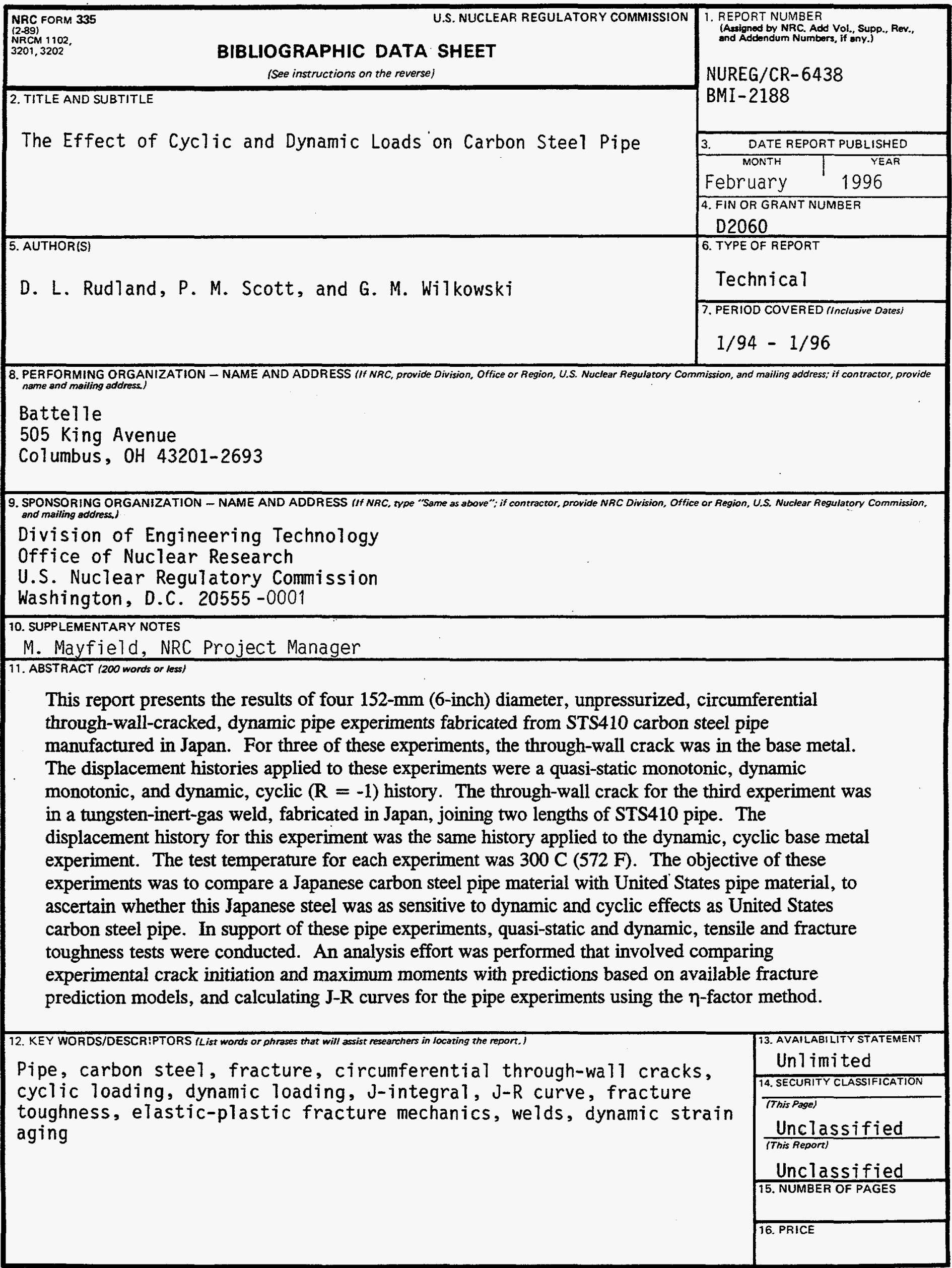

